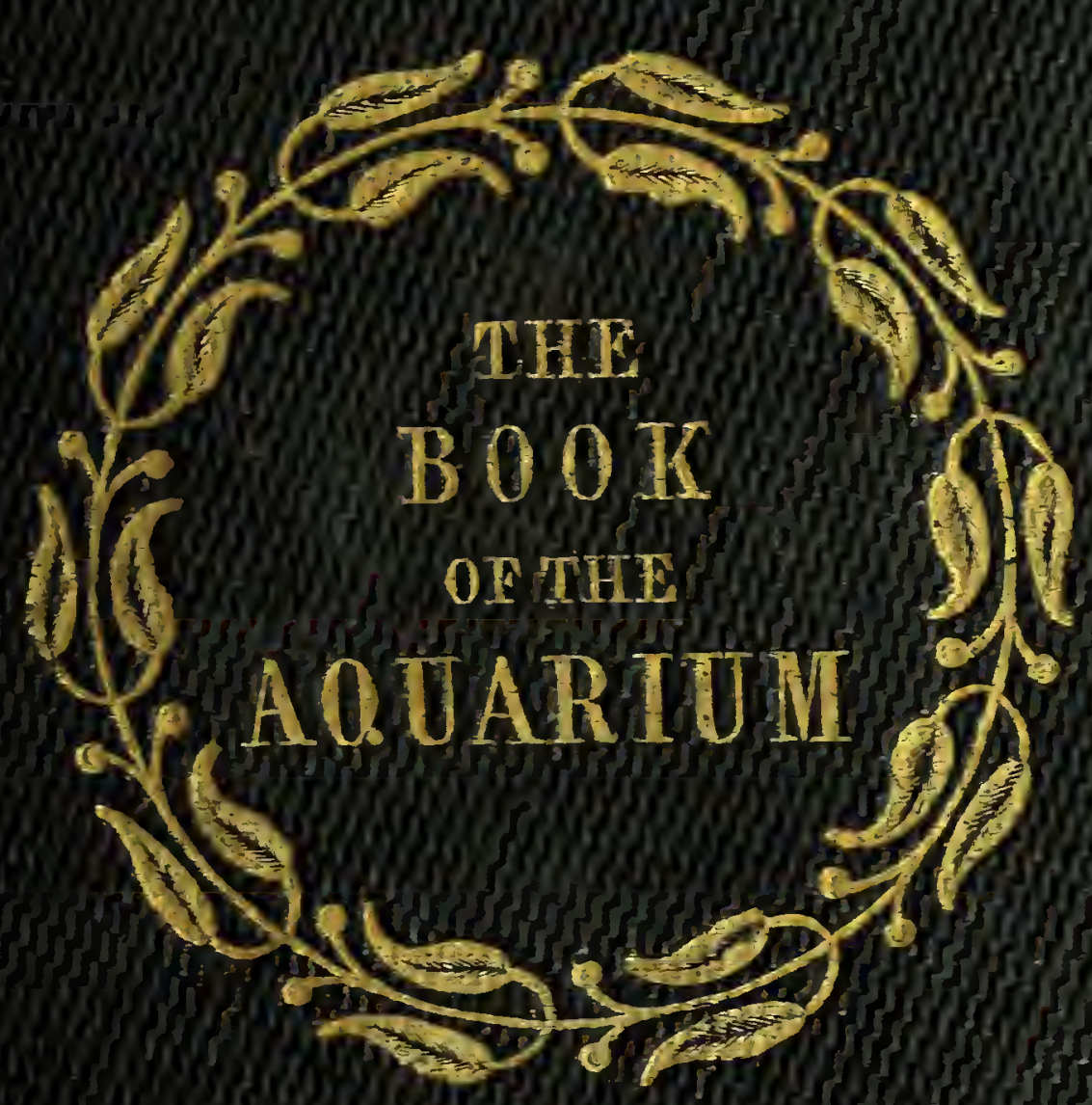



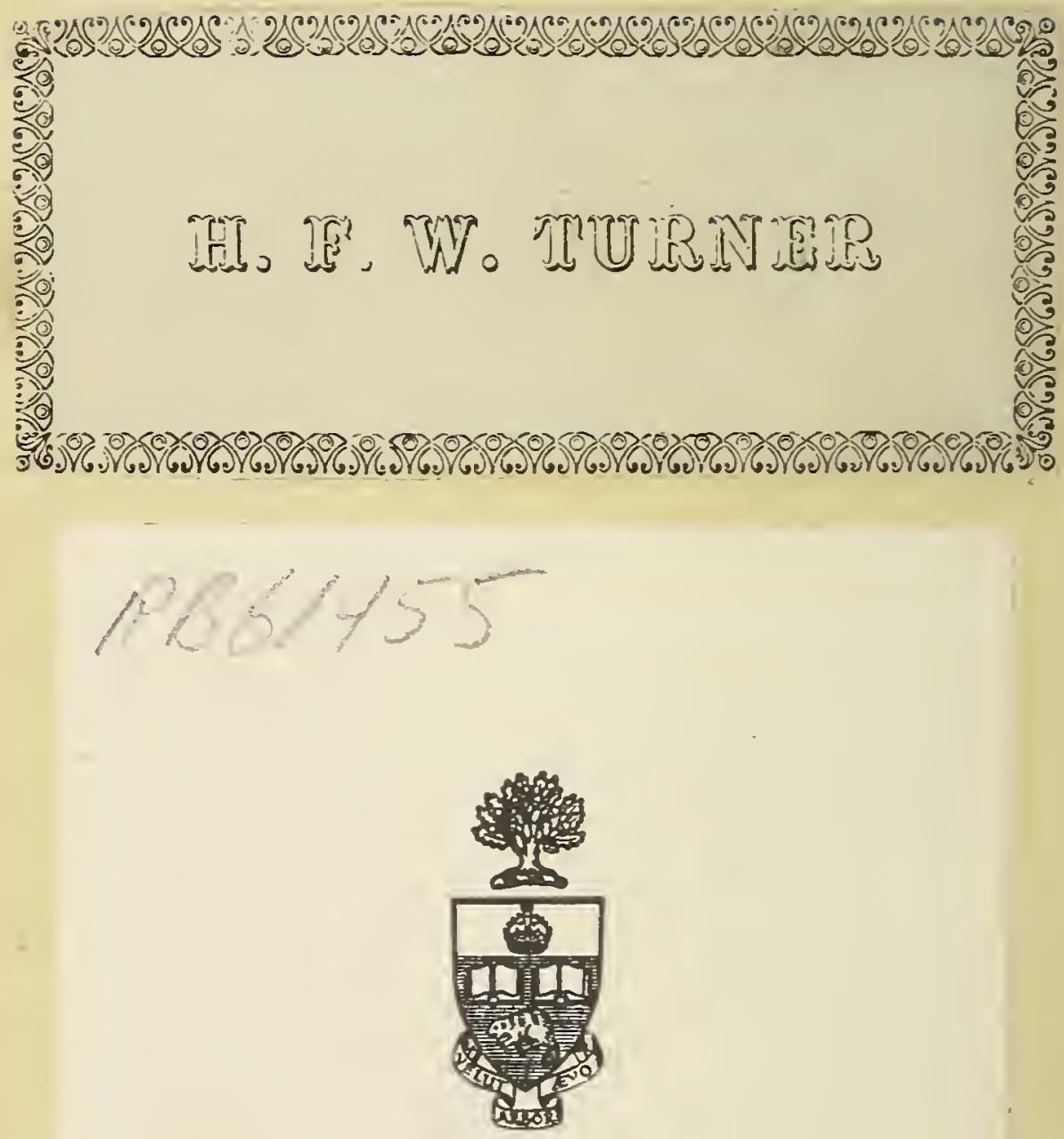

\section{Library \\ of the}

University of Toronto 


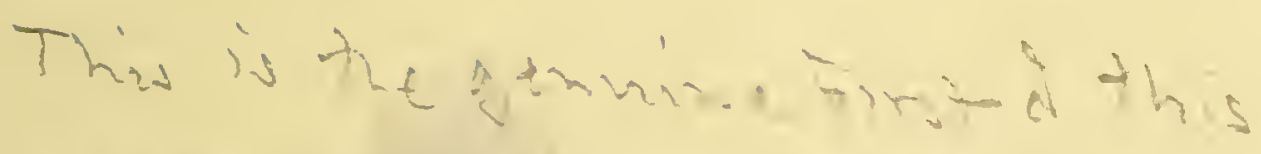
titie, bagionated in is baits $[50+49+40]+8[17866]$. The is andtar doud lest6 wich is pagingted 148 bो. 
Digitized by the Internet Archive in 2018 with funding from University of Toronto 


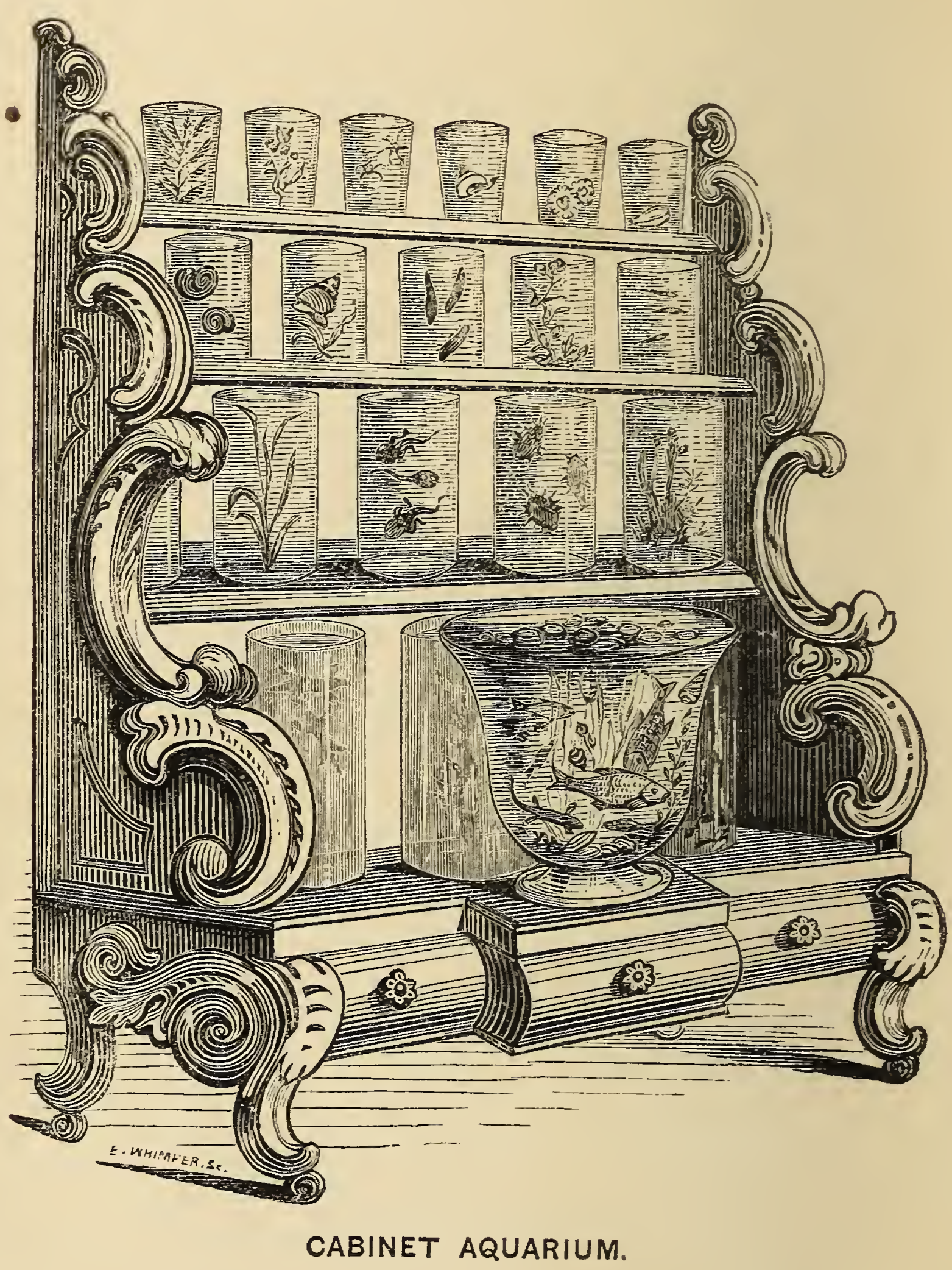




\section{THE B $00 \mathrm{~K}$}

OF

\section{THE A Q U A R U M} $\ln 2$

\section{W ATER CABINET;} OR,

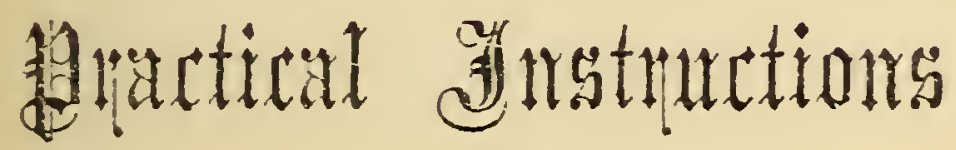

ON THE FORNATION, STOCKING, AND MaNAGERENT, IN ATI SEASONS, OF COLLECTIONS OF FRESH WATER AND MARINE IIFE :

\section{BY SHIRLEY HIBBERD,}

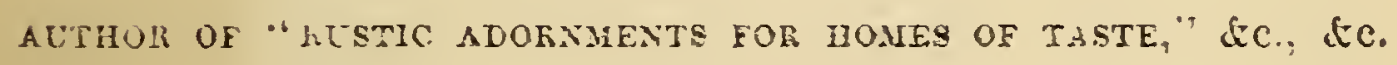

\section{ONDON:}

GROOMBRIDGE \& SONS, PATERNOSTER ROW. 



\section{PREFACE}

Everr day adds to the popularity of the Aquarium, but every day does not add to the accuracy of the published descriptions of it, or the perspicuity of the directions everywhere given for its formation and maintenance. Lately the periodical press has teemed with essays on the subject; but it does not require a very close scrutiny for the practical man to discern that a majority of such papers express the enthusiasm rather than the knowledge of their authors, - a few weeks' management of a tank seeming to be considered a sufficient qualification for the expounding of its philosophy, though it demands an acquaintance with the minutest details of the most refined departments of botany and zoology to do anything like justice to it.

I have done my best to explain and illustrate the whole rationale of marine and fresh-water tanks in my lately published work, Rustic Adornments for Homes of Taste; 


\section{PREFACE.}

but since that work, owing to the expense incurred in its production, is published at a price which every lover of the Aquarium cannot command, I have thought it no less a duty than a pleasure to treat the subject more briefly, but still practically, and I hope profitably, in a volume of less dimensions and less cost, written for another class of readers.

The object of this little work is to teach the beginner how to proceed safely and pleasurably in setting up aquaria, whether for mere ornament or for the study of the novel forms of animal and vegetable life which these collections enable us to observe closely, no less for the increase of our knowledge of the world, than for the exaltation of our sense of the omnipotence and benignity of Him who created it.

S. $H$. 


\title{
THE BOOK OF THE AQUARIUH.
}

\author{
PART I. \\ THE FRESH-WATER TANK. \\ CHAPTEP I.
}

WHAT IS AN AQUARIUM?

The Name.-The term vivarium was first applied to the vessel containing a collection of specimens of aquatic life, and the first rivarium of such a kind, on anything like an extensive scale, was that opened to public exhibition in the Regent's Park Zoological Gardens. Many naturalists had previonsly made experiments to ascertain some certain method of preserving aquatic animals in a living and healthy state; and the vivarium, which is the result of those experiments, may be considered as an imitation of the means employed by nature herself in the preservation and perpetuation of the various forms of animal and vegetable life wbich people the oceans and the streams.

The vivarimm is, therefore, no recent or sudden discovery, but a growth of years ; and its present perfection is the fruit of many patient investigations, trials, disappointments, and determinations to achieve success.

The term vivarium applies to any collection of animals -to a park of deer, a rabbit warren, a menagerie, or even 
a travelling show containing an asthmatic lion, a seedy cockatoo, and a pair of snakes that are hourly stirred up with a long pole. Hence such a term could never convey the very special idea of a vessel containing such specimens as form the stock of the aquarium. When this was felt, the affix aqua was added, to convey the idea of the watery medium in which the specimens are immersed, and hence we had aqua-vivarium, a compound of too clumsy a character to remain long in use. It is the water that gives the collection its special character; and water always reminds us of old Aquarius, who treats us to an anuual drenching from his celestial watering-pot. Aquarius triumphed, and the pretty prison in which his cool companions of the sign Pisces were doomed to be confined, acquired his name; and, since it is better to follow than to oppose usage, we leave the philological part of the question to the learned, and adopt Aquarium as the name of our collection.

The Object of the aquarium is to enable us to study the economy and derive pleasure from the contemplation of various forms of aquatic life, contributed by the lakes, the mountain rills, and the "resounding sea." Collections of objects that inhabit rivers and lakes are of course called Fresh-water aquaria; those that owe their origin to the sea are called Marine aquaria. A more simple name for the first would be River aquarium, which I humbly suggest it shall in future be called. But an aquarium is not a mere cabinet of specimens; it is a water garden in which we cultivate choice plants, and it is also in some sort a menagerie, in which we see living creatures of 
kinds hitherto the least studied by naturalists, displaying to our close gaze their natural forms, and colours, and instinsts, and economy, as freely and as happily as if they were still hidden from us in their native depths. In this sense, the aquarium remunerates for any trouble it may cost, in the lessons it affords of the workings of Almighty Wisdom, in those regions of life and wonder to which it introduces us.

The Philosophy of the Aquarium must be clearly understood by those who purpose to cultivate it. It is a self-supporting, self-renovating collection, in which the various influences of animal and regetable life balance each other, and maintain within the vessel a correspondence of action which preserves the whole. A mere globe of fish is not an aquarium in the sense here indicated; because, to preserve the fish for any length of time, the water must be frequently changed; and even then the excess of light to which they are exposed, and the confinement in a small space, in which they quickly exhaust the vital properties of the water, are circumstances at variance with their nature, and sooner or later prove fatal to their lives.

In an aquarium, the water is not changed at all, or at least only at long intervals, as we shall explain hereafter; and besides the enclosure of fishes in a vessel of water, growing plants of a suitable kind, always form a feature of the collection. Formed on this plan, an aquarium is an imitation of Nature on a small scale. The tank is a lake containing aquatic plants and animals, and these maintain each other in the water in the same way as terrestrial 
plants and animals contribute mutually to each other's support in the preservation of the purity of the air.

What happens when we put half-a-dozen gold fish into a globe? The fishes gulp in water and expel it at the gills. As it passes through the gills, whatever free oxygen the water contains is absorbed, and carbonic acid given in its place; and, in course of time, the free oxygen of the water is exhausted, the water becomes stale, and at last poisonous, from excess of carbonic acid. If the water is not changed the fishes come to the surface and gulp atmospheric air. But, though they naturally breathe air as we do, yet they are formed to extract it from the water; and when compelled to take air from the surface, the gills, or lungs, soon get inflamed, and death at last puts an end to their sufferings.

$\mathrm{Now}_{\mathrm{w}}$, if a gold-fish globe be not over-crowded with fishes we have only to throw in a goodly handful of some water weed, such as the Callitriche, for instance-and a new set of chemical operations commences at once, and it becomes unnecessary to change the water. The reason of this is easily explained. Plants absorb oxygen as animals do; but they also absorb carbonic acid, and from the carbonic acid thus absorbed, they remove the pure carbon, and convert it into vegetable tissue, giving out the free oxygen either to the water or the air, as the case may be. Hence, in a vessel containing water plants in a state of healthy growth, the plants exhale more oxygen than they absorb, and thus replace that which the fishes require for maintaining healthy respiration. Any one who will observe the healthy plants in an aquarium, when 
the sun shines through the tank, will see the leaves studded with bright beads, some of them sending up continuous streams of minute bubbles. These beads and bubbles are pure oxygen, which the plants distil from the water itself, in order to obtain its hydrogen, and from carbonic acid, in order to obtain its carbon.

There is one more feature, which no writer on the aquarium has yet noticed, namely-when a tank is juroperly stocked, the water soon gets crowded with infusorial animalculæ, which swarm among the plants, and on the sides of the glass in countless thousands, visible only by the aid of the microscope. These are in accordance with a natural law; the presence of vegetable matter in water always induces them. But observe their value : they contribute to the sustenance of the smaller fishes, by supplying them with food; and, strangely enough, the researches of modern chemists have proved that these minute creatures respire in much the same way as plants. While all other animals absorb oxygen, and perish if the supply of that gas is withdrawn, these minute organisms absorb carbonic acid, and give out oxygen in abundance. This has been proved by Professor Leibig, who collected several jars of oxygen from tanks containing infusoria only. Every one who has had experience in the management of tanks must have noticed that the water in a tank which has been established some months will sustain a much greater amount of animal life than one of the same dimensions, but recently stocked. The presence of infusoria in immense numbers is one of the reasons for this.

So far I have endeavoured to explain the theory of the 
aquarium, in the merest outline. Still brief as this chapter must be, I must here impress upon the mind of the beginner, that unless the leading features of the theory are borne in mind, success can never be achieved in the establishment of water collections of any kind.

If a tank requires frequent cleansing, or frequent changing of water, if the fishes come to the surface for air, or perish through the presence in the water of offensive matter-in fact, if the whole affair has not a distinctly self-supporting character, such as will preserve its purity, and strength, and beauty, without alteration of any kind -it must be concluded that it has been either unskilfully stocked or injudiciously managed.

It is my object to explain briefly, but clearly, the whole rationale of aquarium management, whether the tank be adopted as a mere ornament-than which there is nothing more beautiful-or as a museum of instruction and a school of study-than which there is nothing more suggestive, nothing than can afford finer lessons of the subtlety of the forces, or the refinement of the instincts, that give life and loveliness to the "world of waters."

\section{CHAPTER II.}

PROPER KINDS OF VESSELS.

Rectangular Tanks.-Any vessel that will hold water may be quickly converted into an aquarium; but as we desire to have at all times a clear view of the contents of the vessel, glass takes pre-eminence among the materials 
for tanks. For elegance and general utility, a properly built ressel of rectangular outline, haring at least two sides of glass, is found by most aquarians to be the best. Of course, no rule can be laid down as to the dimensions or

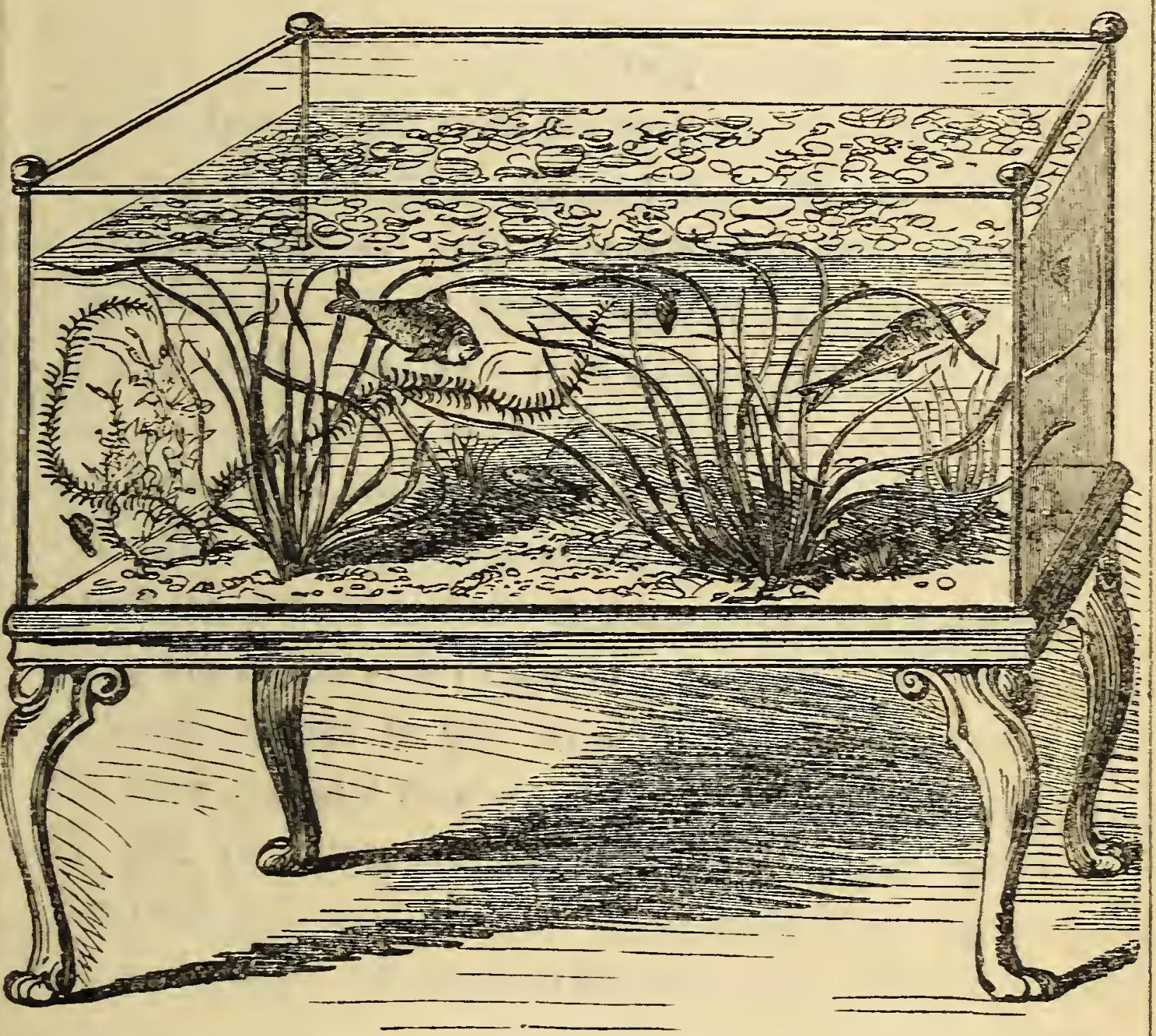

\footnotetext{
VALLISNERIA SPIRALIS, ANACHARIS ALSINASTRUM-GOLD CARP, ROACH, AND MINNOW.
}

forms of tanks-those details will best be determined by the means and tastes of the persons requiring them-but a few general remarks may prove useful. Construction of Tanks. - As this work may reach 
many remote districts, where an aquarian would find it difficult to get a tank properly made, a few hints on the proper mode of construction may be acceptable.

It must be borne in mind, then, that when a tank is filled, its weight is enormous, and hence it is difficult, sometimes impossible, to move it without first removing the whole or greater portion of its contents. Strength in the joints to resist pressure from within, and strength in the table or other support on which the tank is placed, is of the first importance. The bottom of such a tank as we have figured above is best formed of a slab of slate, and the two ends may be of slate also; the front and back of plate or very stout crown glass. The glass must be set in grooves in the slate, and bound outside with zinc or turned pillars of birch wood. The best cement is white-lead putty, or what is known as Scott's cement ; the composition of which it is not in my power to inform the reader. If a coating of shellac, dissolved in naptha, and made into a paste with whiting, were laid over the white-lead cement, as suggested by Mr. W. Dodgson, of Wigton, the water would be kept from contact with the lead, and the tank would require less seasoning.

The use of slate at the ends is to enable us to affix rockwork or carry across a rude arch; the cement used in constructing rockwork does not adhere to glass. But if rockwork is not thought desirable the slate ends may be dispensed with, and the vessel may be composed wholly of glass, except the bottom, which may be of slate or wood. 
In some districts slate is not to be easily obtained, and wood or stone are then the best substitutes, wood being preferable of the two. I have seen some handsome tanks composed wholly of wood and glass ; it is only necessary to choose well-seasoned material, and unite the joints very perfectly.

The yellow clay used by potters would be found suitable in some districts; and if the two ends and bottom were formed of such a material, and buttressed together by means of a rude arch, the fire would unite the whole, and render it as hard as stone. Mr. Dodgson, of Wigton, states, through Mr. Gosse's pages, that he has formed two tanks of this kind of clay: they measure three feet long by thirty inches broad and high, holding thirty gallons each. The weight being very enormous, the cost of carriage is so serious a matter that such tanks can only be had in the neighbourhood of a pottery. In London, the substitute for the clay would be terra cotta.

As a general guide as to form, proportions, and price, I may here describe a ressel which I have had in use during three years past, and which was made for me by Messrs. Treggon, of Jewin Street, London. It forms a beautiful ornament to my hall, and contains a pretty collection of British fishes. It is oblong, with four sides of glass. The joints are moulded in zinc; light, but strong. The base is also of zinc, in bold mouldings, and it has a double bottom, the outer one of zinc, and the inner one, which comes in contact with the water, is of slate. The joints are cemented with white-lead putty, painted white inside, and outside all the metal work is bronzed. Its 
measurements are, from the base to the upper edge sixteen inches, from front to back sixteen inches, and the length two feet seven inches. This is nearly a double cube, a geometric form which gives the greatest possible elegance to an oblong rectangular object. If exactly a double cube, the eye would too readily resolve it into two distinct parts ; it is, therefore, one inch less in length than would be requisite to form a double cube. The cost of this tank was $\mathfrak{E} 5$. Another and very elegant form of vessel is that introduced by Mr. Hall, of 75, London Wall, London, called the Revolving Tank, which is hexagonal in shape, and mounted on a light, but very strong castiron pedestal, on the centre of which it turns freely, for the examination of any part of its contents. It is five feet high to the top rim of the tank, the latter measuring two feet across, and two feet deep. This is a most beautiful object for a drawing room, and is sold for the low price of $£ 510$ s. The ingenuity of the manufacturers has led to the adoption of many other useful patterns, which need no description. But among the curiosities of tank manufacture, the vessels made entirely of glass, that is to say, with glass pillars as well as glass bottoms and ends, have enjoyed considerable popularity, their beantiful appearance proving but too seductive to the eye of many an uninitiated purchaser. I never had faith in these vessels, and never recommended them, and speaking by the best of tests-experience-I can say that there never was a greater mistake in the construction of aquaria. Those who purchased them have, in most cases, long since consigned them to the lumber ronm, 
or, perhaps, converted them into fern cases, and many other's would but be too glad to find some means of stopping leaks, and hiding fractures that arise from the utter absence of any means of expansion in ressels so peculiarly circumstanced. Tanks constructed entirely of glass are at the mercy of every, the slightest change of temperature, and their soundness cannot be counted on even from one day to another.

Mr. Warrington's Tank is of a peculiar construction, and is intended to admit the light from above only, and also to enable the water to absorb atmospheric air freely. Mr. Warrington says:-After fire years' and upwards experience, I have now adopted an aquarium, the form of which consists in a four-sided vessel, having the back gradually sloping upwards from the bottom at an angle of fifty degrees. The chief peculiarity of this tank is, that it admits light at the top only; the back and sides are usually composed of slate." The Warrington tank has been greatly improved by Mr. Lloyd, of Portland Road, Regent's Park, to whom I may here refer, as the leading dealer in ressels and stock of all binds, and whose long experience in aquarian matters is at the service of all who like to apply to him. Mr. Lloyd adopts a somewhat different form to that at first suggested by Mr. Warrington, the base is broader for the construction of a beach, and the angle of the sloping back is thirty degrees instead of fifty, a form which more fully realises the purpose for which this kind of tank is constructed, viz., the imitation of a natural rock pool; the doing away with the use of cement in the construction of a sloping shore of rock, and the exclusion of 
light except from the surface. Having used this form of tank for three years past, and still having my best marine collection in one of them, I can bear testimony to its excellence in every respect. Whoever has seen, at the slow rooms in Portland Road, Mr. Lloyd's mode of fitting the Warrington tank, will give it the preference over all others for a marine collection. To the several makers here named, I may add the Messis. Phillips, of 116, Bishopsgate Without, whose vessels are made on the best patterns, and with general strength and excellence combine the equally desirable quality of cheapness. Messrs. Phillips have for some years past supplied me with bell glasses, fern cases, and aquaria, and I have pleasure in including their names among the manufacturers to whom I can refer my readers, from a practical knowledge of the excellence of their goods.

Bell Glasses, or vases, are now largely used for aquaria. Mr. Hall was the first who thought of turning a propagating glass upside down to extemporise an rquarium; but he surely never thought that in a few months the aquarium would gain thousands of new followers through that simple trick of his in creating a cheap and elegant tank. Bell glasses for aquaria are to be obtained of any of the dealers in aquarian stock, and at most horticultural glass warehouses. The sizes range from ten inches to twenty inches in diameter, and the prices from one to fifteen shillings. For general purposes of use and ornament, I should recommend vessels of from twelve to eighteen inches. Those below twelve inches are too small to be of much service, and those above eighteen are 
liable to fracture on the occasion of any sudden change of temperature, especially in winter. Messirs. Phillips have lately, at my suggestion, produced a bell-glass ex-

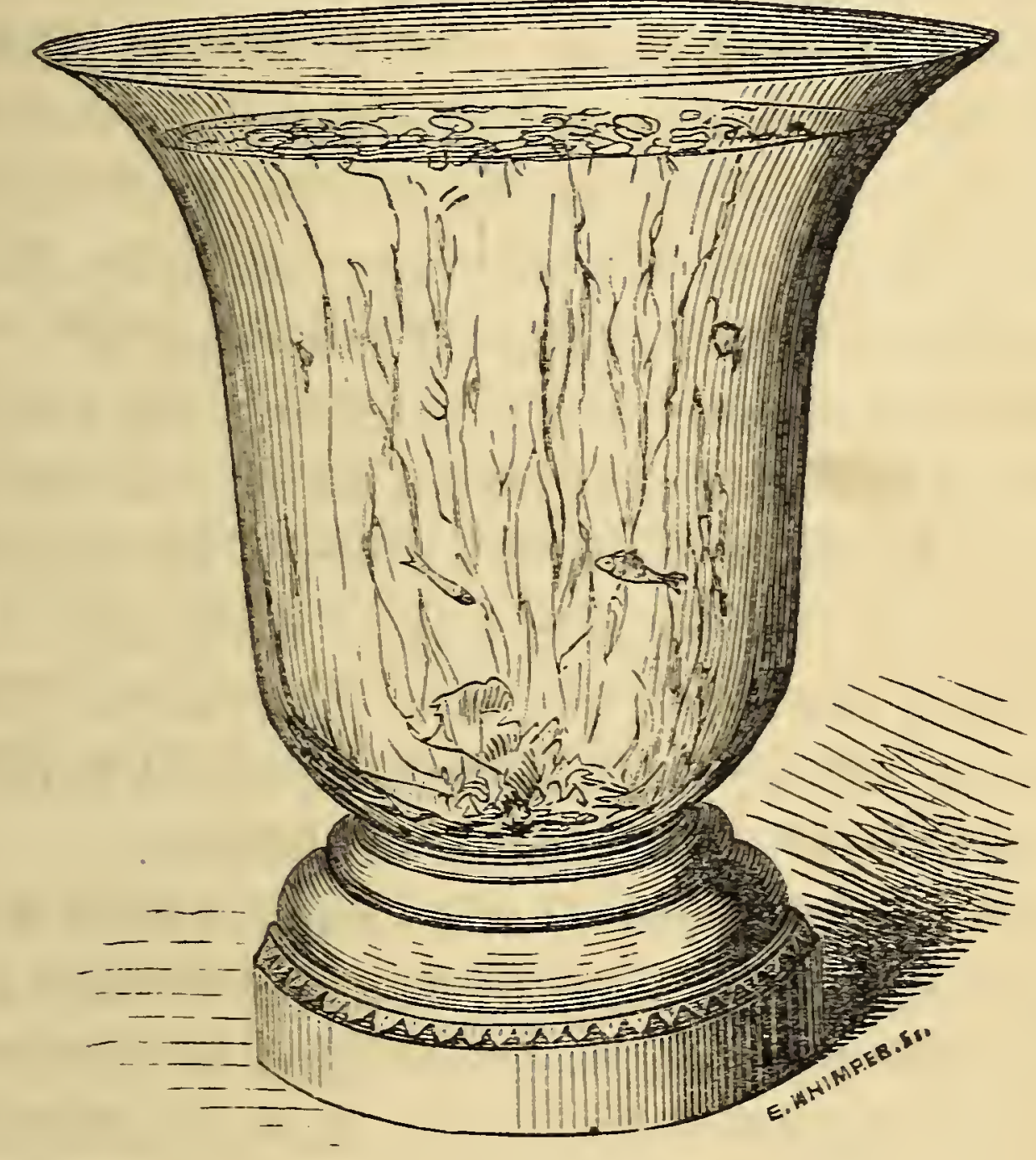

pressly for aquarian purposes; those in use hitherto were made for gardening purposes, and were carelessly blown. The shape I have suggested is one nearly approaching to that of the blossom of the great bearbind, the sides of the ressl describing straight lines, and the edges lipping over in an elegant vase-like form. These are made of whiter and stouter glass than the common propagators, and are, of course, charged at a slightly adranced rate.

Stands for Vases are to be had of virious forms and 
materials. Those formed of turned wood have the preference for elegance and safety; and, as the knob of the vase fits loosely in the depressed top of the stand, the rase can be turned round for inspection. It would be well to glue a piece of green baize to the bottom of the stand before putting it to use; and if the depression were filled in with sand, so as to touch the vase and ease the pressure from the rim, there would be greater safety, and the vase could still be turned round if necessary.

Where extreme cheapness is an object, a deal box, with a hole cut in the centre to receive the base of the vase, will make a suitable stand, or a common seed-pan filled in with sand and the vase pressed down into it may answer, at a cost of only firepence. A stone-vase, or any ornamental object, with a suitable depression in the top, can also be turned to account for the purpose.

When an earthenware or stone stand is used, a piece of India rubber tubing should be placed around its edge where it comes in contact with the glass to prevent fracture. The rigidity of the material renders this necessary to enable it to receive freely any expansion of the vase which may be caused by a change of temperature.

Glass jars, confectioner's show-glasses, a foot-bath of earthenware, or a few glass milk-pans, may be used for the preservation of aquatic objects, when a properly constructed vessel is not at hand; and even as adjuncts to high-class tanks, such vessels are frequently necessary and have special uses of their own. Still the tank, whether rectangular or vase-shaped, is a distinct thing in itself. The beauty is to be found in its completeness and 
the extent afforded for a variety of objects; and when we speak of an aquarium, we mean a ressel holding at least eight to thirty or more gallons of water, formed partially or wholly of glass, and stocked with plants and fishes in a living and healthy state. A glass lid may be used to prevent the entrance of dust and the escape of any of the inhabitants; but, as a rule, neither river nor marine tanks need to be kept covered-the dust sinks to the bottom, and noxious gases must have means of escape.

\section{CHAPTER III.}

\section{FITTING UP.}

Rockwork claims the first consideration when we proceed to fit up and furnish a tank. For a fresh-water aquarium, I do not recommend cemented rockwork; and, in the case of a vase, rockwork is positively dangerous, from its weight, and, unless very skilfully managed, will be ugly rather than ornamental. In the marine tank a few pieces of rock add to the beauty of the scene and the comfort of the creatures.

In fitting rockwork, some amount of taste and judgment must be brought into ercise. Shells and filagree work are largely used by some folks; but they belong properly to the child's aquarium-they suggest dolls and battledores. Some rough fragments of any kind of non-metallic stone may be built up into a dark arch, or piled up after the fashion of a cromlech-one flat piece resting on two or three vertical pieces, so as to form a rude 
table-like structure. These may be fixed firmly in the places they are intended to occupy by merely piling them up skilfully; but if cement is used, it should be the best Portland. The cement should be made into a stiff paste, and worked into the form required. Indeed, the rockwork may be wholly composed of such cement, especially if it is to have the form of an arch. The most important matter in the construction of rockwork is to give it a natural, rugged appearance, and to avoid loading the tank with superfluous weight. Whatever is done should be made secure, the pieces of stone well embedded in cement, and the whole firmly united. The tank must be well seasoned by being frequently filled and emptied, to dissolve out any free salts before being put to use.

The Bottom should be composed entirely of shingle or small pebbles, the whole well washed before being introduced to the tank. Coarse river sand may be used, but it requires frequent washing to remove all traces of iron and vegetable matters. I have used common silver sand and pebbles, sifted from garden gravel with no unfavourable result. In each case the materials were washed till the water could be poured away quite clear, and no matter what kind be used, the washing must be attended to. The coarser the grit the better its appearance, and; therefore, I do not recommend common sand, I merely show that it may be used when better is not attainable.

Mould has been extensively recommended as a bottom for tanks. I used it myself till I became convinced that it could be dispensed with altogether. It necessitates frequent changing of the water for at least a fortnight after 
THE FRESH-WATER AQUARIUI.

the first stocking of the tank, in order to get rid of the soluble vegetable matter, which the water dissolves out of it, and its presence promotes the growth of confervæ, and other low forms of aquatic regetation, that become obnoxious to the sight, and even hurtful to the health of the collection. I now use sand and pebbles only, and I find that aquatic plants of all kinds root freely and flourish in it, and, indeed, if pebbles only be used, they flourish just as well if their roots are covered.

Planting is next to be performed. The arrangement of plants will depend on the shape and size of the ressel. Generally speaking, massive plants look best if set back with lighter plants before them, just the same as a painter sets his chestnuts and elms in mid-distance, and his lady birches in the fore-ground. Stratiotes, Potamogeton, and other plants of a massive and decided character, are well seen through the interstices of Myriophyllums, Callitriche, and such like fragile and delicate structures. The flowering rush makes a fine centre piece for a vase, and appears to good advantage when seen through an archway, in a tank containing rockwork.

If there is a bed of two or three inches of sand, the roots may be gently pressed down into it, and a few clean pebbles laid over the spot to keep the plant in its position. Some plants will require a stone to be attached to them by means of a thread to fix them properly. Crowns of Stratiotes that have not formed roots, may be planted in this way. First cut away any black or decaying matter from the stem, and ull off any discoloured leaves, taking care not to injure the centre, then pass a piece of bass 
round the base, and attach a small stone. The plant will remain firmly where placed, and will throw out roots, and fix itself before the rotting of the bass takes place. It will then throw up new crowns, and become a very ornamental object. Loose stems of Chara, Anacharis alsinastrum, or Callitriche, may be gathered together, fixed by means of a stone in the same way, a strip of bass being better than string for attaching them. They will generally get well rooted in a fortnight, and remain firmly where planted.

The Water should be pure and bright when introduced to the tank, and if the supply is at all faulty, it will be best to pass it through a filter before using it. Spring water will do very well, but must stand a day or two to allow the plants to soften it, before the fishes are put in. My tanks are all filled with spring water, which I find altogether unobjectionable; but for the marine tank I think it preferable to any other in the manufacture of artificial sea-water. Writers on the aquarium usually insist on the use of river water, but in many places this is not attainable, and it is satisfactory to know that artesian, or well water, will serve the purpose admirably.

In filling the tank, a common garden watering pot, with a fine rose, is the best, as there is no dash to disturb the planting; if any other vessel be used, the water should be poured against the side of the vessel to reduce the force of the dash on the bottom.

Aspect.- Sunshine is good for the tank at all seasons of the year. But in high summer it should only have an hour's sun, morning and evening; the fierce solar heat of 
mid-day will give the water so high a temperature as to be fatal to its animal inhabitants. Comparing tanks one with another, I must give a preference to a south or east aspect. A north aspect will do very well, from May to October, but, during the winter months, a tank in such a position, would be feeble, and want watching. Good exposure to daylight is, of course, essential; but it should be borne in mind that the fresh-water tank needs more light than a marine one. My fresh-water tanks I find to prosper best when placed close to the windows, but marine tanks may be kept back two or three feet, in a south aspect. In fact, if you have a cabinet of waterinsects in a series of jars, the marine tank may very well stand behind them, and get sufficient light there, but the light should fall uninterruptedly on the fresh-water ressels.

\section{CHAPTER T.}

WATER PLANTS FOR THE AQUARIUM.

How to stock a Tank quickly. - It is usual to fix the plants and fill up the tank to within a few inches of the top, and then leave the whole for a week before completing the collection by the introduction of fishes. Where a beginner has sufficient patience to wait, this is very advisable, because the whole gets well settled, the plants start into growth, and the water gets softened and charged with oxygen. But this plan is not the only one that may be followed, and if well-washed pebbles be used in- 
stead of mould, as I have advised, the fishes may be introduced the same day as the plants are inserted, by

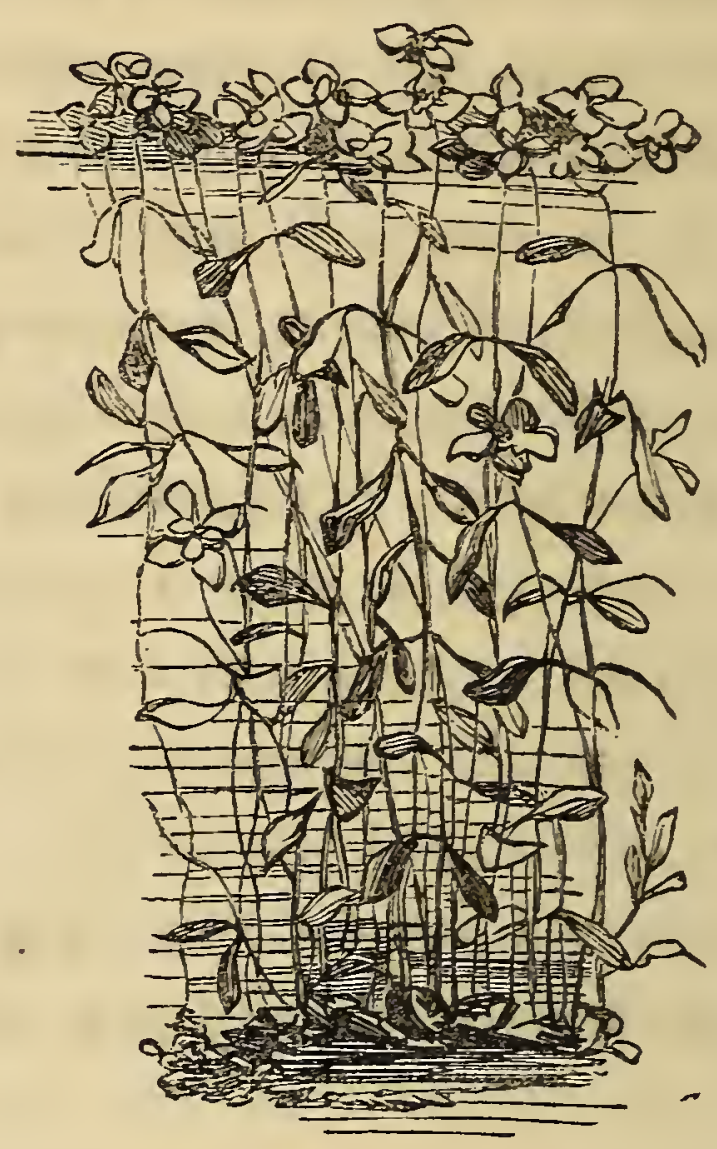

CALLITRICHE.

first taking care that you insert plenty of large healthy plants, and then throw on the top as much of the brook starwort-Callitriche autumnalis-as will cover the whole. I lately stocked two tanks in this way, and performed the whole in less than two hours, forming the bottom, planting the vegetation, and adding the fish,perch, tench, Prussian and British carp, roach, minnows, gudgeon, and chub-and all went on as well as if the tank had stood a month to strengthen, the water being from the first moment as brilliant as any of the Castalian springs that flow through classic verses. The lovely green of the starwort, spread over the whole of the sur- 
face of the water, has a fairy-like effect. It is necessary to get a good supply of starwort from a brook, throw it into a large vessel of clear water, pick off the green heads, with four or six inches of stem only to each, then wash all these picked portions till they are bright and clean, and throw the whole into the tank to take its chance. You must be lavish as to quantity. It soon spreads over the surface, and arranges itself most beautifully, forming a rich green ceiling, giving the verdurous shadow which a new tank wants; it grows freely, lasts for months, continually throwing out new roots and shoots from the joints, and creates abundance of oxygen, from the first hour of its being thrown in. Whenever it seems desirable it can be got rid of by simply lifting it out. My own are the only tanks I have seen stocked in this way.

Selection of Plants. - There is scarcely any aquatic plant but may be grown in an aquarium, and unless some attention is given to the botanical department, only half the pleasure and instruction it is capable of affording is attained. I cannot agree with Mr. Gosse, that the vegetation of a tank has so strictly a secondary place"preserved because they cannot be dispensed with,"for in either a marine or fresh-water vessel the vegetation is a special source of beauty and interest, and fairly divides attention with the animals. Supposing it were impossible to keep animals in such vessels, they would still be acceptable for the formation of aquatic gardens.

Beauty of form and adaptability to confinement are the requisites for this purpose, and the more the lakes and 
rivers are explored, the more the botanical department of the aquarium will be extended, both as to ornament and usefulness.

Water Soldier.-Among the plants easily attainable,

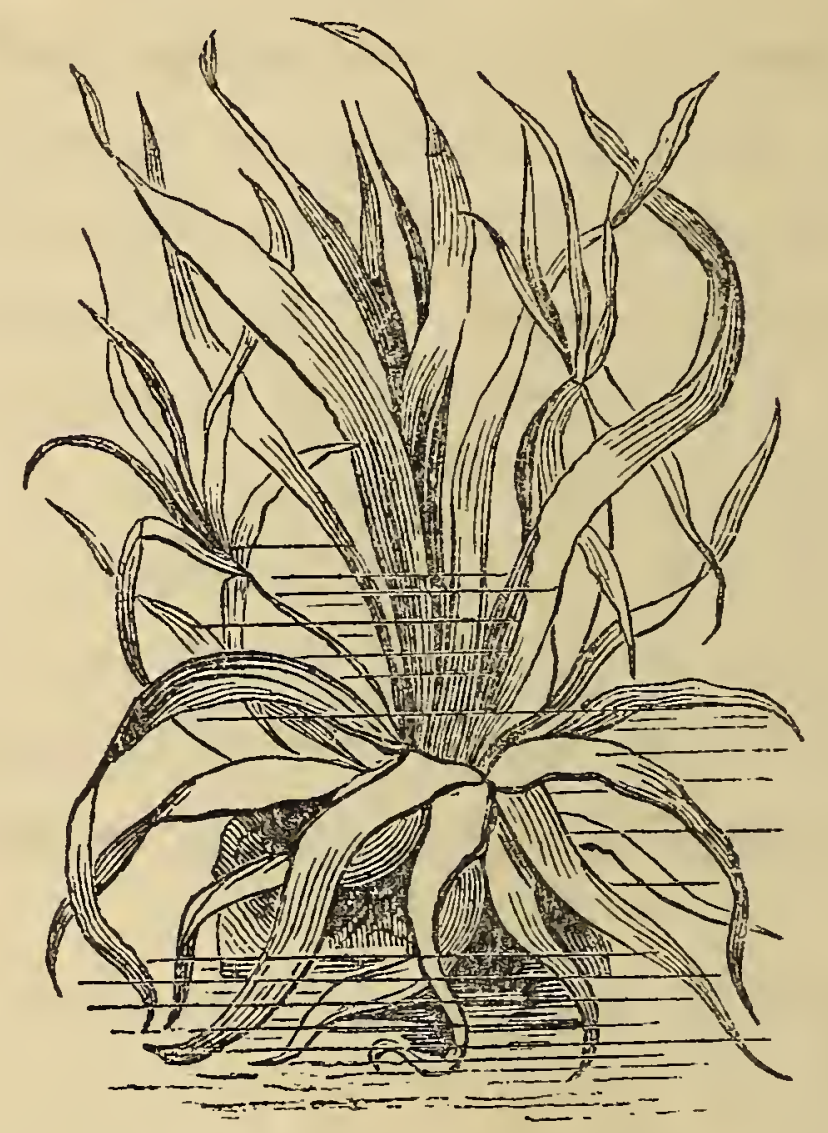

STRATIOTES ALOIDES.

and which combine grace of outline with cleanliness of growth, and tendency to create oxygen, I can recommend, first of all, the famous water soldier-Stratiotes aloides -a lovely cactus-like plant, which grows equally well with or without a root, as indeed most water-plants do. In form it closely resembles the tuft of herbage on the crown of a pine apple, and its leaves have similar serrated edges. If thrown in, it floats on the surface, and puts forth new heads in plenty, each new head springing from the base of a leaf on a long stalk. By separating these 
when pretty well grown, and remoring the stem from the base, any number of new plants may be formed. If it be wanted to root at the bottom (as indeed is best) cut away the decayed portion of the base, and trim off every darkcoloured leaf and throw the plant in again. In a few weeks it will throw out roots, and it may then be attached

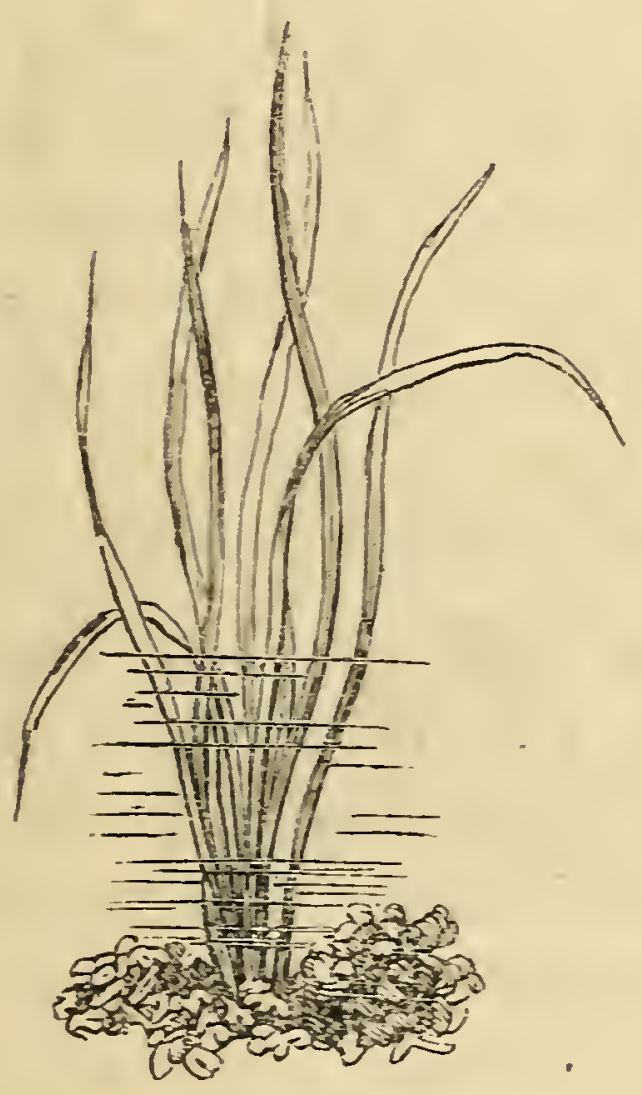

VALLISNERIA. SPIRALIS.

to a stone by a piece of bass, and dropped in to fix itself where wanted, without in any way disturbing the tank.

Stan'ort I have already spoken of as a good purveyo: of oxygen. It is a pretty plant of a delicate green hue, which appears on the surface of brooks and ditches ererywhere, both in this country and all orer the continent. At a little distance it has so much the appearance of duckreed, as to be recognized with difficulty. Its ald 
botanical name is Callitriche aquatalis, but owing to its liability to vary its appearance, botanists have lately divided it into several species, the two most common of which are C. Autumnalis and C. Vernalis.

Vallisneria spiralis is essential to every fresh-water tank. It is a native of Italy, and is named in honour of the Italian naturalist, Vallisneria. The blooming of this plant is very curious and worthy of close scrutiny. It likes abundance of light, and must be grown as a bottom plant, flourishing only when well rooted.

Anacharis alsinastrum, or the new Water-weed, is an interesting plant that grows freely, whether rooted or not; but it can only be considered ornamental when springing from the bottom. It thrives just as well without a root as with one, but, if firmly fixed, usually sends down a number of white rootlets from joints on the stem. I have seen roots of this kind sent down a distance of six inches to reach the bottom, while the lower part of the stem was decaying rapidly.

Myriophyllum contributes some lovely members to the aquarium. All the plants of this genera are of elegant structure, the leaves finely divided and of a delicate emerald green. M. Spicatum is perhaps the best, but there are other species to be had of the dealers that are worthy of attention.

Potamogeton is an extensive genera of water-plants, numbering not less than fifteen species in the brooks and rivers of this country alone. P. fluitans, crispus, and densus are most easily obtained, and they flomish in the tank, and make rich branching masses for the centre, or to 
climb orer rockwork. They are all rather coarse and apt to shed their lower leaves, but, if well placed, produce a striking effect. They blossom freely in the aquarium, and that is a great recommendation.

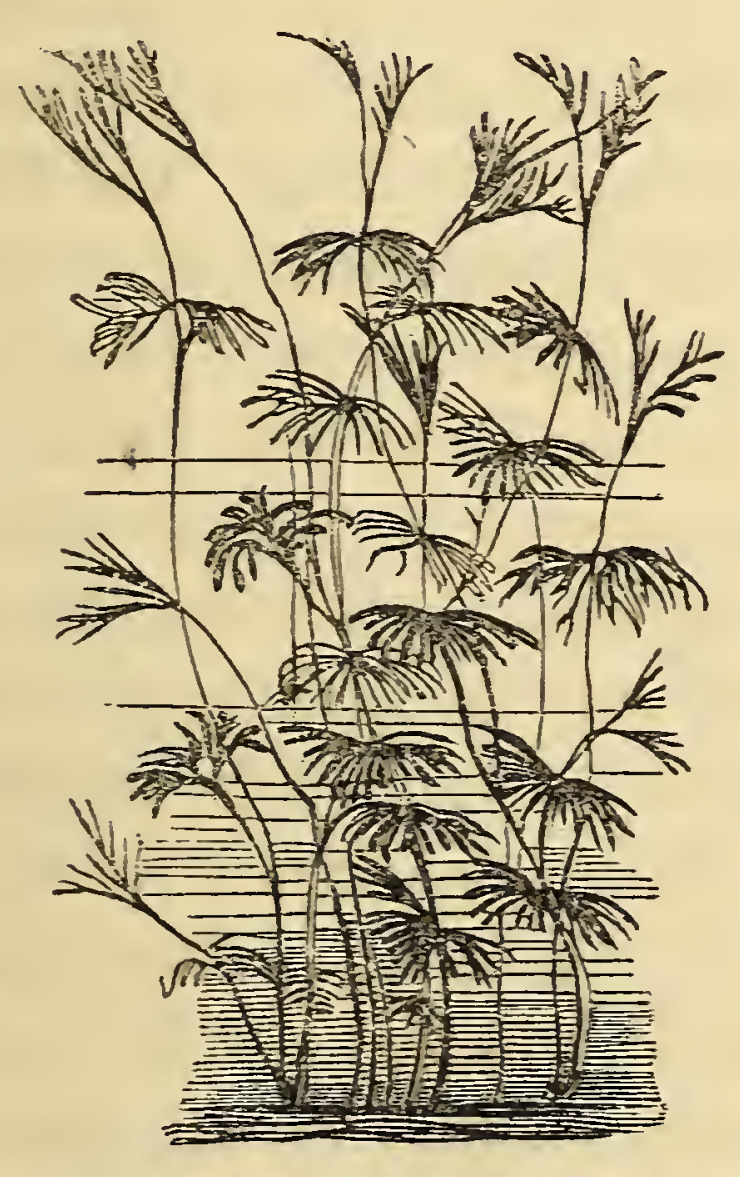

MYRIOPHYLUM SPICATUM.

Nuphar lutea is the best of the water-lilies for the purpose: it grows freely and produces graceful outlines beluw and above. It should be planted early in spring to secure blossom; but if it does not throw up blossoms in summer it may be renoved, and its place supplied by a plant in fuil bloom. The smaller species of Nymphcea are very suitable, and as they require mould to grow in, should be planted in flowerpots of a suitable size, with strong loam, and surfaced over with pebbles, and the pots firmly embedded in the pebbles at the bottom. 
Ericaulon, or the pipewort, sends its only English species-E. septangulare - to the tank. It is a bog plant, rises six inches high, and does not succeed if immersed more than three inches; hence it is suitable for the top of an arch, but not for the deep water of the tank. The plant is perennial and produces a white blossom, with one petal and four stamens. The flower-stem is velvety, and the leaves spread in a tuft from the root.

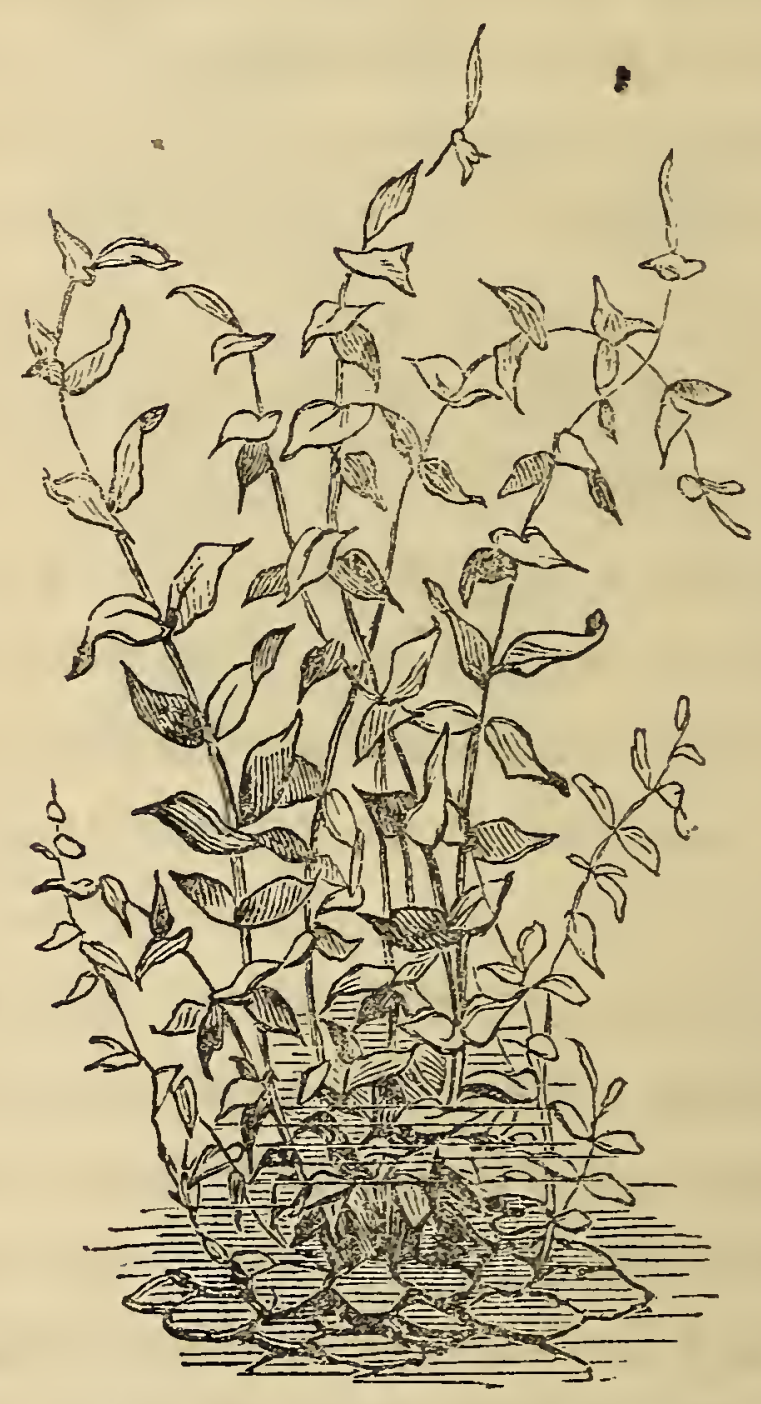

POTAMOGETON DENSUS.

Utricularia Vulgaris, or the hooded milfoil, may be recommended as a botanical curiosity, but is met with only (as far as I know) in the brooks of the southern counties.- 
THE FRESH-WATER AQUARIUM.

Hants and Surrey especially. It produces a yellow blossom in June and July. The root has a curious inflated appendage. There are two other species, U. minor and $U$. intermedia, differing but little in general aspect from the common sort.

Isolepis fluitans, or the floating Isolepis, is another of the curiosities of water botany. It is somewhat common in English ponds and slow streams. The blossom is inconspicuous, having no petals; the stamens are three in number, and there is but one petal.

Subularia aquatica is one of the few aquatic plants furnished by the great family of crossworts, or plants of the cabbage and wall-flower kind. Its common name is awl-wort, and suggested by the awl-like foliage which it produces under water. It is to be found only in clear mountain lakes, for it is a true aquatic alpine, frequent only in the North of England, and in Scotland and Ireland. The aquarian who resides near any mountain lake or pool, should seek for it, and treasure it as the choicest gem in his collection. The lower leares are currepointed, like a cobbler's awl, and in July it sends up a short stalk, bearing a head of snow-white four-petalled blossoms, and presents a somewhat unique example of a flower in full bloom under the water. My attention was first called to this plant by Mr. Dowden's charming work on wild plants, called "Botany of the Bohereens."

Ranunculus aquatalis, or the water crowfoot, must be known to everyone who has been in the habit of rambling in the country quite sober and with eyes open. It is to be found in almost every poud, and by the middle of May is in full bloom, continuing gay till far into autumn. It is 
a member of the buttercup family, and may be recognised as a buttercup of a snow white, with a bright yellow centre. If you step carefully to the edge of a pond or river, where this crowfoot covers the shore-water with its floating foliage and thousands of snow-flakes, you will not be in a hurry to disturb it, it is so truly beautiful. But reach forth your hand, and tenderly take up a head; and, as you draw it from its plashy bed, you will find that it is truly amphibious in structure, no part of the undergrowth being at all like that which floats above in the air and sunshine. The floating leaves are fleshy and

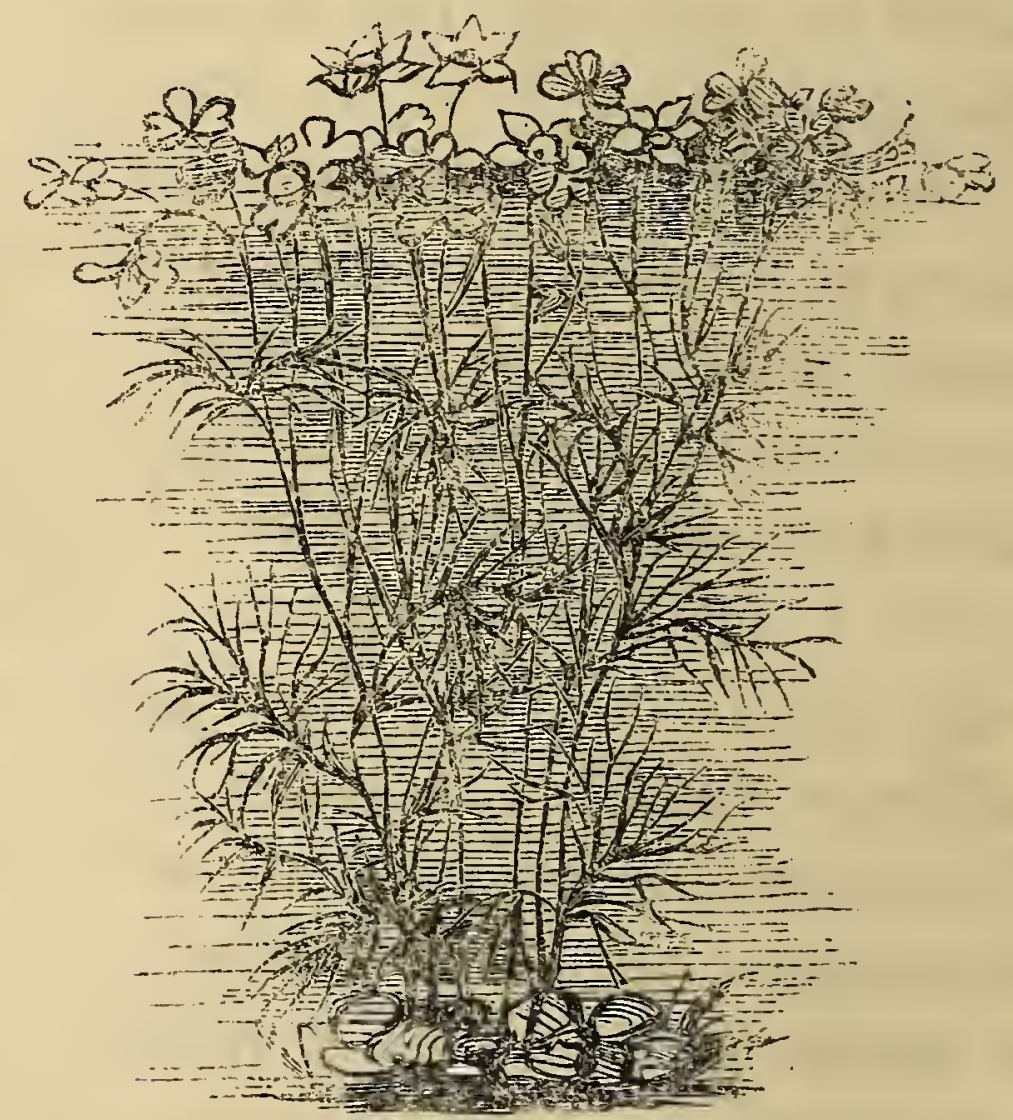

RANANCULUS AQUATALIS.

neatly lobed, the lower ones are as finely cut as fennel, and from every joint numerous white rootlets will be seen protruding, on their way to find root at the bottom. This plant requires good washing in clear water before it is fixed in the tank, or it may be the means of introducing 
many objectionable growths. It will be best to cut away the lower portions, and root it from a good joint, allowing it just length enough to float its ark of green and white upon the surface. When you have secured as many complete plants as yon require-and two strong stems will be enough for any tank-pick off a dozen or more blossom-heads, taking each at a clear joint. When the roots are planted, sprinkle the short flowering tops over the surface, and you will have at once a wide spread of snow-white flowers that will continue gay till the end of the summer, while the fixed roots will give a graceful effect to the vegetation of the mid-water.

Hydrocaris morsus rance, or the common frog-bit, may be obtained of the dealers, and is common in brooks and rivers. It is a perenuial, interesting in its growth, very curious when in flower, and a good maker of oxygen.

Alisma, of sereral species, may be obtained from brooks and rivers in plenty. It is the Water Plaintain of the old botanists, and has an ancient renown, which cannot be dealt with here. The long stems and lanceolate leaves of this genera give a pleasing variety to the regetation of the tank.

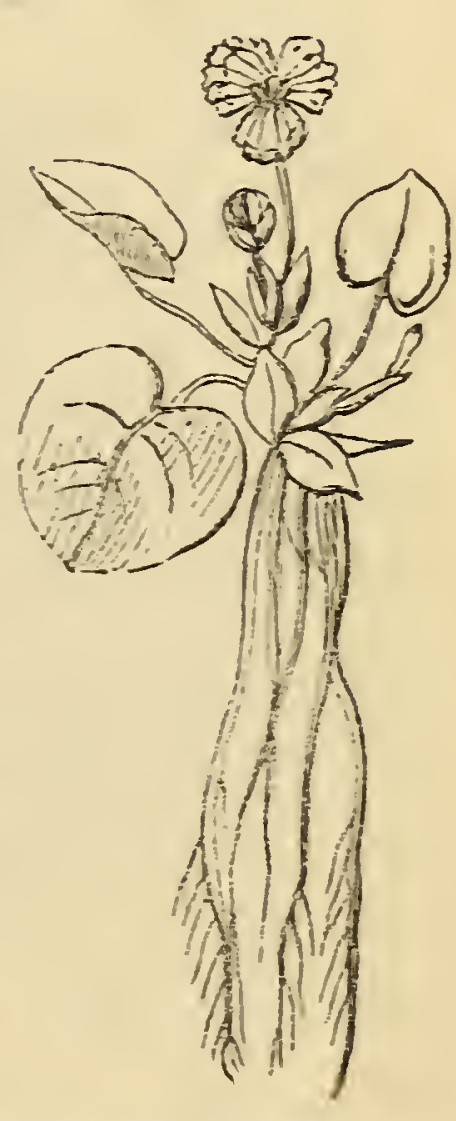

HYDROCARIS MORSUS RANE.

Lemna.-The four English species may be used to advantage. If the whole of the surface be covered with the pretty grass.green fronds of this very common plant, the effect is good, and it gires a salutary shade to the 
finny creatures. A single frond thrown in will soon spread and cover the tank in time, and its growth cannot be contemplated without pleasure. L. triscula is a very pretty kind, common in the neighbourhood of London.

The sweet scented Rush, member's of the Alisma tribe, the noble Sagittaria of six species, the Hornwort (Ceratophyllum) of two species, and, for more delicate purposes, Chara and Nitella may be recommended as suitable additions to the botanical department of the Aquarium.

\section{CHAPTER V.}

\section{FISHES FOR THE AQUARIUM.}

I sHALL here give the names and a few particulars of the history of the fishes that are most suitable for the aquarium, reserving my notes on the grouping and general stocking for a subsequent chapter. It is to the interesting family of Cyprinidae we are to look for our chief supplies. This tribe of fishes belongs to the great division of Malacopterygii, or those having their fin-membranes supported by flexible rays, which are either pointed or branched, or both.

Cyprinus carpio, the British Carp, is a handsome fish, differing slightly in structure from the Prussian and gold carp; yet, in general outline, preserving the true carp type-plumpness of body, iridescence of colour, and ease of movement in the water. This carp has a moderately-developed pair of moustachios, in the form of a barbule, at the upper part of each corner of the mouth, and a second one above it, on each side. Like the rest of its kindred, it is very tenacious of life, and does not 
quickly suffer from exhaustion of oxygen. It is an old fish, so to speak, for it was a favourite with the ancients. Pliny and Aristotle both speak of it in high terms of praise, and record that it lives to a hundred years of age, becoming in that time, as white and hoary as becomes an "ancient mariner." It is not indigenous to our rivers,

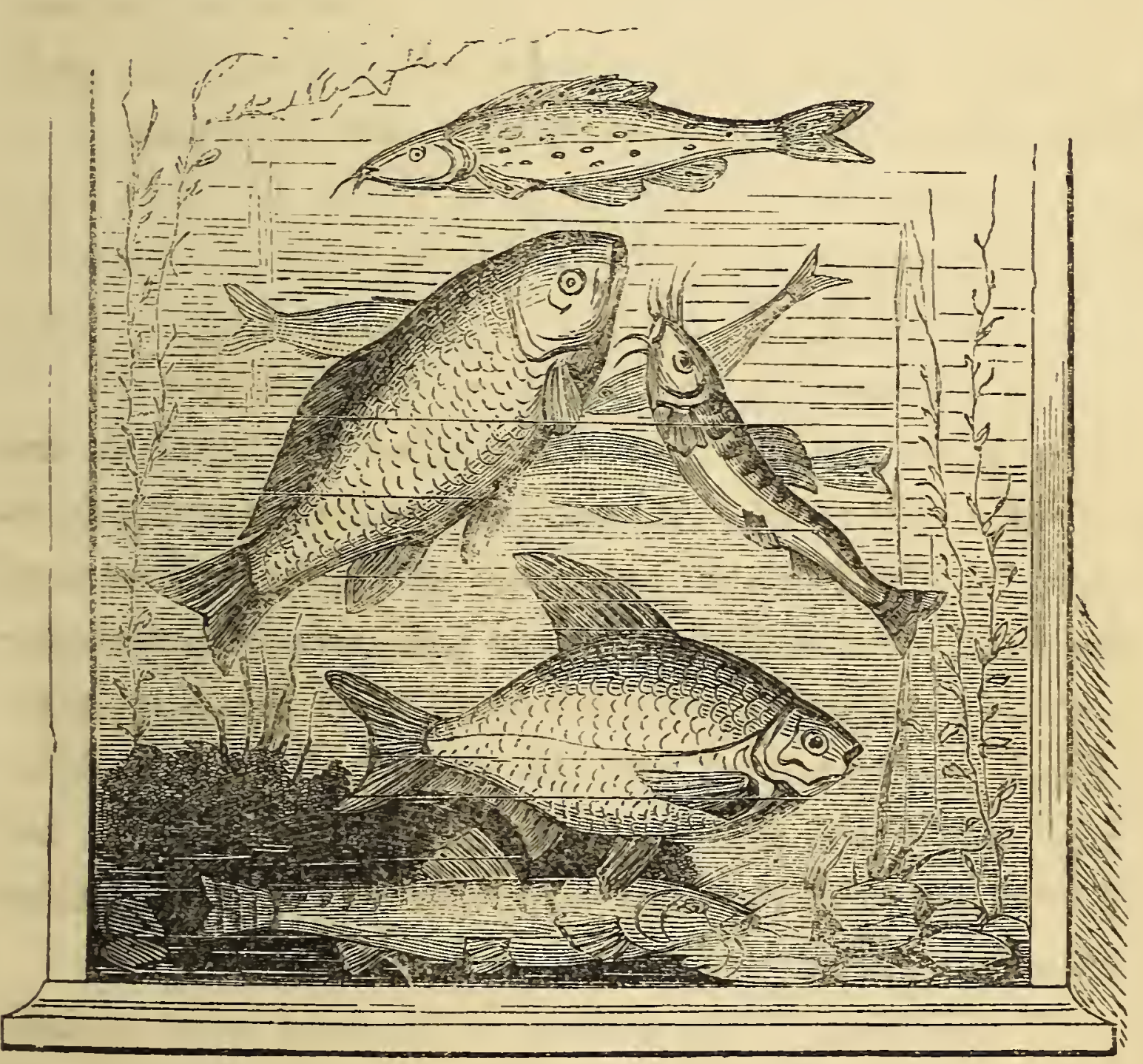

GUDGEON, PRUSSIAN CARP, LOACH, \& BREAM.

though, as far back as 1496, mention is made of it in the "Boke of St. Albans," quoted by Mr. Yarrell. It has been known to attain to a weight of trenty pounds, and in Holland is frequently kept alive in wet moss, and fattened on boiled potatoes. In this way it is said to live three weeks. 
THE FRESH-WATER AQUARIUM.

C. gibelio is the noble Prussian carp, unquestionably the best of all fishes for aquarian purposes. It will survive the wreck of a whole establishment, even if the water gets putrid and almost exhausted of oxygen. The easy, graceful motions, the beauty of the colouring, and the docility of this fish, must make it a favourite and a pet wherever it is kept. I have always had a large number of them, some of considerable size; they group themselves like friends on good terms of acquaintance, take an interest in whatever goes on in the room where the tank stands, and will watch their proprietor, elegantly poised in mid-water, for hours. Small, red earth-worms, young water-snails, and home-made bread, are the best of foods for them. They will seldom eat bread at first, but soon get to like it, eat it greedily, "and ask for more." The Prussian carp may be tanght to feed from the hand, even more boldly than the minnow, and readily assemble themselves for inspection when the side of the glass is gently tapped with the finger-nail. None of the carp family are carnivorous in any great degree. $\mathrm{Mr}$. Yarrell says the Prussian carp will recover after having been thirty hours removed from water.

C. carassius. - The crucian, or German carp, is easily distinguished from its compeers by its bream-shaped back, which rises from the nape into a high arch along the line of the dorsal fin. It is to be found in the Thames, between Hammersmith and Windsor, whether for the angler to kill or the aquarian to preserve. It is less hardy than the Prussian carp, and a little subject to fungoid growths.

C. auratus of Linneans, the lovely gold carp, will hold 
pre-eminence among domestic fishes for its splendour of colouring, though among true naturalists I think the Prussian carp will always compete with it to advantage, for the gold fish is certainly the dullest-minded of the family, and like most fops, lazy and unteachable. Pennant says, "In China every person of fashion keeps them for amusement, either in porcelain vessels or in the small basins that decorate the courts of the Chinese houses. The beanty of their colours and their lively motions give great entertainment, especially to the ladies, whose pleasures, from the policy of the country, are extremely limited." This carp appears to have been introduced into Britain about 1611, though the precise date is now difficult to determine. Mr. Yarrell leaves it an open question .

A large number of those reared for sale are the produce of waters which receive the waste steam from factories, and which are thus kept to a temperature freyuently as high as 80 degrees. In fact this carp is most prolific in tepid water, though those that are bred at a lower temperature are more beautiful. The gold carp is not the only fish that can bear such a high degree of heat, perch and mullet have been found in water's at 86 degrees : live eels were found by De Saussure in water heated to 113 degrees, and other instances, mentioned in Bushman's "Study of Nature," show the adaptability to temperature in fish of many other species. I had minnows frozen into a solid mass last winter, and the same day they were thrown into a tank, in a room where a fire was burning, and in a fer hours were sporting about in a genial warmth of 60 degrees, a change of more than 30 degrees in a few hour's. 


\section{THE FRESH-WATER AQUARIUM.}

The trade has been so long established, that a modern gold fish is truly a manufactured article, and the patterns vary from high class beauty to very decided deformity. Domesticated creatures are all liable to vary from their original type, but in the gold carp this variation proceeds to an extent not observed in any other animal which man has taken under his care. Their colours are as various as their forms; some have stumps instead of dorsal fins, with, perhaps, tails as large as their bodies; some have triple forked tails, and perhaps no trace of a dorsal fin at all, and in purchasing, it is as necessary to look to the structure and outline of the fish as to its colours, or, on after inspection, the purchaser may find himself in the possession of creatures as bright as morning sunshine, but in form as ugly as toads. There is no better food for gold fish than the crumb of bread. Many writers condemn this; I can only say that they thrive for years upon it, but if more be given at a time than the fish can eat, it soon renders the water impure, and does mischief.

Cyprinus Brama, the common bream, is a fish of bold outline and pleasing habit. The depth from the dorsal to the ventral fin is nearly equal to the length of the body, and justifies the comparison applied to a highshouldered biped, "backed like a bream." There is a prettier species, called the Cyprinus Buggenhagi, Pomeranian Bream, a specimen of which was lately supplied me, with a parcel of other fish, by Mr. Hall, the wellknown naturalist, of 75, London Wall, London.

$C$. Leucicus, the dace, C. rutilus, the roach, and $C$. alburnus, the bleak, may be classed together, as fishes well known to all who were ever seduced into playing 
truant, to try their boyish luck with a blood-worm and a bent pin, or who have since sunned themselves in the holiday pages of Izaak Walton, to fall in love with milkmaids, and dream all night of reedy livers that sing and sparkle, and tishes fried in meadow cowslips. These are delicate fishes, whether for the table or the tank. As the latter concerns me most here, let me warn the reader to proceed cautiously, for these lorely creatures have a sad habit of perishing quickly in confinement. In winter time they may be kept with ease, but as spring approaches, the best care for them will only be rewarded by the spectacle every morning of one or tro floating on the surface, never to swim again; while they do live, there are no more interesting creatures to be found for the gratification of the domestic circle. Bleak are even more sportive than minnows, and will chase a fly or small spider thrown in to them, till they tear it into shreds, and then will fight like Irish lads for the pieces. An aquarium, stocked with bleak and minnows, is a perpetual Donnybrook Fair, and will provoke the laugh ter of the dullest melancholic that ever looked at water as a medium wherein to end his imaginary woes. They soon feed from the hand, and eat bread greedily, darting after the crumbs with even more eagerness and vivacity than a party of school boys scrambling for halfpence. Their dazzling silvery scales, marked with the bright lateral line of spectral green, their taper forms, and large bright eyes, enlist all our sympathies, and compel us to doat upon them. If they are the best of fishes in this respect, they realise Wordsworth's famous passage- 
"The best die first,

But they whose hearts are dry as summer's dust, Burn to the socket."

and hence, as to longevity, they prove themselves the worst. Dace are very tameable, and soon grow bold and familial in captivity, comporting themselves in their attitudes and motions much like Prussian carp. Of the three, dace are the most hardy: I have had them survive three years in confinement; but to keep them through the summer, involves considerable trouble.

The aquarian, contemplating the silvery spangles of his white fish, may like to be reminded that the scales of dace, roach, and bleak, were formerly used in the manufacture of Oriental pearls, and are still used to some extent in making the imitations of pearl that occasionally gleam under the chandelier upon the brows of laughing belles.

C. phoxinus, the minnow. An aquarium without minnows is no aquarium at all-it is a makeshift. With a shoal of minnows and a few Prussian Carp an aquarium may be considered fairly stocked, because there is really something to look at, something to amuse, and something to iustruct. The minnow is a bold and impudent fish; he is at his ease in less than an hour, and in a week will show a sign of attachment and familiarity. They do not live beyond three years, but will reach that age in the confinement of a tank. Like carp and tench (and asses), minnors may be said never to die, for they survive the severest trials of heat and cold, neglect and bad treatment. The colours are pleasing, and bear some close resemblance to the mackerel; but fright will make 
them assume a pale fawn colour in an instant. Disease seldom attacks them, and when it does, they speedily recover if thrown into a large pan under a jet of water. Minnows spawn in June, and just before that time acquire their gayest mottlings of green and bronze, and silver, losing colour considerably after spawning.

C. gobio-The gudgeon is an every-day sort of fish, proper enough in a general collection, but where room is scarce it may very well be spared. In its markings the gudgeon has a striking appearance. It is a hardy fish, and rarely shows signs of exhaustion.

C. Tinca.-The tench is a quiet, shy fish, distinct in outline, and easily recognised; but, like the gudgenn, destitute of any highly attractive features. The tench is the most tenacious of life of any fish in the collection, and never shows signs of exhaustion by gulping air from the surface. Tench are easily tamed, and take great pleasure in nibbling their proprietor's fingers. Mine eat bread and cheese with me, and nibble my fingers fiercely whenever I permit them.

C. Barbus. - The barbel takes the lead in the aquatic moustache movement. His barbs are really ornamental, and altogether he is a handsome but shy fish. The dorsal and caudal fins are very symmetrically shaped, and the lateral line arrests the eye when we contemplate his pleasing colours. If small newts, small carp, and minnows are kept in the same tank with barbel, they are likely to disappear one by one; for when all is quiet he makes his meal without seeking aid from the culinary art.

C. barbatula is perhaps the most interesting fish in 


\section{THE FRESH-WATER AQUARIUM .}

the $\tan { }^{k}$, considered as an individual. With no attractive colours, and with an outline as straight and rigid as a piece of bark, he surprises you with his graceful motions as he hawks along the surface of the glass, propelled by the easy undulatory action of the caudal end of the spine. Towards dusk he wakes up from his daylight stupor, and commences his queer, but pretty gyrations; and, after gliding ghost-like all round the tank, suddenly drops down as if dead, and rests on any leaf or stone that may receive him, remaining motionless, and in any attitude - on his head, his tail, or his side - that the power of gravity may give him. Then, with an uneasy fidgetting, he flounders up again, and off he goes, as graceful as before, his pectoral fins spread out like samples of iace, looking as much like an eel with frills as it is possible to conceive. When ascending, his motion is so undulatory, that he may easily be mistaken for a smooth newt, going up for a bubble. Nor is our interest in him essened by his displays of individuality of character. $\mathrm{He}$ is a savage on a small scale. When he is quietly dozing, half hidden among the sand and pebbles, throw in a small red worm, and, as soon as tho water is tainted with the odour of this favourite food, he is awake and on the search. A triton seizes the worm, and shakes it as a cat would a mouse. The loach hunts him down, snaps at him fiercely, and tears the worm from his mouth, and woe to any minor fish that attempts to remove it from those bearded jaws. He flounders from place to place, shaking the prey as he goes, and stirs up such a cloud from the bottom, that the beauty of the scene is spoiled for a hour; at the end of which time you will probably 


\section{THE FRESH-WATER AQUAPIUM.}

find him gorging the prog, half of which still protrudes from his mouth, while two or three hungry minnows loiter about, looking wistfully at what they dare not hope to obtain.

It is a pity the loach is so delicate; it shows signs of exhanstion sonner than any fish in the collection. If

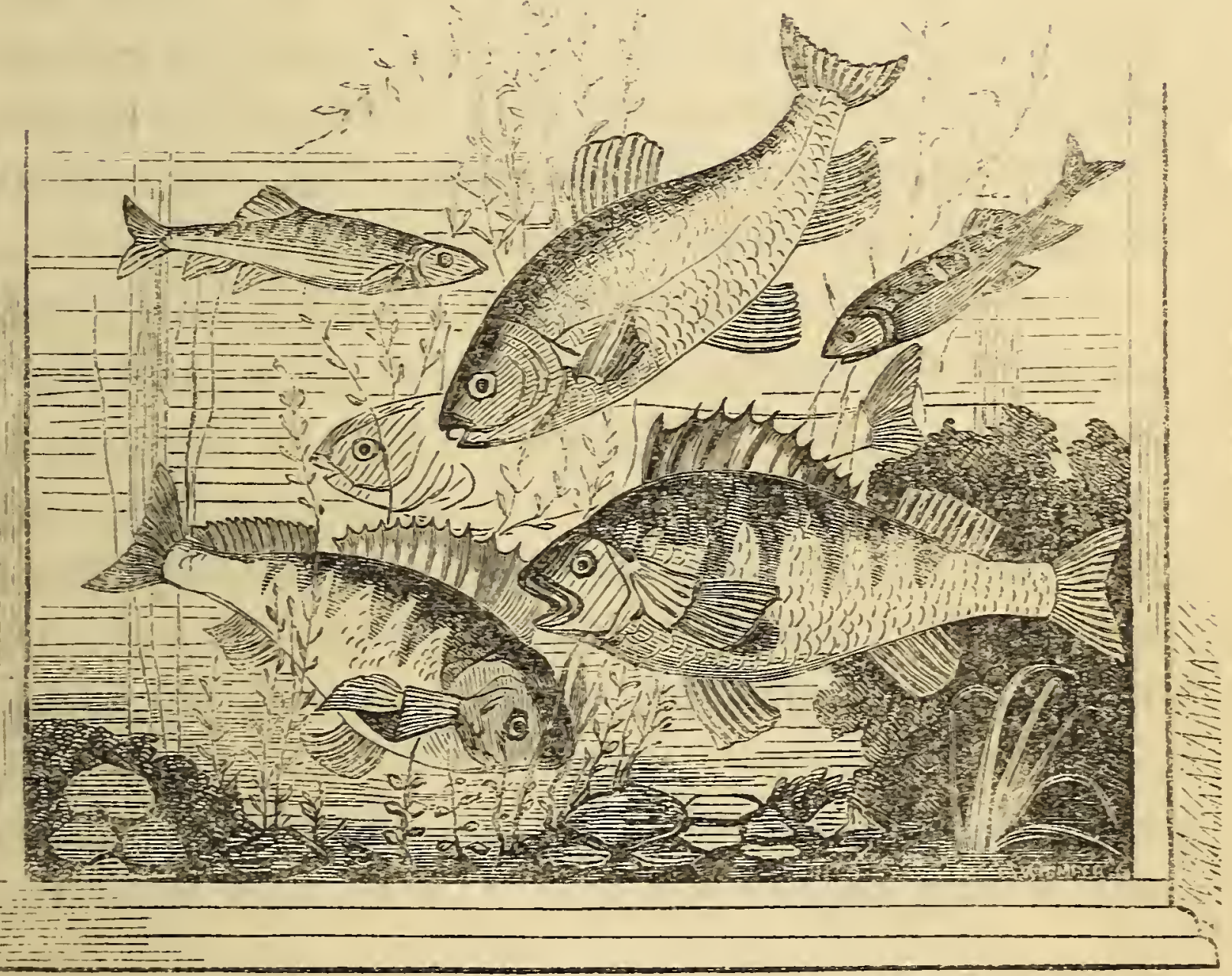

MINNOW, TENCH, \& PERCH.

oxygen fails, it comes to the surface to gulp air, and at last rolls over on its back, and pants in a way that is very painful to witness. Removed to a pan, under a jet of water, it soon recovers; but if long confined in a vessel the least overstocked, especially in warm weather, finishes its career by convulsive gaspings at the surface. 
A curious species of loach, known as the spine loach is met with occasionally in Wiltshire, in the Trent, near Nottingham, and in some of the tributaries of the Cam. Mr. Yarrell describes it; but as I have not yet had the good fortune to possess a living specimen, I can only refer to it casually.

C. cephalus. - The chub is a good aquarium fish. It is shy, but grows familiar under good treatment. Insects sooner attract it than any other food. Mr. Jesse says, that those in his vivarium throw off all reserve at the sight of a cockchafer, which they devour with eagerness. My own specimens of chub are exceedingly tame, and eat freely from the fingers.

Among the Acanthopterygii, or the spiny-finned fishes of Cuvier's arrangement, the only one suited to the freshwater tank, is the noble perch, Percidce. These are bold and dignified, and their decisive markings make them attractive in a general collection. They require plenty of room, or they soon show signs of exhaustion; and, under the best of circumstances, cannot be pronounced a hardy fish in confinement. They are capricious. I have had healthy specimens, taken by net, die off in a week; and weakly ones, taken by the hook, with portions of the lower jaw torn away, recover, and live for a year, after the ragged portions had been removed by scissors.

Gasterosteus needs a word or two. The sticklebacks are all pretty and interesting fish, plentifully found on the sea-coast, and in brooks and ponds all over the country. The species most trequently met with are G. semiarmatus, the half-armed stickleback, and $G$. pungitius, the ten- 
spined, but $G$. brachycentrus (short-spined), and G. spinulosus (four-spined), are rare.

Aquarian amateurs seem a little divided about the policy of keeping these in tanks. I can only advise the beginner to be careful, or he may regret having made their acquaintance. They are all savages, untameable savages, that delight in destruction, even if they cannot eat what they destroy. They will attack anything, and, with their spiny armour, dare the stoutest to retaliate upon their mischief-making pertinacity. In fact, they pass all their time in worrying the more peaceful members of the aquarium; and any one who has a few months' experience of them, will consider them the savagest of imps.

I have tried them on several occasions, and found them at spawning time more savage than usual; but at all other times savage enough. My favourite Prussian carp, that love me as I love them, that come when I call them, that burry to the side when I fillip the glass with my finger-nail, that watch me with all their eyes when I sit in the room with them, and that feed from my hand as a dog would, show at the tips of their pretty tails the sanguinary signs of gasterostean rengeance. Their transparent tails are ragged through the attacks of those sharp-toothed sarages, and more than one has succumbed to their persevering spite since my recent trial of them under the persuasion of a little friend, who begged me to put in some "robins" he bad canght at the brook. "Robins," indeed, the red jaws of G. acrleatus are suggestive of his blood-thirsty propensities, and he now does penance with a dozen of his kindred in a glass jar of 
THE FRESH-WATER AQUARIUM.

Callitriche autumnalis. With tench, gudgeons, and minnows they do better, but they are very annoying to carp of all kinds.

\section{CHAPTER VI.}

REPTILES, MOLLUSKS, AND INSECTS.

THE lower orders of creation supply many interesting specimens for the aquarium. Among the reptiles, newts, or water lizards, and the common frog, may be recommended as offering some forms of positive elegance, and some habits worthy of observation. The smooth newt; the warty newt, and the noble triton, are almost essential to the completion of the collection, and as they respire air at the surface, they do not exhaust the water of oxygen. The beautiful markings on the belly, and the graceful motions of these strange creatures, are sure to afford entertainment to those who can overcome the very common repugnance felt towards such creatures.

Some of the mollusks commend themselves for their beauty, and will be prized by the aquarian enthusiast. Among the univalves, lymnea, physo, planorbis, and paludina, are the most useful and ornamental. I must caution the amateur against the too ready adoption of any species of lymnea ; they are destructive, and particularly fond of Vallisneria, Stratiotes, and Callitriche, and while they are the best of cleaners, they are also the most indiscriminate of gluttons.

Paludina Vivipara is a handsome snail, with a bronze tinted, globular shell; but Planorbis Corneus and carri- 
THE FRESH-WATER AQUARIUM.

natus are still handsomer, having a spiral form, resembling the horn of a ram. These latter are to be trusted anywhere; they are good cleaners, and seldom attack the plants. Water suails breed rapidly in tanks, but the carp devour the young as fast as they appear; hence it is

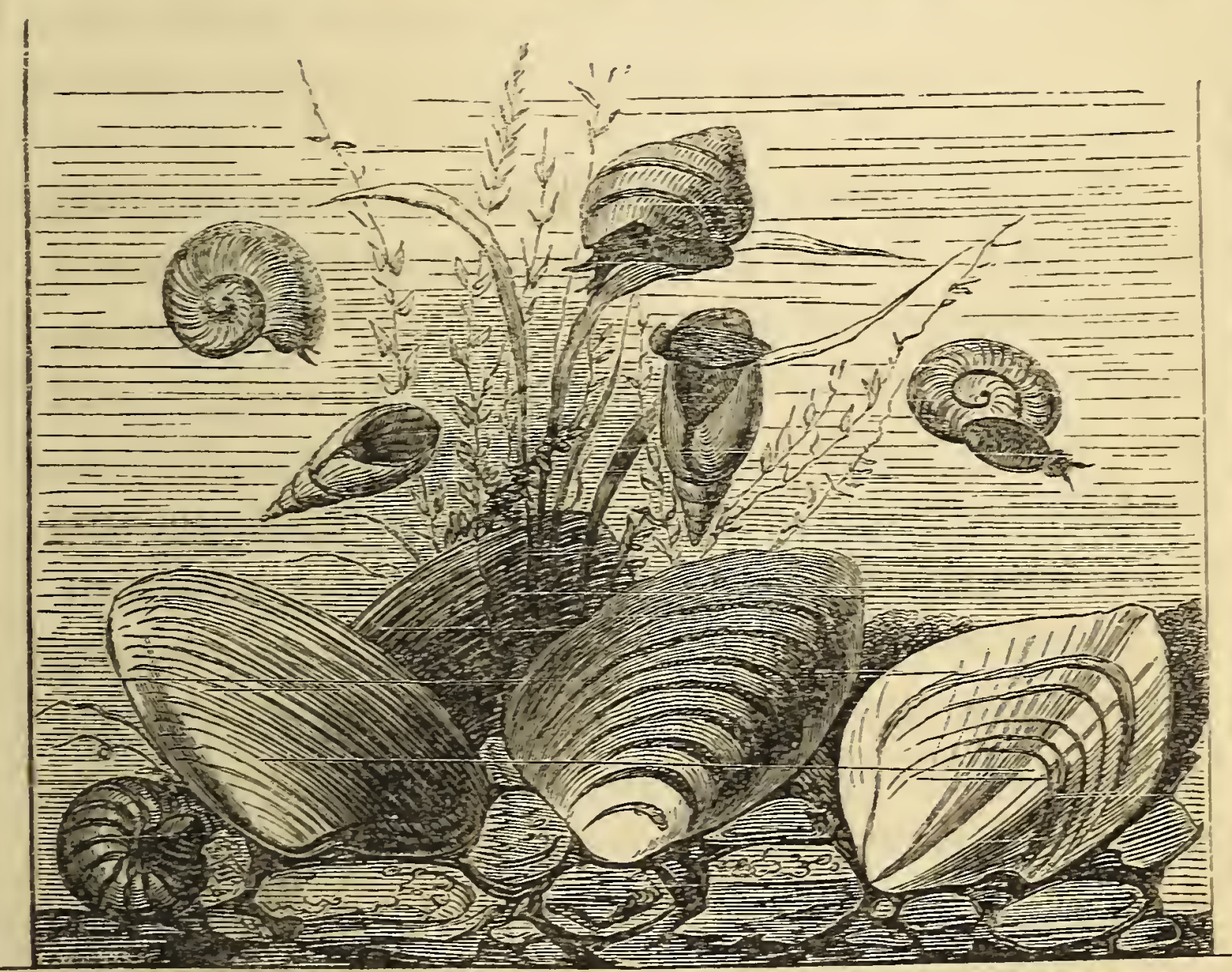

PLANORBIS CORNEUS, PALUDINA VIVIPARA, LYMNEA, STAGNALIS, UNIO PICTORUM, TUMIDUS, \& ANODON CYGNEUS.

advisable to remore the spawn into jars containing healthy plants, such as Callitriche, in which they may remain for observation of their growth, till stout enough to be committed to the tank.

Among the bivalves, the fresh-water swan mussel, Anodon cygneus, and the Duck mussel, Unio pictorum, are interesting burrowers, and perform a great service in 
the tank. They act as scavengers, not by the process of eating off objectionable growths, as in the case of univalves, but by the straining off of matters held in suspension in the water, and filtering it in a pure state, by the mechanism of their syphons, and ciliated gills. It is very interesting to watch them thus engaged, and to note the force of the stream which they project from time to time.

The only insect I can recommend for general adoption is the caddis worm, a comical and interesting creature, that can never mar the beauty of a tank. Half-a-dozen may be thrown in, and searched for occasionally-the search will always be well rewarded. When the cad closes his hybernacle, it will be well to remove it to a jar, to obtain a better opportunity of witnessing the transformation of the dormant worm into a four-winged fly of Stephens's family of Phryganea. The handsnme Hydrophilus, and the lively whirwig beetles are, however, quite harmless, and may be added to general collections with perfect safety.

\section{CHAPTER VII.}

\section{SELECTION OF STOCK.}

THE first thing to guard against is over-stocking, the common error of all beginners; taking large fish with small, I think about two or three to every gallon of water is the utmost that should be attempted. For a vessel of twelve gallons, I should recommend the following, as giving great variety, with considerable safety:-Four Prus- 
sian carp, of various sizes, one at least of fire inches in length; two small Crucian carp; one small perch; one small loach; two tench, of fire or six inches; six or eight minnows; one small eel; a dozen Planorbis corneus; half-a-dozen Paludina vivipara; three or four fresh-water mussels; and a dozen of different sorts of newts. There must be plenty of healthy regetation, or these will be too many. A tank so stocked, will be well filled with life; and if in a good light, all will go well.

Another, and to some, perhaps, prettier selection, might be made thus :-Three gold carp, of various sizes; three Prussian carp; two perch; four large loach; a dozen minnows; half-a-dozen bleak; and two dozen planorbis.

If stocked with great care, with a bottom of pebbles only, this would do very well; and the sides would never want cleansing. For a smaller ressel, the same selection might be made, but with a proportionate reduction of the numbers.

Those who make their own selection, may choose from the following:-

Plants.-Vallisneria spiralis, Anacharis alsinastrum, Callitriche vernalis and autumnalis, Nuphar-lutea, Potamogeton crispus, densus, and fluitans, Stratiotes aloides, Ranunculus aquatalis (apt to foul the water in a north aspect), Myriophyllum spicatum, Myosotis palustris, (the real forget-me-not-it flower's above the surface), Butomus umbellatus (for the centre-it flowers abore the surface), Lemna, Nitella, and Chara. For a list of suitable ferns and instructions on their culture I must refer the reader to my work entitled, "Rustic Adornments for Homes of Taste," where this department is amply treated. 
Fishes.-Gold carp, British, Prussian, and Crucian carp, pike, perch, tench, minnows, chub, loach, gudgeon, bream, and, in winter, roach, dace, and bleak.

Reptiles. -The smooth and warty newt, tadpoles, frogs. Mollusks.-Univalves, Planorbis corneus, and carrinatus, Paludina vivipara, Lymnea stagnalis, putris, auriculata, and glutinosa, Physa fontinalis, Bythinia tentacula.

Bivalves.-Anodon cygueus, Unio pictorum, tumidus, and margaritiferous, Dressinia polymorpha, Cyclas corneus.

\section{CHAPTER VIII.}

GENERAI MANAGEMENT.

FeEding should be performed twice or thrice a week, and will be as amusing to the observer as gratifying to the fishes. Bread is not so objectionable as many have stated. Carp, bleak, and minnows eat it greedily, and soon grow tame if regularly fed with it. Most small fishes take insects, such as flies, spiders, ants, and soft larva, greedily; but the large fish disdain such diet. Small red worms, and white of egg, are good general foods, and seem highly beneficial. When feeding, see that the carp get enough, for they are slow fish, and get robbed wholesale by their more lively neighbours. Food not eaten will decay, unless speedily removed, hence care must be exercised on this head.

Conferva. - When the tank has been established a few weeks, the inner sides of the glass will show signs of a green tinge of a slimy nature. This is owing to the 
growth upon it of minute forms of regetation. If this is allowed to go on unchecked, the glass will in time become opaque, and the view of the interior will be lost. Hence it must either be kept down in growth or occasionally removed.

Uses of Mollusks. - It is to prevent this rapid growth that water-snails are registered among the tenants of right, for these creatures subsist on vegetable matter only, and if a goodly number be thrown in, they will be found perpetually at work, eating the green growth from the sides, and thus preserving an open prospect.

Objections to Mollusks. - In a highly ornamental tank, water-snails may be thought objectionable, as interfering somewhat with the beauty of the scene. I know the ardent naturalist will cry out against this remark, and ask me if I can find a prettier object than a Planorbis corneus, coiled round like a horn of plenty; or a fullgrown Paludina, with its globular hybernaculum richly bronzed and mottled. I tell my friend that I love the pretty creatures as much as he does, yet, as I write for everybody who wishes to keep an aquarium, I feel bound to consider how it is to be managed without them, if their absence is desired. I confess, too, that I do object to their appearance in some cases myself, as I do also to beetles, and all other insects in a tank fitted up for the adornment of a drawing-room, howerer necessary they may be in the tank of a student.

In the first place, Paludince and Planorbis are the 
only kinds to be trusted in a general collection of plants, and the last is nost trustworthy of any. Lymnea are all fond of substantial dishes, and eat as much vallisneria as they do of the mucuous growth. A dozen of these gentry will most effectually check the vegetation of the tank, by eating holes in the handsomest leaves of the Stratiotes, and biting into the very heart of the Vallisneria. Starwort, too, they are very fond of, and soon clear the bottom of every fragment. Yet, the Lymnea are admirable cleaners; the pity is, that they will not see what is required of them, and do that only.

Again, the univalve mollusks do not keep the sides so clean, but that an occasional cleansing of another kind is sometimes necessary, and if the aquarian is not disposed to keep an army of quite semi-efficient scavengers, the remedy will be found in an occasional cleansing of the front glass, by means of a sponge attached to a stick, which must be plied over the surface, and occasionally taken out and washed in clean water, to remove the green scum, that it soon gets covered with.

Use of Confervoid Growths.-But I should object to any frenzy about cleansing tanks. They should be selfsupporting, and if Planorbis or Paludinæ are used in the proportion of about four of each to every gallon of water, a good view will always be preserved; and when the sponge is used, it should be on the front glass only, the back and sides should be allowed to get as green as they will.

Periodical Cleansing. - When a tank has stood twelvemonths or more, the water not having been changed at all during the whole time, it may be necessary to turn out the contents and restock it. This is not to be done 
unless the bottom has become black, and the roots of the plants show signs of decay, in fact, not unless it really wants it, and if bottomed with mould it certainly will, and it must be done accordingly. The live stock should be removed by means of a hand-net, the water drawn off by means of a syphon of glass, or gutta percha, and the plants taken out carefully and put by themselves, and then after remoring the bottom the glass can be quickly cleaned with the aid of water and fine sand, or rottenstone.

Exhaustion of Oxygen is made manifest by the fishes coming to the surface to gulp air, and it is also manifested by their retiring to the bottom, and quietly extending themselves on their backs in "horizontal repose"the repose of death. If too many animals be crowded into the ressel, this will soon happen, and either the number must be reduced or the water must be frequently changed, or we must have recourse to aeration. I consider the two latter remedies a proof of the incompetency of the aquarian-the necessity marks very bad management indeed.

Temperature. - If the aquarium be too much exposed to the heat of the sun in summer, or to the heat of a fierce fire in winter, the water will get tepid, and signals of distress will be shown by the protrusion of many panting mouths at the surface. I find that if the temperature rises above sixty degrees, things do not go on so well. The use of a blind or paper screen is, therefore, essential in summer time.

On winter evenings, when the room is made cozy by blazing blocks of coal, the collection will often show 
signs of distress. By opening the lower window-sash one or two inches when leaving the room for the night, things may be restored to a normal state in a few hours, and even if the weather is somewhat severe no harm will be done. At the same time intense cold checks the growth of the plants, and throws the fishes into a state of torpor, and the freezing of the water may cause the bursting of the tank.

In summer time, if the tank should get accidentally heated, it may be quickly cooled by wrapping around it a coarse cloth, saturated in water, and keeping it wet from time to time. These matters may be much simplified by fixing a small thermometer within the tank below the level of the water.

Dead specimens must be removed as quickly as possible. Bivalves are generally very hardy, but if death happens to one, the production of sulphuretted hydrogen is very rapid, and quickly fouls the tank.

Disease of Fishes. - I have tried numerous remedies for the diseases which beset fishes in winter, but with very little success. When the caudal fin gets coated with a fungoid growth, I have at once cut it off by means of a pair of scissors, and the fish has generally recovered, though much shorn of its beauty. Diseased animals should always be removed to a pan of fresh river water, with plenty of well-washed pebbles, to scrub themselves in, and placed in a quiet cool place, where they will probably recover, if occasionally fed and cared for. 


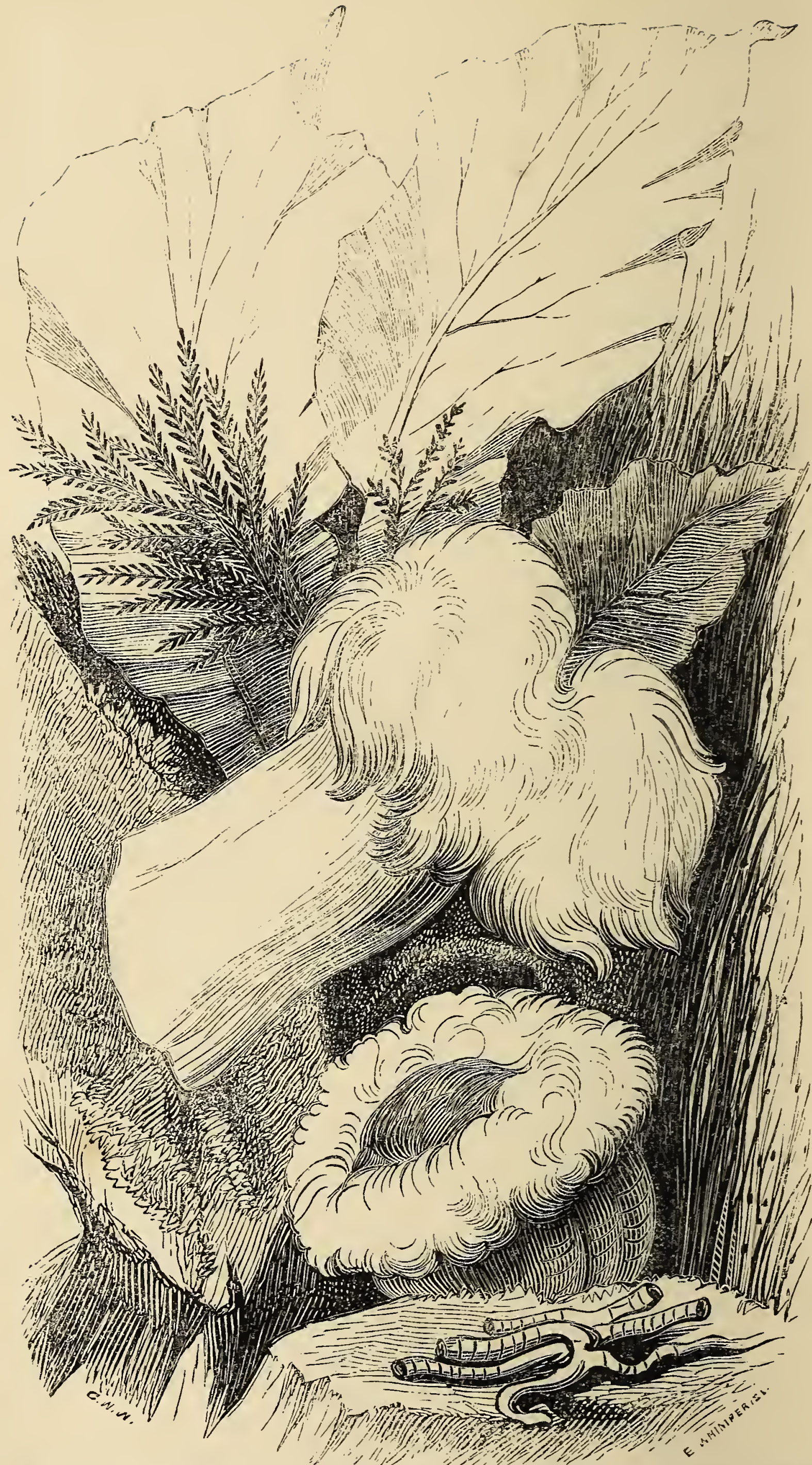

ACTINIA DIANTHUS, DELESSERIA SANGUINEA, CALLITHAMNIUM ROSEUM, GRIFFITHSIA SETACEA. 


\section{THE BOOK OF THE AQUARIUM.}

THE MARINE TANK.

\section{CHAPTER I.}

\section{T H E VE S E I.}

Points in which the Marine differs from the River Tank.-Though vessels of precisely the same construction are used for marine as well as fresh-water aquaria, yet, as the peculiar necessities of marine life demand some conditions of a special kind, I must here again briefly treat of the ressels in which marine stock may best be kept. Every variety of tank or vase referred to in the description of the fresh-water aquarium may be used in the formation of marine collections; but while vases are eminently suitable for river stock, they are not to be strongly recommended for marine, and for this important reason, that we do not generally have, as in the former case, a variety of moving forms poising in midwater, or chasing each other through every part of the tank; but in the present case ground stock constitutes the main feature of attraction, and hence we require a vessel which admits of examination in every part, which a tank does and a vase does not. In a ressel containing actinia, madrepores, serpula, \&c., we require to have at all times 
a clear view of the bottom, and a vase does not admit of this unless we look from above, the amount of refraction being very great at the base of the vessel. Hence, though marine stock may be well kept in vases, it must be borne in mind that such vessels are far inferior as to the means of inspection to rectangular tanks.

It is also important to bear in mind that marine stock invites the use of the microscope in a greater degree than river specimens, and a flat-sided vessel is the only one which affords proper facilities for the application of a magnifier to its contents.

Stained Glass.-But there is a still more important matter requiring notice here. We are indebted to that accurate observer, Mr. Warington, for valuable information on the effects of light upon certain forms of sea weeds, and his mode of overcoming this is by passing light through variously coloured media. It can easily be understood, that plants, whose natural habitat is at a considerable depth beneath the surface of the ocean, bear exposure to the full daylight very indifferently, and that some special arrangements are necessary in order to cause the solar rays to fall upon them as nearly as possible in the same manner as in the twilight recesses from which they have been removed. This is accomplished by fitting that side of the tank, which is intended to be placed next the window, with a sheet of glass stained of a soft sea green, and the softened light, so admitted to the tanks, promotes the healthy growth of the Algæ, and very materially increases the beauty of the vessel as seen from the other side. Mr. Lloyd, whose ripe experience ever 
THE MARINE AQUARIUM.

takes the most practical turn, has adopted this plan of construction, and strongly recommends it for every vessel intended for the reception of marine stock. Where it is desired to stock a ressel, in which the back plate is composed of colourless glass, with marine products, a substitute for coloured glass will be found in diaphanie; but the paper chosen for the purpose should be of the lightest shade of sea green, because it is less transparent than stained glass. In stocking vases, this plan of staining the side next the window, is to be strongly recommencled, no less for securing a healthy vegetation than of enlivening the beauty of the collection. I have used for this purpose, the paper and rarnish prepared by Messrs. Faudel and Phillips, of Newgate Street, and can commend it for cheapness, and the ease with which it can be applied.

Another point deserving of note is, that marine aquaria need a less depth of water than river collections:-For purposes of study, a number of glass dishes or milk-pans, will be found preferable to any kind of tank, or rase, especially for Zoophytes, though fishes and crustaceans require more room than mere bowls would afford them. In fact, the lower forms of marine life may be kept for many months without the help of sea weeds, if placed in shallow vessels - the absorption of oxygen, at the surface, being quite equal to their demand upon the water.

In all other respects, what has been already said on the subject of vessels must be understood to apply to all kinds of aquaria; the rectangular tank, and the bell glass, are the two leading forms, and to them I shall always refer when speaking of the tank in a general sense. 


\section{CHAP'TER II.}

FITTING UP-MATERIALS FOR THE BOTTOM.

CoArse sea sanả and pebbles, all well washed, make the best bottom; but if sea sand is not to be conveniently obtained, common silver or gritty river sand will answer every purpose, if washed until they cease to stain the water. Most writers on aquaria-Mr. Gosse especially-condemn silver sand, but I find it a most suitable material: its appearance is cleanly, and it only requires frequent washing in fresh water to fit it for the purpose. In the waterpipe which runs along the wall to supply the kitchen, I have had a hole pierced to form a jet, and this I find of great service in many aquarian operations, and especially in washing sand and pebbles. Where this can be done conveniently, or where the pan containing the materials to be washed can be placed under a tap turned on so as to drip rapidly, the washing can be accomplished with very little trouble, and the materials can remain for a week or two, being stirred up occasionally to hasten the dissolution of solvent matters. The sand should have a depth of two or three inches on the floor of the vessel, and above it should be placed a layer of pebbles, also well washed. The little white pebbles found among gravel look bright and pretty, and if the aquarian is also a lover of the garden, he will turn up plenty of them in digging, so as to keep a supply at hand for use when wanted. The pebbles are not essential, but the sand is, because many of the creatures delight in burrowing, and must 
THE MARINE AQUARIUM.

have opportunity afforded them of living their own life in a state of confinement.

Rock work is generally considered an essential of a marine tank, but experience has convinced me that the less we have of it the better. I have, in describing the fresh water tank, given instructions for its formation, and here desire only to caution the beginner to repress, as much as possible, any desire for mimic arches, cares, and grottos. In the first place, it must be remembered, that every cubic foot of rock work displaces a cubic foot of water, and reduces the capabilities of the tank for supporting a number of creatures. The more rock the less water, and the less water the fewer animals. Beside this, it is questionable if the use of cement of any kind is advisable; free lime may be expected to dissolve out of it, however much seasoning it may have previous to the introduction of the stock; and as marine creatures are more delicately constituted than fresh water ones, the subsequent loss of many may fairly be attributed to the presence of cement.

In the place of built-up arches, a few rough pieces of stone tastefully disposed at the bottom may be made to produce a good effect: a rough block of granite, or a stem of branching coral in the centre will be far preferable, except for vessels of large size, in which pyramids and arches may be less objectionable. It must be borne in mind, however, that rock work in some form or other is useful, as affording shelter and shade to such animals as love seclusion, and that, in a well managed tank, the rough blocks often get coated with a vegetable growth that 
increases the strength of the collection, and adds very much to its beauty. In this matter, the mischief arises out of the desire of beginners to display more ornament than is consistent with the nature of the case.

The water, of course, may be obtained direct from the sea, and should, if possible, be dipped in mid-channel. Shore water is not altogether objectionable, for where we find the greater part of our specimens it is evident the water must be suitable for them. In fact, I have found water that I have brought from the sea-side in jars serve just as well as that supplied by the steamer from the open sea; but near the mouth of a river it would be found unsuitable, as it would, also, from any parts of the coast where land springs abound. Earthenware vessels are the best for the conveyance of sea-water and specimens, but if a large quantity be required, a new cask should be used, and the greatest care taken to have it stopped with a new bung, and conveyed quickly to its destination. Mr. Gosse recommends a cask of fir-wood if it can be procured, "the wood of the oak, of which wine casks are usually made, gives out tannin or gallic acid to the contained water, which by its astringency, converts, the animal integuments into leather." In fact, our poor anemones get their hides tanned if any vegetable bitter comes into contact with the water in which they are to be kept. I make it a rule to filter sea water through charcoal before using it; this is not essential if the water appears bright, but is, at least, a precautionary process that may have its advantages.

-Artificial Water is now used so extensively as to justify some special remarks here upon it. It must be 
understood that where real sea water can be easily obtained, as at spots near the coast, it is undoubtedly the best, though, in some respects, the artificial preparation is preferable, because less liable to certain eccentric changes of constitution, which will fall under our attention further on. Sea-water contains the spores of plants, and the germs of many forms of animal life which may have development in the tank, and when these births occur, it is a special gratification to the possessor. But such germs may also decay, and cause putrescence; and if a tank is neglected, the water is liable to get cloudy, the stones black, the sides of the ressel semi-opaque, and the animals diseased. Death soon sets his black seal on the undertaking when such a state of things occurs, and the collection, however costly or well formed at first, may be lost. Now such misfortunes as these are preventible, as it will be my duty to show presently, but I here call attention to the fact, that artificial sea-water is much less liable to get out of condition from the very absence of organic matter, which on first reflections, we should regard as a disadvantage. Thus, the prepared material has certain advantages over the natural; we lose the chance of rearing new additions to the stock through the introduction of minute organic germs; but incur no danger of those same germs perishing and polluting the bright lymph.

But artificial water is quite unsuited for animal life of any kind, until it has been brought into condition by means of growing weeds for eight or ten days, and for crustacea, star fishes, and fishes proper, it is not suitable till it has been in use for many months, and even then 
some species lose their health in it, and at last perish. But for anemones of all kinds, many mollusks and crustaceans, and some other forms to be presently described, artificial water does well, and improves daily if properly managed. Unless, therefore, the aquarian is bent upon domesticating the rarer and more delicate sea specimens, he may avail himself of the aid of the chemist, and manufacture sea-water from the river or the pump.

Composition of Marine Salts.-The limited space of this work will not enable me to enter upon the consideration of the chemistry of this question so fully as I have done in "Rustic Adornments ;" nor, perhaps, is it necessary here to do more than point out the - simplest method of procedure. There are at least seven ingredients besides water, used in the natural laboratory, but the chemist dispenses with some of these, and finds every purpose served by using a selection of the chief of them. The composition of sea water is as follows:-

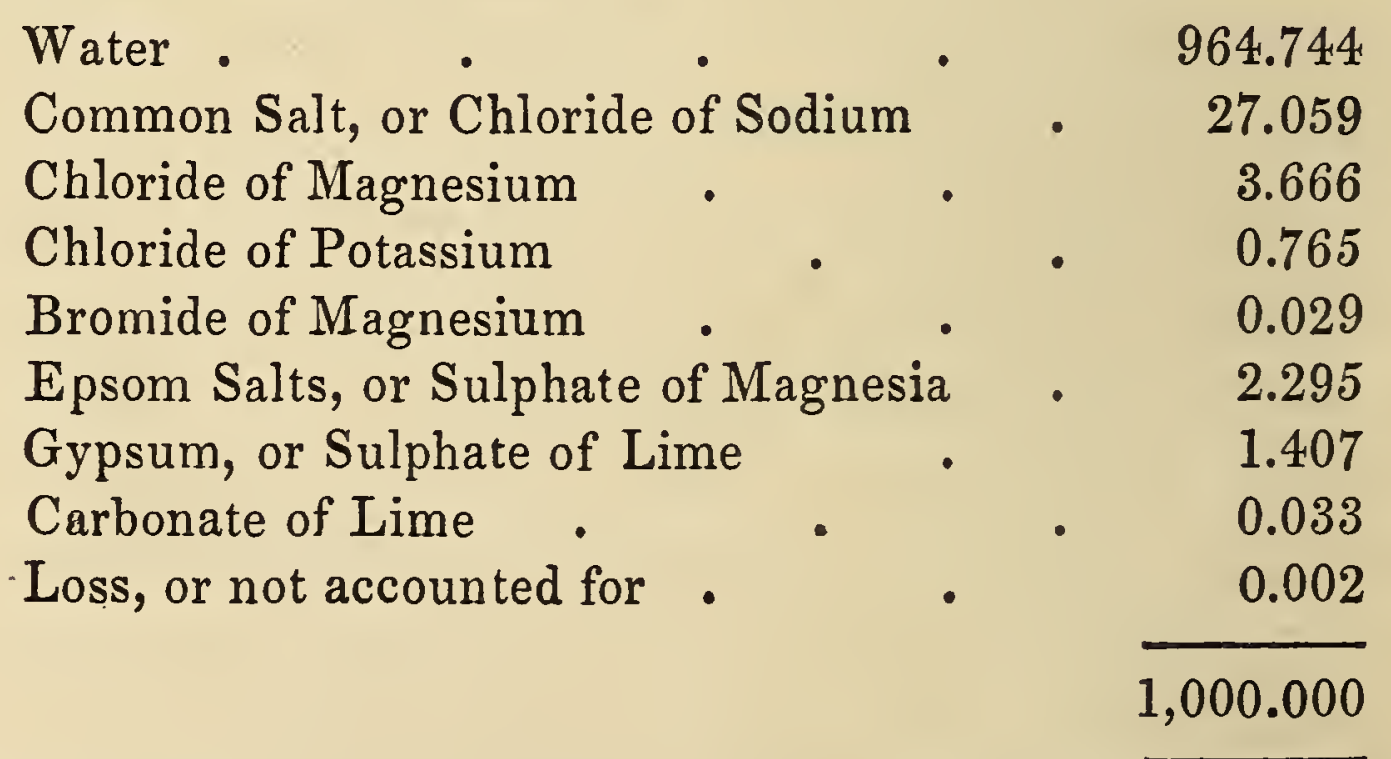

Mr. Gosse, in July 1854, communicated to the "Magazine of Natural History" the results of experiments in the imitation of this composition, and a formula for the 
artificial preparation of sea-water. In the fictitious preparation the component salts were reduced to four, so that no less than three of the original ingredients were dispensed with. If the reader will note in what minute quantities the bromide of magnesium, the sulphate and carbonate of lime occur, and at the same time bear in mind that river and spring waters always contain a considerable proportion of the last-mentioned ingredient, it will be easily understood that the absence of those materials in the preparation does not materially affect its value. The preparation on Mr. Gosse's plan is composed as follows:-

Common Table Salt

Epsom Salts .

Chloride of Magnesium

Chloride of Potassium

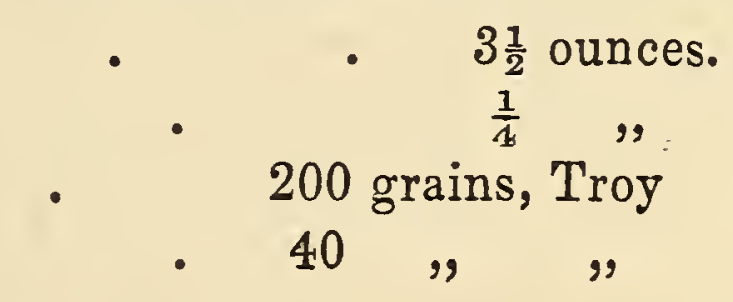

The recipe may be given in another form to aroid the perplexity of avoirdupoise and troy weights, thus :-

Common Salt

Epsom Salts

Chloride of Magnesium

Chloride of Potassium
81 parts.

7
10,
2

Management of Artificial Water.-When the salts are ready, it is best to mix them in an earthern pan or jar, and allow them to settle and refine for a day or two. To dissolve them in the tank is decidedly a bad plan, though it is daily recommended by the dealers. Any one who will dissolve a portion in a clean bell glass, and allow it to stand for a week, using the clearest water, and adding nothing but the saits, will observe, at the end of that time, a minute gritty deposit, similar to iron rust, mixed 
with minute fragments of sand. This deposit proves that the chemicals we obtain are not pure; and, perhaps, it is not desirable that excessive purity should be obtained, but it certainly is desirable to keep such matters out of the tank. When the salts have been stirred up once or twice, so as to dissolve them thoroughly, test them for the last time with the hydrometer, till it registers 1.027 or thereabouts; it may safely range from 1.026 to 1.028 without interfering with the success of the experiment. Hydrometers, registered for sea-water, are not everywhere obtainable, and the specific gravity-bulb, sold by Mr. Lloyd, for a shilling, answers the purpose just as well. Mr. Cox, of 100, Newgate Street, has lately supplied me with an hydrometer of a register of 1.000 to 1.050 , made in Paris-the cost was seven shillings. I prefer it to the bulb because it can be put to other uses.

A Caution to the Uninitiated.-Some beginners have attempted the preservation of marine specimens in solutions of common bay-salt, and have expressed surprise that they perish rapidly in a solution of salt obtained from the sea. Anyone at all acquainted with chemistry would readily predict, that there could be no more certain way of killing the creatures than the adoption of such a plan of preserving them. When bay-salt is prepared, many of the more soluble materials, chloride of magnesium especially, remain behind in the mother liquor, because the chloride of sodium crystallizes first, hence bay-salt alone does not produce sea-water; we must have the aid of the experienced chemist, or turn chemists and prepare it for ourselves. 
THE MARINE AQUARIUM.

Those not experienced in chemical manipulations may find some difficulty in obtaining and weighing accurately the several ingredients; and I should advise them to purchase the preparation sold by $\mathrm{Mr}$. Bolton, of 146, Holborn Bars. This merely requires to be dissolved according to the instructions just given. Mr. Bolton has given minute attention to the preparation of the salts, and is now improving them by compounding with them the minute quantities of the more subtle ingredients, which were originally omitted by Mr. Gosse. The salts are sold in packets, at the rate of three gallons for a shilling; a price which must be considered reasonable when we consider the purity of the article, and the care taken in its manufacture.

Filtering. - When the salts are well mingled with the water, pass the liquid, through a filter, into the tank, which is supposed to have been already well-seasoned, and furnished with a bottom of sand and pebbles, and any ornaments that may be deemed necessary. A bee glass, with a bit of sponge thrust into the orifice, is a convenient form of filter, but if such a thing is not at hand, take an old flower pot, and wash it quite clean, thrust a piece of sponge through the hole in the bottom, and throw into it a handful of powdered charcoal. This may be suspended above the tank, or stood on two slips of wood, and filled from time to time, till the whole of the water has been passed through it.

Some healthy plants of Ulva latissima and Enteromorpha compressa are now to be introduced, and the whole left undisturbed for at least a week or ten days, when the 
THE MARINE AQUARIUM.

stocking with animal life may commence; some of the hardy Actinia being the best of all to start with. But if the aquarian is in a fever to see something alive in the new vessel, he may drop in half-a-dozen Actinia mesembryanthemum, one day after the introduction of the plants, and unless he has made some mistake in the preliminaries

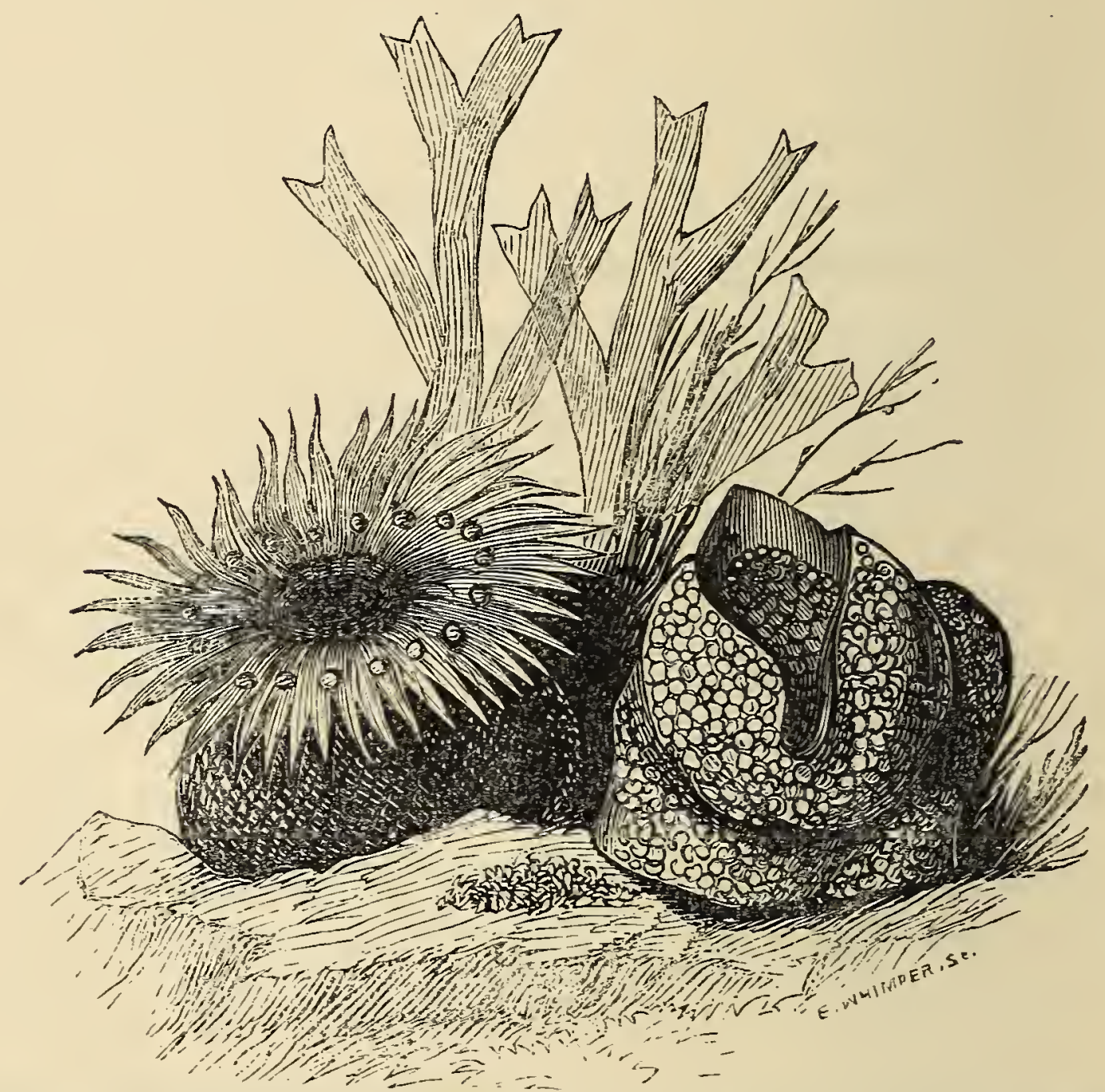

ACTINIA MESEMBRYANTHEMUM, DYCTYOTA DYCHOTOMA.

they will do well. I have, for the sake of gaining information, placed this anemone in water the instant it was prepared, and without filtering it, without suffering the loss of one ; indeed, I have some by me now which a year ago were so operated on; they attached themselves directly, and lived through all the trials incident to a new 


\section{THE MARINE AQUARIUM.}

tank, in which there was not a single drop of natural sea water. Mr. Hall tells me he has, on emergencies, kept them alive for a week in soap-suds, and eren in more offensive liquids; and judging by the life the creature leads on the sea shore, now submerged in the cool waters, and now exposed to the burning sun, it is not at all surprising that it has a hardy constitution. Still, this hasty proceeding is not to be recommended; let time develop the powers of the water, let the solar light reach the plants through the green medium of the stained glass, and soon a lovely beading of oxygen bubbles will appear, to indicate that all is right, and then the animals may follow each other in proper order to their domestic home.

If a little real sea-water, even a pint or two, can be obtained to mix with the artificial, the ripening of the latter will be considerably hastened, but it is an interesting fact in the chemistry of the aquarium that, though in the first preparation of sea-water certain of the ingredients are left out of the prescription, in process of time those very same ingredients are to be discovered in it by means of analysis. How do they get there? They are communicated to it by the regetation, and hence as the water acquires age, like good wine, it increases in strength, and after some months use, will maintain creatures in health that would perish in a day in water recently prepared.

The preparation costs, when prepared from ingredients bought at wholesale price, about three-pence a gallon; but it is a much better plan to purchase it ready prepared, the price then being only four-pence per gallon, or a three gallon packet for one shilling. 


\section{CHAPTER III.}

\section{COLLECTING SPECIMENS.}

To gather specimens is much more pleasant than to purchase them, though an inexperienced person would be pretty sure to bring home, from the sea side, many things utterly unfit for the tank. As a rule, green weeds are the best, the red sorts offer some lovely specimens that do well in an established tank, though none of them succeed in recently prepared artificial water. Brown and olive coloured plants are to be wholly avoided, they wither soon, and spread pollution around them so as to endanger the whole collection.

Ordinary shore gatherings are quite useless for the purpose of the aquarium; the drift is composed of torn specimens of unsuitable plants, and we must seek for specimens at the extreme low-water mark, or in the tide-pools which remain full during the whole of the ebb.

During spring tides is the best time for making collections, and it behoves excursionists who cannot go to the sea side very often, to make their arrangements for such trips, in accordance with the state of the moon as indicated in the almanac. New and full moon are the times in which the tide rises highest and sinks lowest, and much disappointment will be avoided if such proper times are chosen.

Any one who may wish to gather a few specimens for a tank, should be provided with a jar or two, and a basket. A geologist's hammer and a chisel are also necessary. By 
THE MIARINE AQUARIUM.

searching the tide-pools and the boulder's at low-water mark, masses of rock will be found covered with weeds of various forms and colours. Select the green grassy kinds, and chip off each with a portion of rock attached, for a sea-weed has no root, and if detached from its rocky site ineritably perishes.

Any one using a little perseverance and judgment may secure, at any part of the coast, sufficient good specimens to stock a tank of moderate size; and if the collection be watched closely for a week or two, the unsuitable sorts will make themselves known by their increasing shabbiness, and must either be removed altogether or treated according to the instructions to be included under the head of management in a subsequent chapter.

A few anemones may be detached from the rocky hollows in which they have ensconced themselves. The common smooth anemone, which may be known in a moment by its near resemblance to a large deep coloured stramberry, should be secured in plentiful numbers, for it is equal to most of its kindred in beauty, and is so hardy as to submit to the harshest treatment unhurt; the more delicate kinds of anemones, especially the white ones, should be obtained in the same way as the weeds; namely, detached with a portion of the rock on which they are found adhering.

In packing the collection for carriage, care must be taken not to allow any pieces of rock to press upon the soft anemones. The whole may be brought away in jars of sea-water, or packed in masses of wet fuci gathered from the beach. 


\section{THE MARINE AQUARIUM.}

There are very few of the specimens so obtained, but may be as well or better conveyed in wet sea-weed than in water, and if they remain a couple of days so packed, they will take little harm, and may be quickly revived if put into shallow bowls, with a little sea water, and oxygenised by means of the syringe before being placed in the tank. On this head I can say no more here, but must refer the reader for minute instructions to the chapter on specimen collection, in my work on Rustic Adornments, though, what should be sought on the beach, may be judged from the kinds recommended in the succeeding chapters, as well also as to what should be purchased from time to time. Before any specimens are placed in the tank, they ought to be rinsed with sea-water, and any barnacles or sponges scraped off the pieces of rock to which the plants are attached. Any neglect of this will be sure to be followed by the production in the tank of sulphuretted hydrogen, which blackens and kills all before it. Nor should any animal that appears exhausted be consigned to the tank until it has been kept some little time in a shallow bowl with a few weeds, and revived by the occasional use of the syringe. Otherwise, delays are dangerous, and no time should be lost in conveying the several objects to their proper home in the little crystal palace, where blue eyes are to admire, and ruddy lips smile approval of your work. 


\section{CHAPTER IV.}

THE PLANTS.

As already stated, the green weeds are most suitable, the red next so, but of the brown and olive sorts there are very few that can be kept in a state of health for any length of time. There are only two plants suitable for the commencement of the experiment, and these are Ulva latissima, the common sea lettuce, and Enteromorpha compressa, a delicate grass-like algæ, of a very cheerful green. Of these Mr. Lloyd and Mr. Hall have always plenty on hand, ready cleaned and prepared for immediate submersion. Artificial water soon acquires the properties of natural sea water under the influence of these plants, which grow rapidly, and disseminate their spores throughout the tank, at the same time giving abundance of oxygen for the support of animal life.

When a few weeks have elapsed Chondrus crispus, better known as "Carrageen moss," may be added, it is a free grower found in plenty on the ledges at extreme lowwater mark. The green weeds Codium tomentosum, Cladophora arcta, and rupestris, and Bryopsis plumosa may be considered safe stock when the water has been in use a month or two, but the growth of the more delicate of the Rhodosperms must not be attempted in artificial water for at least three or four months.

The best weeds of the latter class are Phyllophora rubens, Corallina officinalis, and Iridcea edulis. In collecting, no doubt the Dulse, Delesseria alata, and san. 
guinea, with, perhaps, some of the Polysiphonice will be considered valuable prizes, but they will not succeed in any but experienced hands, for whom this work is not written.

Dasya, Chylocladia, Nitophyllum, Griffithsia, Rhodymenia, and Ptilota will all contribute specimens as time goes on, and opportunity affords for obtaining them. But not one of these lovely weeds of the red class are fit for ordinary aquarian tactics, they are the "florists' flowers" of the aquarian world, and refuse to be domesticated by any but adepts. The exquisitely delicate Griffithsia setacea is perhaps the only one of the above that may be safely used in a well-seasoned tank of artificial water; the other genera seem to be still more delicately constituted and to require their own native element in a state of great purity.

Once more I urge the beginner to be content with Ulva and Enteromorpha at starting, with half-a-dozen plants of each of these, a large and pleasing variety of animal life may be preserved, and in the case of disaster of any kind, these are the most readily restored to health by a little timely and judicious management.

All coarse and dark coloured weeds, however tempting at first sight, are to be avoided. The sprawling tangles. that one steps over in traversing the boulders and the slimy masses of sea-weed, everywhere cast upon the coast, are quite unfit, however fine the specimens, or strong the desire to possess them. Neither must much value be attached to any weed cast up by the surge. The only trustworthy specimens are those chipped from the rock in situ and brought away without being detached from their natural basis. 


\section{CHAPTER V.}

THEANMAIS.

THough Anemones take precedence in the order of stocking, and frequently monopolise the tank-for, after all, these are the main attraction of most marine aquaria -yet, as they do not stand the highest in the order of nature, we must recount zoologically what creutures are best fitted for domestication, and in another chapter give directions as to their selection and management.

Fishes take the first place, because they are the highest forms of life admitted to the marine tank; but they are the last introduced, because, being more delicately organized than the tribes beneath them, they require either real sea-water, in a state of high presertation, or artificia] water of some months' seasoning, and good management.

The fishes best adapted for tank life are the queerlooking gobies, the lively blennies, small specimens of wrasse, rockling, and eel. The grey mullet is a pretty fish, but not to be domesticated without some difficulty. Some kinds of flat fish may be kept in tanks, but beginners had better have nothing to do with them. Small sticklebacks may be taken in plenty by means of a handnet in quiet tide-pools, and do well in the tank, but they are pugnacious, and harass less vigorous creatures; so that some judgment is required in grouping them.

Mollustis. - The common Periwinkle is useful as a cleaner, and interesting also to those who find pleasure in contemplating the startling resources of Divine Wisdom, 
as evidenced in the construction of the most humble creatures. The winkles accomplish for the marine-tank what the fresh-water snails do for the river-tank, they scrape confervoid growths from the glass, and so help to preserve the crystalline aspect of the tank. All the species of winkle are capable of domestication, Littorina littorea, the commmon sort, and $\boldsymbol{E}$. littoralis, a pretty little fellow, with a gaily mottled hybernaculum.

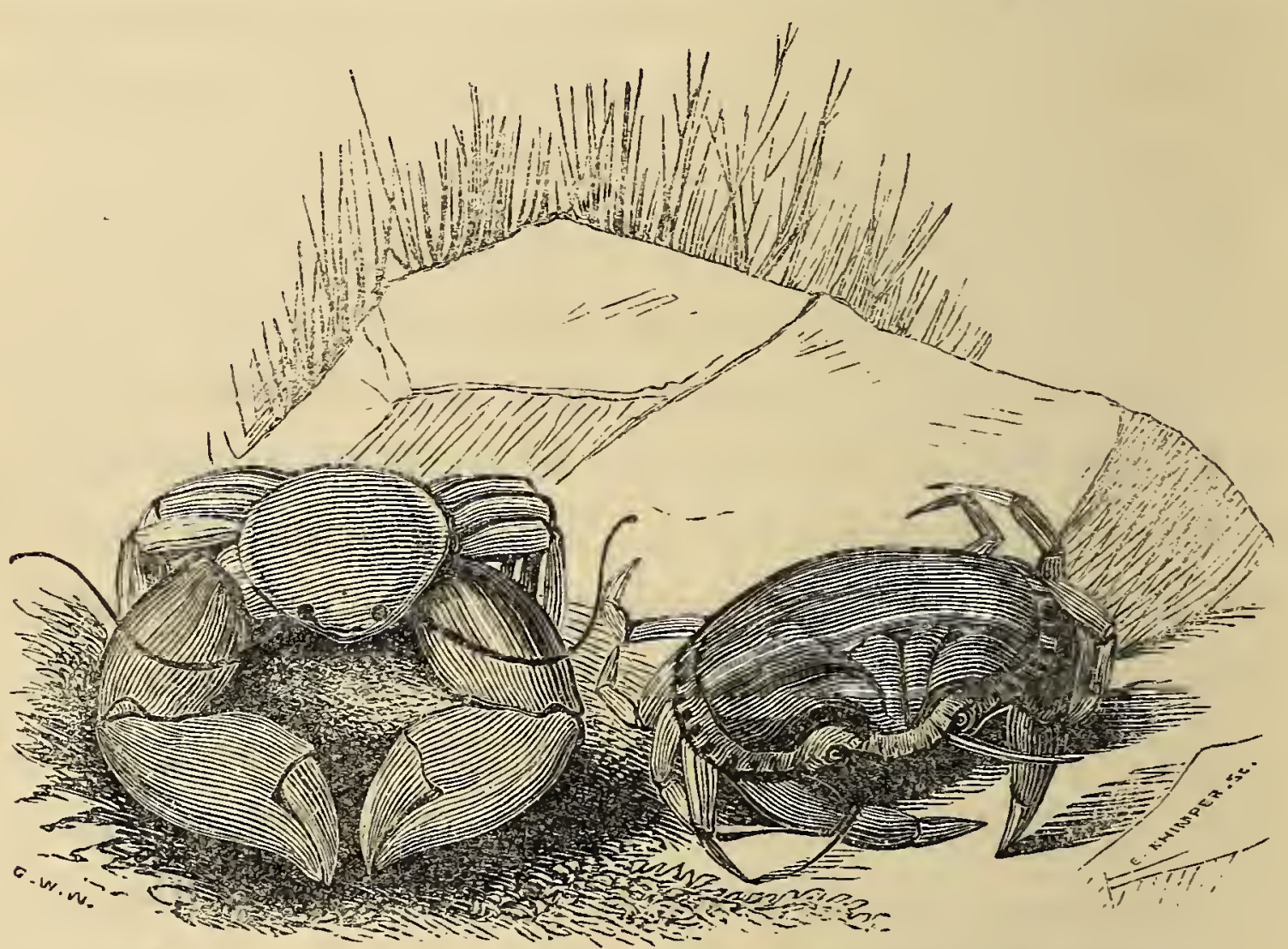

PORCELLANA PLATYCHELES, CANCER PAGURUS.

The Trochus tribe, better known as Tops, are also useful as cleaners, and in appearance are more stately and ornamental than the winkle, their cleanly marked conical shell attracting as much attention from strange eyes as the noble planorbis corneus does in the river-tank. Generally speaking, univalves are more easily kept than bivalves; many of the latter are apt to die off, and cause some amount of putrescence before their demise is discovered. 
Crustacea are lively and interesting, but of course small species, or small specimens of large species are the most suitable. The Soldier crabs (Pagurus) and the Swimming crabs (Portunus) are eminently suitable, so is the pretty Strawberry crab, Eurynome aspera, and the interesting Broad-claw Porcellana platycheles. Shrimps and prawns may be used freely ; they are lively creatures,

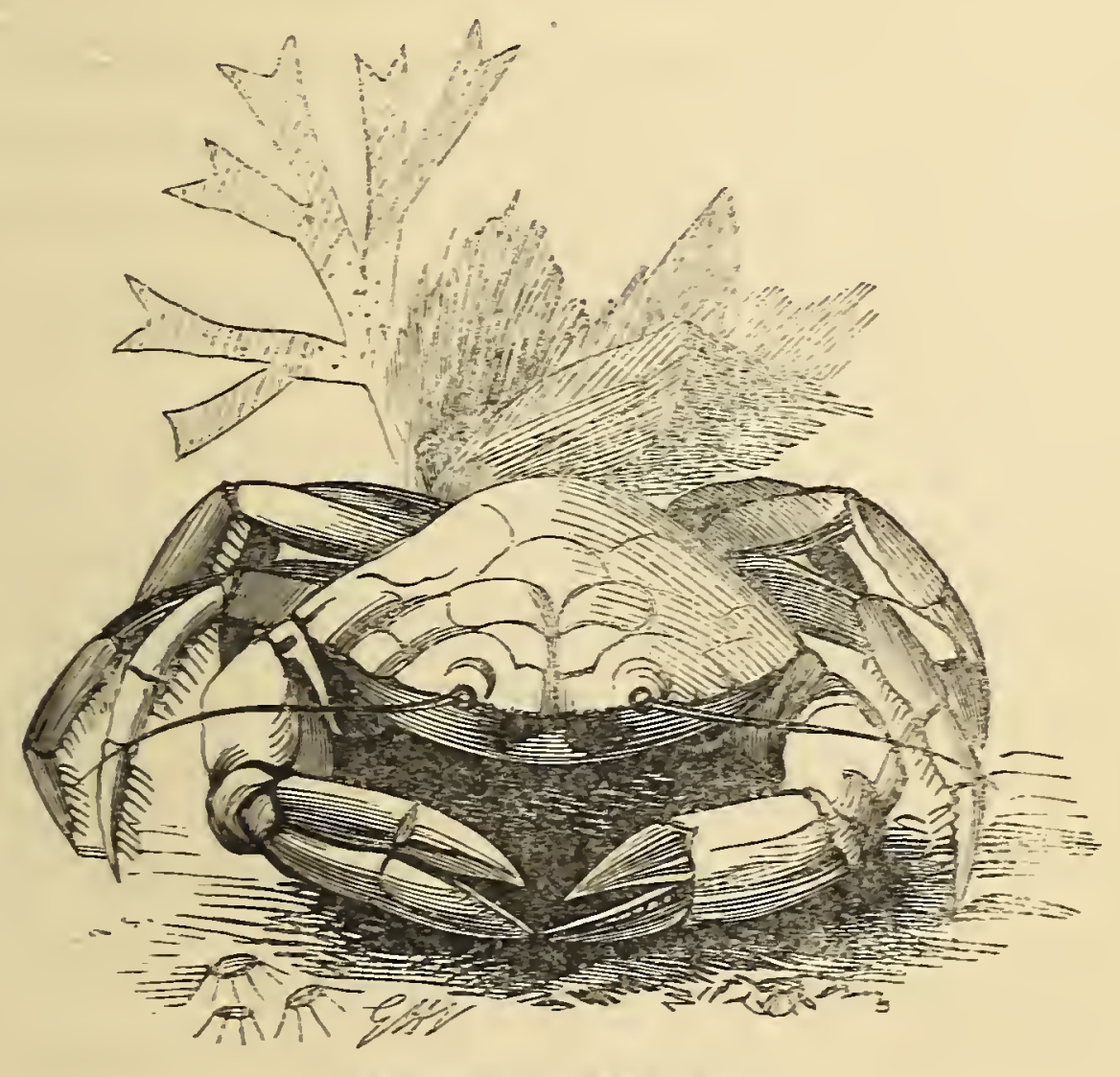

CARCINAS MENAS.

and much more beautiful when seen in motion, gliding about like ghosts, than would be imagined by any one judging from the appearance of specimens on the table.

Annelides afford us the interesting serpulas, some pretty sea-worms, and the terebellas, all easy of preservation, and remunerative of the attention bestowed upon them.

Zoophytes. - This is the division from which the most prominent attractions of the tank are derived. Of these 
the Actinia take precedence of all the ordinary inhabitants of the tank, because of their exquisite beauty, strange habits, and still more general certainty attending their preservation.

Actinia mesembryanthemum is the common Smooth Anemone which abounds on every part of our coast. Its colour varies considerably, but it is usually of a deep, warm chocolate, dotted all over with small yellow spots, and when closed has the best possible resemblance to a large ripe strawberry. Every stone about the sea-beach is studded with this anemone, and a collector may secure any required number in a few hours, slipping each from its base, and dropping the whole into a jar with some fragments of fresh wet weed to keep them moist.

When it expands, a circle of bright blue beads, or tubercules, resembling torquoises, is seen just within the central opening; and, as the expansion proceeds, a number of coral-like fingers, or tentacles, unfold from the centre, and at last spread out on all sides like the hundred petals of a Peri flower, reminding one of Hinda's boon :-

- Be it our's to embellish thy pillow

With everything beauteous that grows in the deep;

Each flower of the rock, and each gem of the billow,

Shall sweeten thy bed and illumine thy sleep.

Around thee shall glisten the loveliest amber

That ever the sorrowing sea-bird has wept,

With many a shell in whose hollow-wreathed chamber

We, Peris of Ocean, by moonlight have slept.

LALLA RoohK.

This anemone will remain expanded for many days together, if the water be kept bright and pure; but if the 
THE MARINE AQUARIUM.

tank gets fouled, it closes and falls from its foothold, and perishes if not attended to. It is the hardiest of all the creatures that are regarded as stock for tanks, and survives many a wreck unhurt. To induce it to climb up the sides of the vessel, let it be placed with its base lying partly against it, or bring it close to a stone in the centre,

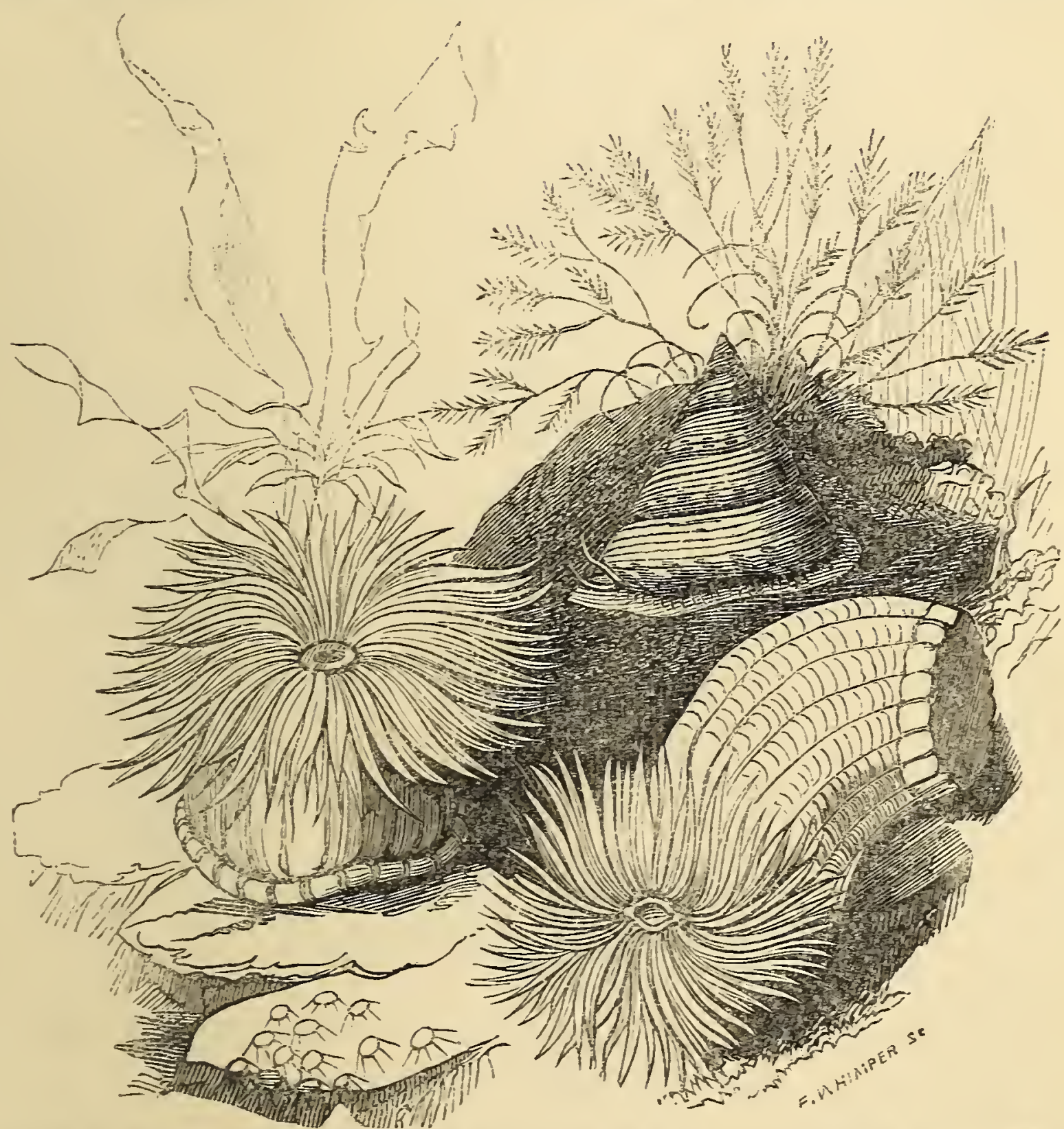

ACTINIA ANGUICOMA, TROCHUS ZIZIPHINUS, ULVA LATISSIMA, BRYOPSIS PLUMOSA, ACORN BARNACLE.

and it will be pretty sure to attach itself where you desire in the course of a few days. This last suggestion applies to anemones generally; novices are surprised to find how 
well disposed the creatures are in a well-kept tank. The disposition dates from the day of introduction, for none of this tribe are fond of locomotion; and the arrangement of them for effect, depends upon whether you drop them quietly just in contact with the spot you wish them to adhere to, or throw them in pell mell, to cling to the weeds or to each other.

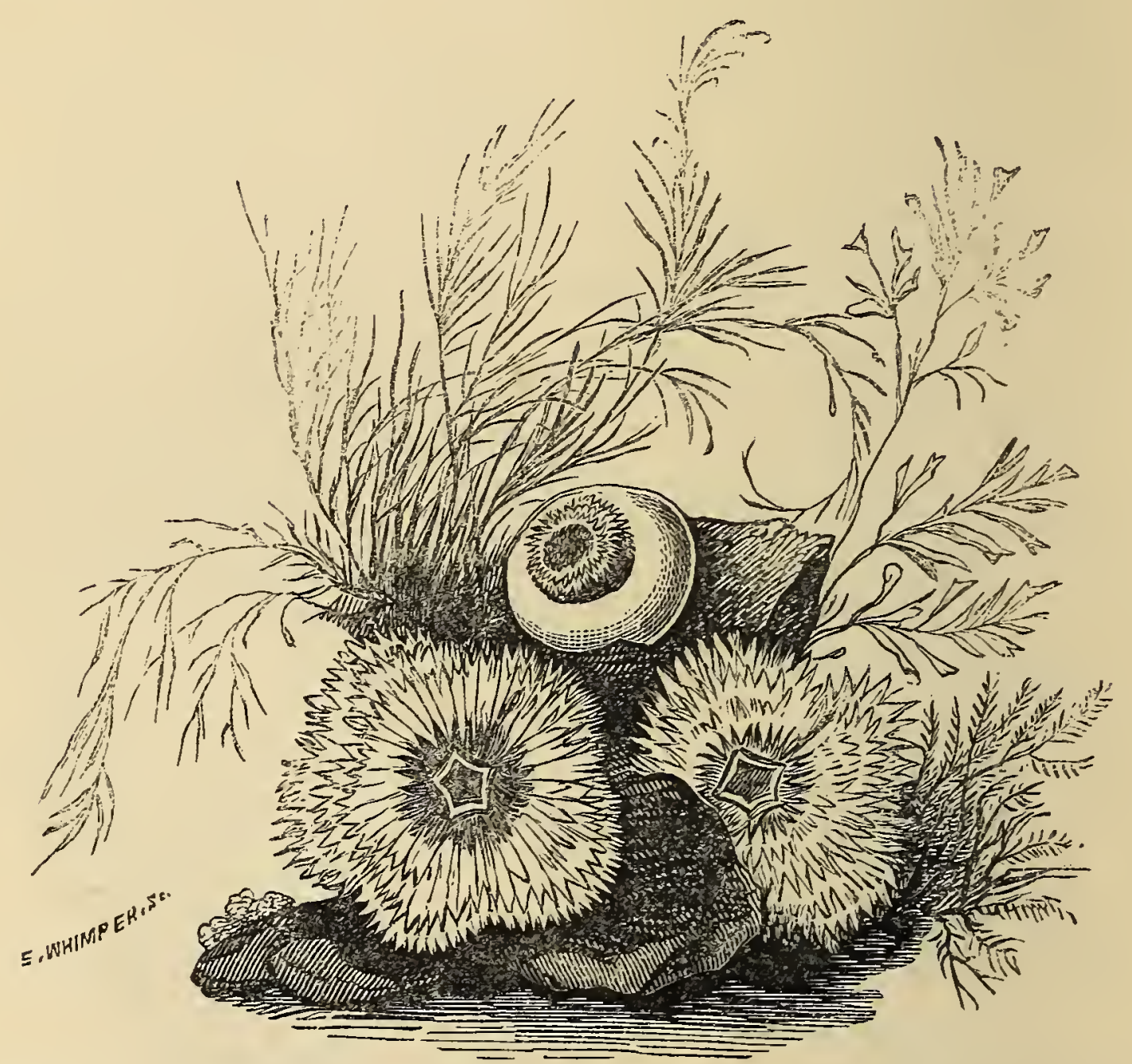

ACTINIA BELLIS AND GEMMACEA, DELESSERIA ALATA, POLYSIPHONIA URCEOLATA.

$A$. anguicoma, or the snaky-locked anemone, is a pretty but curious creature. It is all arms, just as a crab is all claws; but so delicate in form, so beautifully striped in the tentacles, that it stands quite apart in the tank as a thing unique. When found on the sea-shore, as it is 
usually after a storm, it is a flat-looking, smooth mass, of a brown tint, delicately striped with yellow and white. After a few days' residence in the tank, it begins to expand, and rises to so tall a figure, especially in the twilight, that it appears quite a different creature to that introduced a few days before. In fact, its actual bulk is increased vastly by expansion. It is constantly expanded.

A. Bellis is another good species. It is a delicate pink and brown and pink and white anemone, and certainly does resemble a daisy very closely indeed. Though much prized it is not rare. Mr. Lloyd usually has abundance of them on sale, at a shilling each, and a few should be used to give variety to the collection. In newly-made marine-water it will not do at all; but if it falls into the possession of an aquarian who has no ripe tank at hand for it, it may be kept for weeks in a shallow pan.

If anything goes wrong with this kind, it throws out a number of white threads, and shrinks out of form, and perishes in a few days; but once obtained in a sound state, and carefully treated at the outset, it is as hardy as mesembryanthemum, and more readily expanded at all seasons than most of its compeers.

Actinia Gemmacea.-This is a delicately-constituted anemone, that displays itself freely only in the most pure sea-water, in which there is abundance of oxygen. It is quite unfit for early experiments, but well repays the trouble it occasions when it can be successfully kept. A few weeks since I had the pleasure of witnessing the birth of a large cluster of this pretty anemone in the extensive collection of Mr. Lloyd, at Portland Road. To the 
naked eye they appeared mere flocculent specks, but a lens revealed their true form as they adhered to the side of the ressel; every one of the little creatures, with its tentacles expanded, a real microscopic gem, combining the grace of a flower with the tinting of a pearl, and the delicate volition of a new-born animal.

When full grown, the gemmed anemone is very showy in its tintings. Pink, yellow, and grey are all beautifully blended, and the rows of glands which reach from the margin to the base, add their dots of white to the garments of this tiny harlequin. The disk is brilliantly coloured, scarlet, green, and orange, shading into each other, and occasionally mingled with half-tints of every colour of the rainbow. The lip is usually of a vivid green, and the tentacles exhibit rose, violet, orange, and white on their upper surfaces. In the cut, this anemone is seen partially closed on a piece of stone behind two specimens of $A$. Bellis.

Actinia Crassicornis is another of the more delicate kinds, that dies speedily, unless treated with great care, and in a well-established tank. It is very abundant on every part of our coasts, and must be removed with the stone to which it is found adhering; for if removed, or even handled, it perishes in the course of a few hours. It is, however, too beautiful not to be worth an effort to preserve it; and, if the tank is in good condition, it will be well to obtain two or three specimens, and watch them narrowly, so that if any of them die, they may be immediately removed to avoid polluting the water.

The colour of this anemone varies considerably in dif- 
THE MARINE AQUARIUM.

ferent specimens. Violet and amber shades frequently predominate in the tentacles. Sometimes the disk is of a pearly white, at others of a warm fawn or bright orange and scarlet, sometimes a deep crimson or a dull chocolate ; while the tentacles vary from pure white to dark brown, dingy fawn, and brick-dust red. The latter organs are very numerous and tubular. When irritated, the creature has the power of attaching the tentacles to the object which annoys it, and in this way it frequently clings to the fingers when handled, and at the same time squirts out numerous jets of water, until it is quite empty and collapsed.

Actinia Parasitica.-This is a good aquarium species, on account of the ease with which it may be kept. It is a species that the rambler on the sea-beach will not be at all likely to meet with, for it is truly pelagic in its habit. It is only to be obtained in a state fit for the aquarium by means of the dredge, and when so obtained it lives a long while in confinement.

The most interesting feature in the history of this zoophyte is that of its usually inhabiting the shell of some defunct univalve mollusk, such as the Trochus, or the great whelk, Buccinum undatum. This is not the most curious part of its history. The anemone loves company, and in the same shell as that on which it extends itself, we usually find a pretty but pugnacious crab, Pagurus bernhardus. To the anemone the crab acts as porter; he drags the shell about with him as if it were a palanquin, on which sits enthroned a very bloated but gaily-dressed potentate, destitute of power to move it for 
himself. Like most lazy dignitaries, this showy Actinia attracts more attention than the lively servant who drags it from place to place, for its form and colouring are beautiful in the extreme.

It is of large size, frequently attaining to a height of four inches with a diameter of two and a half. Mr. Gosse's description of this fine creature is so minute and interesting, that I must beg the reader to accept it in preference to any that I can write. He says, the "ground colour is a dirty white, or drab, often slightly tinged with pale yellow; longitudinal bands of dark woodbrown, reddish, or purplish brown, run down the body, sometimes very regularly, and set so closely as to leave the intermediate bands of ground colour much narrower than themselves; at other times these bands are narrower, more separated, and variously interrupted or broken. I have seen a variety in which the bands took the form of chains of round dark spots, the effect of which was handsome. Immediately round the base the bands usually subdivide, and are varied by a single series of upright, oblong spots of rich yellow, which are usually marginal, with deeper brown than the bands. The whole body is surrounded by close-set faint lines of pale blue, sometimes scarcely distinguishable, except near the summit, where they cut the bands in such a manner as to form, with other similar lines which there run lengthwise, a reticulated pattern.

"The disk is somewhat wider than the diameter of the body, which it over-arches on all sides. Its margin is somewhat thin, and occasionally thrown into puckered 
folds to a small extent. Thus it appears to approach the peculiar form of $A$. bellis. The disk is nearly flat, or slightly hollowed, but rises in the centre into a stout cone, in the middle of which is the mouth, edged with crenated lips. The tentacles are arranged in seven rows, of which the innermost contains about twenty, the second twenty-four, the third forty-eight, the fourth ninety-six ; the other rows are too closely set, and too numerous to be distinguished. Probably the whole number of tentacles, in a full-grown specimen, may be considered as certainly not less than $500 . "$

Actinia Dianthus.-This is the Plumose anemone of Mr. Gosse, and sometimes bears the very appropriate name of the Carnation anemone. It is the most superb of our native Actinias-a gorgeous creature, that in itself more than realizes our brightest imagining's of the hidden splendours of the ocean floor, and of the gems that bedeck the caves of Neptune. How will future poetry be affected by the revelations of the aquarium, and how far will the sober facts of scientific research influence the pictures and the incidents of romance? Even Keats's glowing description of "God Neptune's palaces" becomes tame in the presence of this splendid creature, which carries the fancy-

"far below

The sea-blooms and the oozy woods, which wear

The sapless foliage of the ocean,"

and peoples the dark slippery slopes with wondrous forms of life and beauty, as if the lost argosies and the perished 


\section{THE MARINE AQUARIUM.}

navies, that have found a common sepulchre in the waters, had given up their myriad souls to the conjuration of Glacus and Scylla, and all the dizzy troop of ocean spirits. It is, verily, a wondrous creature, of enormous size, and so delicately tinted, so light and fairy-like in structure, so constantly expanding and retracting its thousand delicate fingers, like the Indian blossom that the Brahmin believes to be endowed with life, that it never ceases to attract the attention of the coldest, and fill the ardent lover of nature with-

\section{"the amaze}

Of deep-seen wonders."

I have before me now five specimens of this splendid anemone. They are all expanded, and they glow in the sunshine like huge carnations of the brightest amber, one of them verging towards a pure white. Two of these are represented in the engraving, surrounded by fronds of Delesseria sanguinea, Callithamnium, and Griffithsia. The one attached to the perpendicular side of a stone is of the golden amber variety; when fully expanded it forms a massive column of five inches in height, at least, and nearly three in diameter. From the summit of the column the tentacies fringe over in rich masses, like the petals of a monster carnation, all of them in motion as if seeking something which they cannot find. The tentacular disk is deeply frilled and puckered, and constantly changes its outline under the capricious will of the animal; while, at the same time, the tentacles arrange and rearrange themselves into most confusing forms ; then again expand to their utmost, and expose the oval mouth and 
crenated lips, of a pellucid softness that would appear as if chiselled out of alabaster, were they not constantly varying their form, and every instant undergoing a new "sea-change." The tentacles are very regularly arranged around the mouth, but towards the margin they thicken and thicken till they form a dense fringe that overlaps the column, and continues ever waving as if stirred by trembling ocean currents. If I now strike the glass with my finger, or even breathe lightly on the surface of the water, they are all withdrawn, the stately column shrinks down into a mass of pulp, and in a few moments swells out like a globular balloon, so tight and large that one momentarily expects it to burst. For an instant only it remains thus blown out; it is suddenly constricted as if clasped by a cord, and it then becomes double like a pair of globes placed one upon the other, and flattened where they meet. Suddenly the imaginary girdle slips downward, disappears, then it contracts, rises again, assumes its noblest proportions, expands its thousand fringes, all delicately waving above the dark stones, and is once more as lovely, or lovelier than ever.

This has been described as one of the most tender of its class, but I have long been convinced that it is comparatively hardy, and may be preserved with very great certainty. So long as the water is kept moderately pure, by an occasional filtering through charcoal-which aerates and purifies at the same time-it lives and prosper's, occasionally moring from place to place, but almost always expanded, and every instant assuming some new form. It is, however, so far delicate that, if frequently 


\section{THE MARINE AQUARIUM.}

disturbed, it is sure to perish. When removed from its native "oozy bed" it should be kept on the stone or shell to which it is found attached, until it floats off of its own accord, and fixes itself elsewhere. When handled it throws out a number of white threads, which are afterwards withdrawn.

\section{CHAPTER VI.}

\section{WHAT IS AN ANEMONE?}

IT is very strange that where the animal and vegetable kingdoms meet, the forms should assume such close resemblances to each other, as to make it frequently a matter of difficulty to determine to which of the two great departments some special specimen shall be assigned. Here are the lovely sea-flowers-flowers only in name and appearance-representing the lowest links of animal life and pointing to that last link where the animal and the vegetable blend into one, bearing all the outward resemblances to flowers from which they take their appropriate names, yet all of them strictly animals, endowed with volition, and in their general organization assimilating to the extensive series of zoological orders which stand above and beneath them. The sea anemones are animals of the lowest class-zoophytes of the great Cuverian division of RADIATA. It is in this division that animation is seen to tremble and flicker in the socket, and to become gradually extinguished as we descend the 
THE MARINE AQUARIUM.

scale and approach the confines of the kingdom of verdure. Here, then, life has its lowest if not least lovely forms; the individuals have less individuality, many of them live in groups and clusters, and increase in a semi-vegetative manner by gemmation, or the formation of bud-like germs, while others generate by spontaneous fissure, and break up into numerous forms, each of which rapidly acquires the form of the parent, and proceeds in the same way to increase its kind.

The RADIATA are so named on account of the ray-like form generally observable in the structure of the creatures; in some the ray-like divisions give such a speciality to the structure as to distinguish them at once as member's of this division; as in the star-fishes, for instance, in which the intestinal canal branches out from the body into the several rays which form the star, and in the anemones, in which the relation to the tribe is at first sight perceptible in the tentacles which surround the mouth, and which render it so exquisitely beautiful as a marine representative of a true flower.

But though the term Radiata is applied to an extensive division, in which the members have many characteristics in common with each other, the ray-like form is not equally distinguishable in all. In some tribes there is a tendency to associate into groups, in which each individual has a certain degree of connection with the rest, as in the infusoria common in our brooks, and indeed most of the polypes which thus live in community. The resemblance to regetable forms is, however, common to a great portion of the Radiata, and those in which this 
resemblance is the strongest are grouped together under the general designation of Zoophytes. In Zoophytes, the leading feature of a radiate animal is very distinctly observable, and that leading feature is the arrangement of the vital organs around a centre, the organs composing

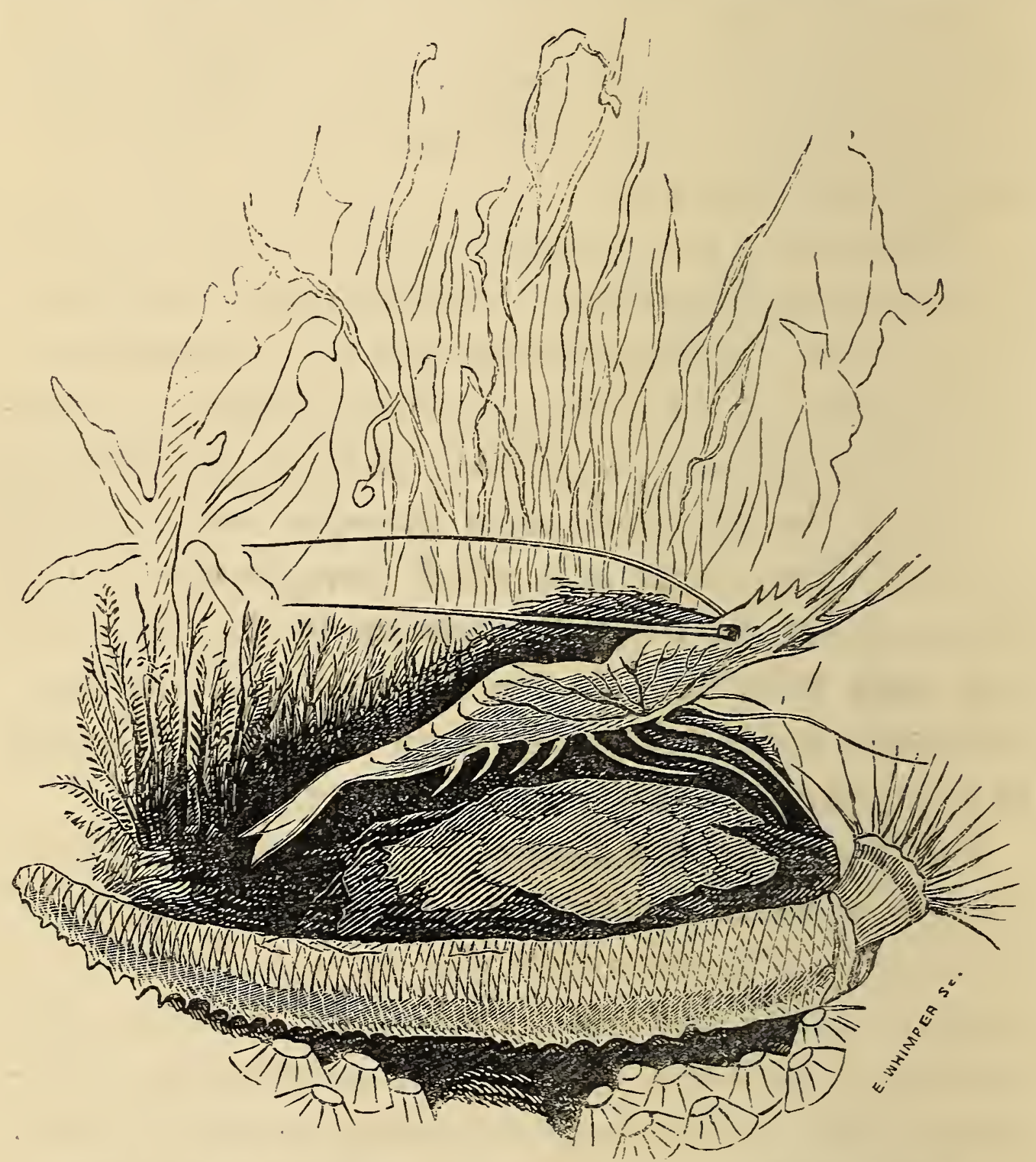

EDWARDSIA VESTITA, ESOP PRAWN, ENTEROMORPHA COMPRESSA, ULVA LATISSIMA.

the rays of the imaginary star, or the petals of the imaginary flower, to which the mouth or stomach is the centre. 
Among the Zoophytes we meet with many of the creatures which have the greatest attraction for the student of the Aquarium. The brooks supply him with the curious hydra, the seven-headed monster that perpetuates one of the triumphs of Hercules-withal a beautiful and wondrous creature, that may be cut in pieces, turned inside out, or even thrust one animal within the other, and still remain the same. The sea supplies the madrepores, the builders of ocean-reefs, and the founders of islands and continents; as it also supplies the sea anemones of more than a hundred species, from the curious Edwardsia vestita, here figured, from the first seen in this country, at present in the collection of Mr. Alford Lloyd, to the familiar members of the genus Actinia, obtainable everywhere on our coasts.

The true Zoophytes have all, more or less, the plantlike form, and they readily separate into two great classes, namely, the Anthozoa, or flower-life, and the Polyzoa, or many-life, in which the individuals are associated together in numbers. They are all inhabitants of water, are all destitute of joints, lungs, nerves, and proper blood-vessels; but in the place of nerves possess what naturalists call an irritable system, in obedience to which they expand or contract at will. At the upper part of the body is situated the mouth, which is usually surrounded with tentacles, which are mostly used in securing prey. There is no alimentary duct, for the stomach has the form of a simple sac, the aliment being injected and ejected by the same orifice.

The Anthozoa comprise animals which are perfect in 
themselves, and these are mostly soft bodied, having no shelly covering, and are protected only by the leathery integument which surrounds them, and the thousand weapons of offence and defence which they expand in the form of tentacles. Among the Polyzoa we meet with creatures that encase themselves in horny shells, or calcareous coatings, such as the Madrepores, which, like submarine masons, elaborate the carbonate of lime which the sea supplies them with, into shelly retreats; and the tubed Hydrioda, which construct winding galleries and convoluted tubes, from the mouths of which they protrude their fans and tentacles in search of prey.

Among the higher orders of the Radiata we meet with the strange Sea Cucumbers and the Sea Urchins, and the Star fishes; and among the lower orders the Sea Anemones, many forms of which are described and figured in these pages.

A Sea Anemone, then, is a Zoophyte belonging to the class AnthozoA, or flower-life, and the order HeLanTHOIDA, or sunflower-like creatures. The central disk of the sea flower is composed of the lips, which open into a mouth which communicates with the simple sac which constitutes the stomach, and the petals and fringes which surround it-now like the anemone, now like the sunflower or the mesembryanthemum, or the richest carnation that ever won for a florist a golden prize. The further subdivision is dependent on the details of individual structure; and a large section-that of Actiniacomprehends most of those on which the aquarian bestows his patience in the work of domestication. 
THE MARINE AQUARIUM.

The Actiniadce-so named from the Greek-signifying a ray of the sun-are an extensire family, of which more than a hundred species are to be found on our coasts, or in the deep bays adjacent. But few of these are suited for confinement in aquaria, and of these the chief are the Actinia proper, the Sagartia, most of which are usually grouped with the Actinia; the Anthea Cereus; the splendid Adamsia Palliata, which is the only known species of the genus to which it belongs; and a few of the Bunodes, Edwardsia, and Corynactis.

In all the varieties of sea anemones the mode of life is similar; they are carnirorous, and obtain their prey by means of the ever-seeking tentacles that search the lymph around them, and secure sometimes fishes, at others mollusks, but more frequently the minute forms of infusorial life that abound in the sea, or in the artificial water of the tank. The mode of reproduction is by ora, which are sometimes vivified in the body of the parent, and not only do they gire birth by ejection from the mouth of a numerous progeny, but actual divisions of the body may be made, and each division will acquire completeness. Dr. Johnson relates sereral instances in proof of this, one of which is particularly interesting. A specimen of Actinia crassicornis had swallowed a large, sharpedged shell, which so completely stretched the body of the creature as if on a ring of wire, as virtually to cut it into two equal parts. Thereupon it put out from the base a new disk, with mouth and tentacles, and became at once a double anemone, to which the gorged shell served as an intermediate base of attachment. Dr. Cocks 
has seen specimens of Bunodes alba acquire complete forms in duplicate when the original specimen has been severed into two or more parts; and there are many other instances on record of this plant-like division of sea anemones having been observed.

Though apparently immobile, there are few species but possess some power of locomotion. We frequently meet with anemones attached to stones, sand, or shells, by a wide sucking base, and if some species be moved from their chosen site, certain death is the result. Yet in by far the greater number there is a distinct faculty of progression - the anemone, by a slow, gliding motion, gradually removes itself, and climbs up the sides of the vessel, or takes possession of a tuft of weed, or shifts from one stone to another, or fairly leaves go of its anchorage, and floats like a balloon upon the surface. Thus low in the scale as they are, they possess will, and a power of obeying it ; they have their organs of locomotion, of attack, and defence; though naked, they are armed for combat on an equality with their enemies, and succomb at last to manthe universal destroyer and appropriator-who turns them to account as food, or treasures them as gems of beauty that gratify his eye, and even win over the affections of his heart, while they lead him to contemplate the variety and profuseness of that life to which the Almighty has given so many wondrous forms, and instincts, and economies, every one of which proclaims-

"The hand that made us is divine." 
THE MARINE AQUARIUM.

\section{CHAPTER VII.}

\section{GENERAL MANAGEMENT.}

I sHALL in this Chapter only notice such particulars in the management of aquaria as belong especially to the marine department, since some of the directions given in the former division of the work apply to tanks of all kinds, and need not be repeated. When preliminary difficulties have been surmounted, the matter of first importance is the selection of the stock, and its arrangement in accordance with just principles.

Grouping. - In Chapters IV. and V. I have enumerated the kinds of animals and plants most suitable for aquaria, and must now caution the beginner against the injudicious grouping together of creatures of dissimilar habits. Anemones may, as a rule, be kept together. The several species agree well, and seldom or rarely injure each other; but star-fishes and crabs are best kept in ressels apart from them. Star-fishes are very destructive, and readily absorb the bodies of mollusks out of their shells. If exception is to be taken to any particular anemone, I think the grand plunosa must suffer by it; for this noble creature gives off a flocculent exudation, which seems injurious to other kinds. I have generally kept the plumose anemone in company with $A$. mesembryanthemum, $A$. bellis, troglodytes, and others, without perceiving any bad result; but I have always been careful to remove the slimy exuria daily, by means of the dipping tube. Respecting mollusks, and especially trochus and 
most bivalves, it should be borne in mind that they are apt to die off rapidly, and to cause a putrescence of a most obnoxious character, which soon spoils the water, and causes a general havoc. Another remark applicable to mollusks is this, that the Eolids-members of the $N u d i$ branch, or naked mollusks-are destructive of anemones, and delight in nibbling holes in their coats, or eating off their tentacles; whereas the pretty doris may be kept as long as it will live, in company with the most delicate creatures, without offering offence to any. The more varied the collection the more is our interest in its examination increased; and the possessor of a single vessel, or of a tank, and a few auxiliary jars, will be naturally anxious to preserve representatives of as many tribes as possible; and this may be done, to a certain extent, by appropriating the vessels to such creatures as agree amicably in confinement. It is, indeed, possible, if a vigilant watchfulness be observed, to bring together and preserve, for a length of time, specimens of creatures that are naturally antagonistic to each other; but where Crustaceans can be kept apart in one vessel, with perhaps a few fish, such as gobies and blennies-a second appropriated to anemones and madrepores-and. a third to mollusks, madrepores, and tubeworms - there will be the greater certainty of success, and less supervision will be required. Crabs are very annoying to anemones, as they scratch and sprawl over the delicate creatures; and shrimps, prawns, and fishes frequently fall a prey to the barbed threads and the tentacles of the anemones; the latter also frequently take possession of the mouths of the 


\section{THE MARINE AQUARIUM.}

cells of tube worms, and of the openings of the shells of mollusks, and thus suffocate the inmates, and insure their own death by the putrescence that ensues upon the demise of their victims.

Sulphuretted hydrogen.- When the death of an animal occurs, the water soon gets putrid; the stones assume a rich brown tint, the sides of the vessel lose their brightness, and an effete odour indicates the cause of the disturbance.

Preservation of the Water.-To those who live near the sea it is an easy matter to change the water, as soon as it shows signs of disorganization, but since the majority of those who will consult this work will have to depend on Mr. Bolton's marine salts, it is necessary that I should suggest in what way, and in the best manner, the water may be preserved, not only to aroid the expense, but the trouble attending a new supply. Charcoal is the grand restorative, purifier, and preserver; and for this department of aquarium management may be regarded as the ne plus ultra.

In the second Chapter of this part of the work I have described the process necessary in preparing artificial water by means of the filter. Now, whatever happens, set the filter to work, it will revive exhausted stock by aeration, destroy sulphuretted hydrogen by the contact of the water with the charcoal, and remove all fragments of decayed weed, flocculent threads given off by anemones, and restore the whole to strength and purity. I repeat what I have already said more than once, that the necessity for changing the water is a proof of injudicious 
management; every new supply is a witness of the aquarian's lack of skill, as Mr. Lloyd wisely says, "properly managed, the water and other contents of an Aquarium may be kept unchanged for periods indefinitely prolonged." For the sake of aquarian science, I do implore the student to surmount any and every difficulty, rather than own the weakness implied by changing the water.

Aeration is frequently referred to in works on the Aquarium. It is at variance with the self-sustaining theory, and there is something wrong where it is wanted. If the tank is stocked before the plants are well established, or if overstocked with a crowd of animal life, or if sulphuretted hydrogen be produced and make its presence manifest to the nose, then aeration may be necessary. A cup or jug may be used to dip water from the surface, and pour it back again from a height in a thin stream. Or a filter may be placed over the tank and filled from the surface, and the water allowed to drip back. But the most efficient instrument is a common syringe. This is simply to be charged at the surface, and discharged again with some force, so as to send a stream of oxygenised water deep into the tank. The process should be repeated for a quarter of an hour at least.

Filter.-A bee glass or a common flower-pot may soon be made into a filter. Thrust a piece of sponge into the hole in the bottom, and upon it lay a stratum of washed sand and powdered charcoal. Pass the water through it, and it will be purified, and saturated with oxygen at one and the same time. With the river-tank, the simplest way of 
reviving exhausted stock is wholly or partially to change the water; with marine stock, such a change is not easy, and the filter comes more legitimately into use. As already remarked, the necessity for aeration marks error in management, except when you have stock for which no proper receptacle is at hand, or any such special contingency.

Decay of Plants. - The sea-weeds are apt to acquire a pale tint, which is the first evidence of decay. This generally happens with the first marine stock, when Ulva and Enteromorpha are used to season artificial water When the water gets ripe, the plants recover and make healthy growth, but if many white fronds appear, lift out the blocks on which the plants are fixed, trim away the decayed portions with a pair of scissors, and then scrub the stones with a small brush in a little waste sea-water, and replace them; they will soon recover. If red plants have been hurriedly introduced, and decay manifests itself, remove them at once, and waste no time in attempts at revival. Mr. Lloyd will supply a new stock for a trifle, and it is better to begin de novo than to attempt to cure the incurable.

Death of Anemones.-If you observe any of the anemones to shrink up like button-covers, lift them out into a shallow vessel, and aerate them liberally. When small beads of gas appear upon them, you may rest assured that they have gone beyond the-

"Bourne from whence no traveller returns;" for the first outward proof of death is the formation of 
bubbles of sulphuretted hydrogen upon their bodies, and they should be removed before this spreads and devastates the tank.

Removal of Objects. - For the removal of portions of decayed weed, and other small noxious bodies, from the bottom, a glass tube of $\frac{1}{4}$ or $\frac{1}{2}$ inch diameter, open at

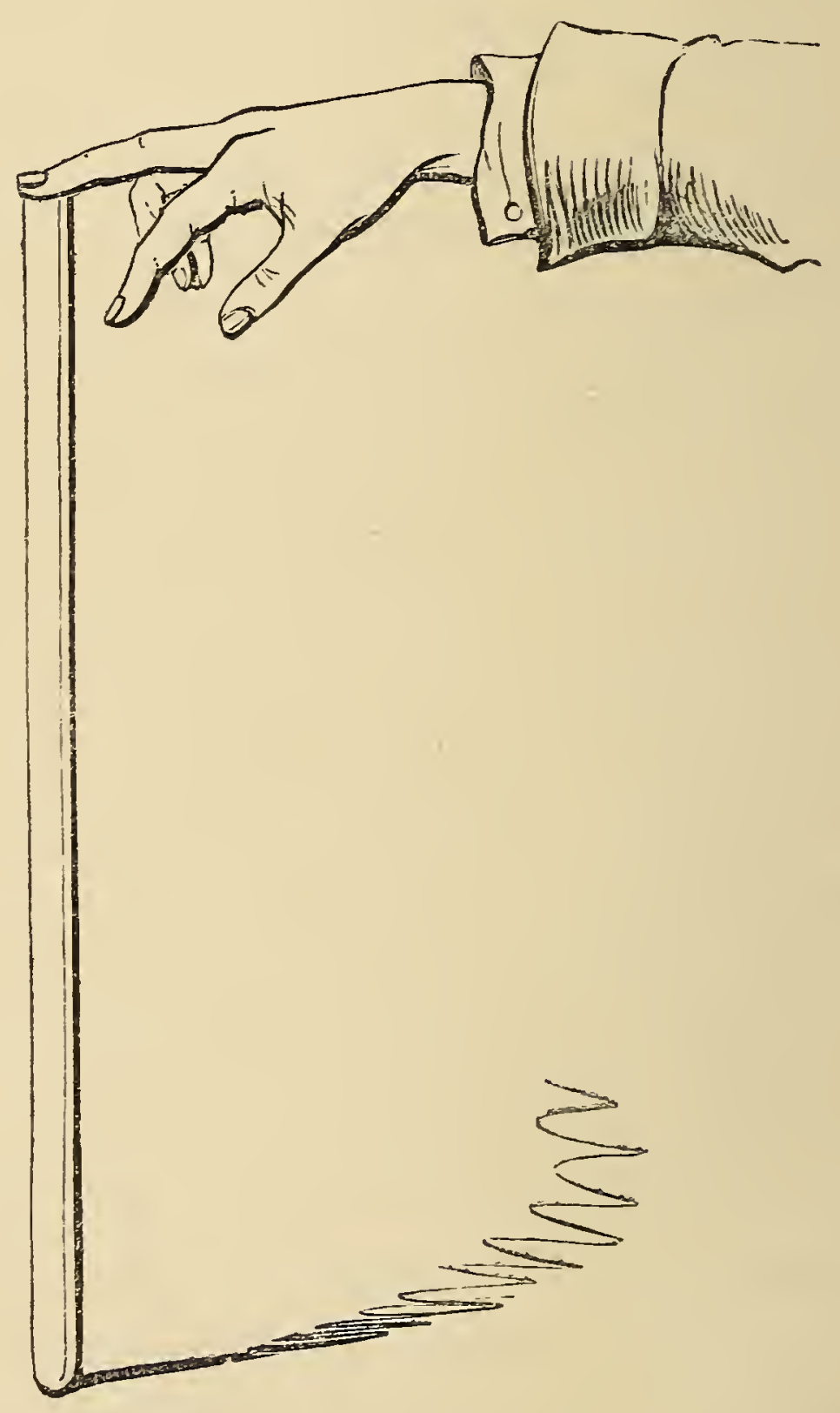

both ends, will be found very useful. Place a thumb or finger on the top of the tube, and thrust it down over the object to be removed, then remove the finger, and the matter will rise in it. Lift the tube up to the surface of 
the water, then place the finger on again, and lift the whole away. The advantage of this plan is, that no disturbance is occasioned. A pewter spoon bent to a right angle, and attached to a stick is very useful for lifting up objects that are too large for the dipping tube.

Density of the Water.-Evaporation causes the pure water to escape from the Aquarium, and hence there is a constant tendency to increase of density-in fact, if left alone, the water in the tank soon gets too salt. To prevent this, additions of pure spring or distilled water must be made from time to time, and the amount regulated by a specific gravity bubble, which it would be as well to leave at all times floating in the tank. This instrument registers the density much more accurately than the hydrometer, for it is more delicate in its determination of a balance. I find it expedient to use two bubbles of different specific gravities-one which just floats when the water is sufficiently fluid, and another which just sinks when it is sufficiently saline. The movement of either indicates at once the exact cause, and enables the aquarian to regulate the density to perfection.

Green Stain.-I have never been troubled with confervoid growths in tanks filled with artificial water, though the same water has been in use during periods of from a few months to two years. When it occurs, the mollusks are the natural remedy, the sponge the artificial one. But a strange affection-which I think is most common in spring-is the sudden occurrence of a green turbidity, which destroys the translucence, and for which neither sponge nor winkle can afford a remedy. It is not a 
growth on the side of the vessel, but a green stain pervading the water, as if a green colouring matter had been dissolved in it. Mr. Gosse says, "it is vegetable in its origin, and arises from an infinite number of the spores (or seeds) of green Algre dispersed through the fluid, and held in suspension there." Mr. Gosse further says, "I know of no cure for this," but he quotes Mr. Lloyd's experience as demonstrative of its curability by placing the water "in a dark closet for two or three weeks."

From the experience I have had in this matter, I have no hesitation in saying that the filter will be found an instantaneous remedy; the water need not be drawn off at all, but kept filtering through charcoal by frequent filling of the filter from the surface. In May last, a tank of mine became suddenly opaque, though otherwise in excellent order. The collection was valuable, and a disturbance of it would have been attended with risk. I suspended an old flower-pot half filled with fiesh charcoal and sea-side grit above it, and set the filter to work. As fast as the filter ran out, I filled it again from the tank, without disturbing anything, and a change for the better was perceptible in an hour. Two days after, the water was as bright as ever, and the stock in the finest possible condition, owing to the brisk æration they had gained by the experiment.

Feeding.-Anemones generally do not require feeding, though the Daisy and the Dianthus will greedily partake of small fragments of oyster and minced mutton, and some other kinds will occasionally eat of the same food; but I cannot recommend the beginner to feed Anemones, for, in 


\section{THE MARINE AQUARIUM.}

a well managed tank, Infusoria are sufficiently abundant to provide them with all they require, and food not eaten soon decays, unless speedily removed. Crabs and prawns positively require feeding, and Madrepores may be fed for amusement. Small fragments of the lean of raw meat should be given, or the flesh of a cooked prawn, and twentyfour hours afterwards, the undigested morsels should be removed.

The Syphon is a simple affair enough. In using it, place the short end below the surface of the water in the

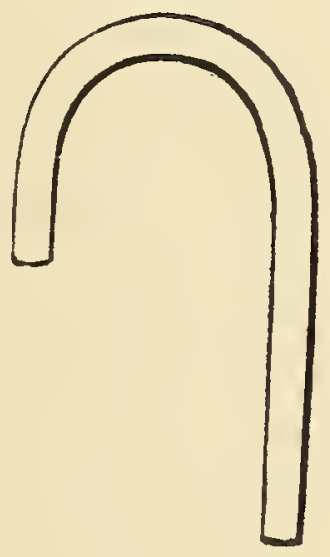

tank, and apply the mouth to the longer end, and draw till the water flows; it will then continue to flow as long as the short end is kept under water. If you object to promote aquarian science by means of suction, first fill the syphon with water, and apply a finger to each end, and so turn it over, and withdraw the fingers when the short end is dipped beneath the surface of the water in the tank. Mr. Lloyd sells a syphon expressly for the purpose, which the aquarian should possess.

Purchase of Specimens.-There are now many dealers in Aquarian stock, but very few of them supply marine 


\section{THE MARINE AQUARIUM.}

sto ck in any variety. I have my readers' interest only at heart when I suggest, that no one should attempt to set up an Aquarium without first paying a visit to the establishment of $\mathrm{Mr}$. W. Alford Lloyd, of No. 20, Portland Road, Regent's Park, where choice may be made from a stock consisting of thousands of specimens, supplied, as, the oyster shops say, "fresh every day." Mr. Lloyd was a labourer in the field years before the Aquarium became popular, and his experience, attained by patient study, is now at the service of all who need advice or assistance in any department of the subject.

I have no interest in this matter beyond doing justice to my reader, and beg to add that Mr. Hall, of City Road, has supplied me with marine stock of high character, and that I can recommend him as an honest and intelligent naturalist, though, on marine matters he will not attempt to compete with Mr. Lloyd, for the latter has now the name, the trade, and the organization, and since he keeps everything, so he can supply everything of the commonest or rarest kind, in the highest condition.

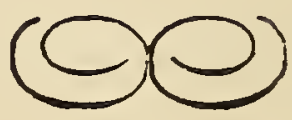




\section{THE BOOK OF THE AQUARIUII.}

\section{THE WATER CABINET.}

\section{CHAPTER I.}

\section{CONSTRUCTION OF CABINETS.}

Distinctions between the Cabinet and the Aquarium.The Aquarium has not only spread abroad a love for Natural History, it has also increased the facilities for the study of nature by removing the difficulties which have hitherto attended the preservation, for any length of time, of living specimens of aquatic life. The tank had scarcely taken its place among the resources for pleasureable recreation, and scientific study, when the field of culture extended itself, and every variety of minute life found in the waters, came to have its share of attention for the general profit and delight of the studious. The ordinary tank was found insufficient for the wants of the aquarian, and wherever a large vessel was to be seen stocked with fresh water fishes or marine objects, a collection of small jars, phials, or show glasses, was pretty sure to be found also. In an aquarium, we may group together many dissimilar objects; but it must be evident to the most superficial observer, that when immersed in a large body of water with other creatures, many objects are ill- 
THE WATER CABINET.

placed for examination, especially if we use the microscope. Hence, where the study is pursued with any degree of ardour, some special arrangements are necessary to enable us to keep in a healthy state, and in a way that admits of close scrutiny at any moment, such of the smaller aquatic objects as most commend themselves for beauty or scientific interest. Many beginners, unable to resist the temptation of a jar of beetles, or a collection of larva, and having no other means of keeping them, have placed them in the tank to mingle with the stock of finny creatures, and have thereby either lost the better part of the collection or have been compelled to break up the stock and begin anew. I have already suggested that a few species of water beetles, and aquatic larra, may be safely preserved in an aquarium; but an aquarium is by no means the best place for them, if we wish to study their habits closely, or investigate their mechanism and economy by the aid of lenses : all insects, many mollusks, larva, and other small objects should be kept apart, and a collection of such objects is what we mean by a Water Cabinet.

To the genuine student, there is really more for remunerative study in such a collection than can be found in the Aquarium, though the tank, whether river or marine, will always prove most attractive as an ornament, and because it requires less care and study, will be pretty sure to retain the greatest number of admirers. But the Aquarium and the Cabinet are distinct things; they cannot be combined in the same ressel, and, though a Water Cabinet is but another form, or rather a series of 
separate and smaller aquaria, the uses and economies of each are in a great measure distinct. It is possible to cultivate either without the other, though we should generally expect to find them in company, the Cabinet being a growth or extension of the Aquarium.

Construction of a Cabinet.-Ingenuity, under the control of circumstances, will devise many modes of preserving the smaller specimens of aquatic life, and I shall here describe a plan which I think will be found most generally useful, particularly as it may have a very simple form, and be produced for a very trifling outlay; or may be elaborated into a noble piece of furniture for the adornment of an elegantly furnished room.

The frontispiece represents a series of shelves fitted into a carved frame-work, the lower portion of which forms a table with drawers. My own cabinet, which is a simple affair of stained deal, is made after the model of the one here represented, but without ornament of any kind ; and if I describe its measurements, it may serve as a guide to any who may desire to have one constructed of a similar pattern, though, as a matter of course, the plan admits of endless modifications to suit the means of the student, or the position in which such a cabinet is to be placed.

The table measures nineteen inches from back to front across the centre drawer; and from back to front across the two side drawers, twelve inches. On this is placed a row of seven-inch cylindrical glasses of clear fint glass, and in the centre, behind the jars, stands a twelve-inch bell glass aquarium, to be stocked with choice fishes or superfluous cabinet specimens. The first shelf has a 
breadth of eight inches to receive a row of six inch glasses; the second shelf a breadth of five inches, and the jars upon it measure four inches in diameter. The top shelf is only three-and-a-half inches wide, and the glasses on it measure three inches across the top, and, two-and-ahalf at the base; the jars of this size, in my own collection, are of a tapering form, half an inch narrower at the bottom than at the top, though I am not aware whether such is the usual form of the small vessels. The entire frame-work has a breadth of about thirty-two inches, and a height, from the floor of the room to the level of the top shelf, of about sixty-six inches.

The breadth and height of the window, in which the cabinet is to be placed, must have the first consideration, with any one who may intend to construct such a piece of furniture; the respective sizes of the vessels must be an after consideration, because, unless the whole be so adapted, as that it shall enjoy a full share of uninterrupted daylight, very little progress can be effected, especially if the growth of the more delicate forms of aquatic vegetation be attempted.

In the absence of a properly constructed set of shelves, a few plain ones may be fitted up in a window. A single strip of deal, on brackets, would afford room for a dozen jars, and in these by judicious grouping, specimens of from fifty to a hundred kinds could be kept, whether for observation by the naked eye, or the microscope.

Glasses.-In common with many aquarians I used phials and confectioners' show-glasses for a considerable length of time; but to preserve the uniformity of the 


\section{THE WATER CABINET.}

collection, I should recommend cylindrical glasses of fint glass of the form represented in the engraving. Chancing to unearth a number of such glasses, at the warehouse of the Messrs. Phillips, of Bishopsgate Street, I have since abolished the olla podrida of acid bottles and phials, with which I had previously been content, and now use no other kinds, and I think their strength and clearness of colour must commend them to the student, as the best that can be had for the purpose. The cost of them is a shilling a pound, though common show-glasses may be had at ninepence a pound. If there is much dust in the room, where the cabinet stands, a strip of green gauze might be stretched on light cane frames over each row of glasses.

The jars are intended for the reception of separate or grouped species, and the bell glass may be an ordinary aquarium or a receptacle for the omnium gatherum of general collecting. My jars are now (July, 1856, stocked with minute aquatic plants, beetles of several species, diving spiders, water worms, and mites, larva of beetles and flies, tadpoles in progress of transformation, mollusks of choice kinds, and spawn of all kinds, removed from the tanks. The bell glass contains a miscellaneous assemblage of duplicates of all kinds, such as water weeds for renewal of tanks, tadpoles, leeches, whirlwigs, mollusks, crustacea, and infusoria for the microscope. Species that do not agree, may be introduced to the bell glass for the sake of teaching us the nature and incidents of the strife maintained in the great world out of doors; the battle may there have its way, and we may study destruction with as 
much profit as we may the momentary creation by which the system of nature is maintained in its completeness. In fact, the bell glass is a reservoir into which we may dip for almost anything we want to fill "up vacancies in the jars, and in the proper tanks, and to which we may consign the superfluities of a day's collecting; having first assorted, and set apart such as are wanted for separate observation and study.

\section{CHAPTER II.}

\section{COLLECTING AND ARRANGING SPECIMENS.}

Implements for Collecting.-Most of the ordinary productions of ponds and brooks may be purchased of the dealers, especially beetles, larger kinds of larvæ, water spiders, and tadpoles; but very little progress can be made in the study of this branch of natural history, without personal visits to the fishing grounds.

An hour spent in dragging a brook or pond, will do more towards stocking a cabinet with wonders than a hundred purchases. To the pleasure of an excursion is added the intellectual profit of learning the nature of the haunts, and many of the habits of the creatures obtained; every haul of the net will bring forth from the oozy bottom, an immense variety of the most curious kinds of life.

Nets, for the purpose, are easily obtainable. At least, two kinds will be necessary, namely, a small hand net attached to a short rod, or made to slip on a common walking stick, and a larger one for a long rod, or for 
hauling with a line. The small net should be of a fine mesh, and for convenience of carriage, may be fitted on a jointed ring of brass, so as to fold together. The large net need not be very fine in the mesh, but it should be very strong, both in the texture and the fittings, and should be lined inside with muslin so as to prevent the escape of the smallest game. Every variety of pond and drag-nets may be obtained of the dealers in fishing-tackle, at prices varying from one to five or six shillings, and of a quality that may be depended on for serviceableness.

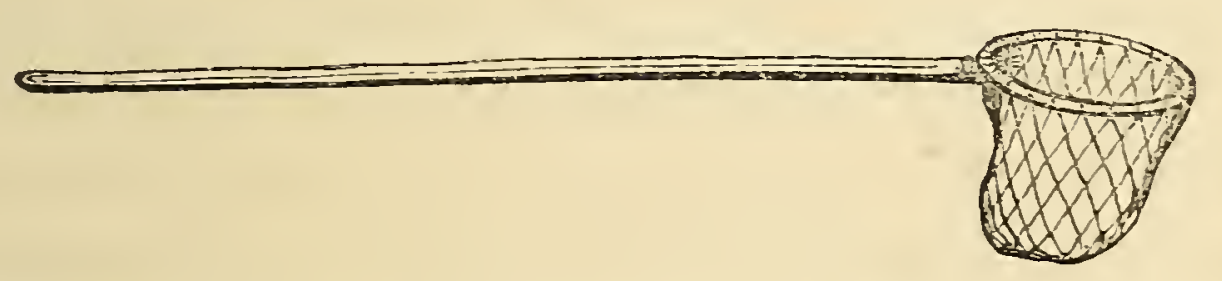

Some water-cord, a jointed rod or walking stick, and a few earthen jars, or live bait cans, make up the stock of implements, the whole of which, with the exception of rods, may be packed into a basket in which suitable divisions are made, and transported easily. Living in the neighbourhood of many prolific brooks and ponds, I have very little experience in the carriage of specimens, and, indeed, seldom use more than a single jar, and a single net at one time; but I should suggest to those who have to travel a distance for the pleasure of beetle fishing, to provide themselves with a basket or box, made after the fashion of the baskets in which bottles are sent out by vintners, the divisions being fitted with stone jars ; and one division left the whole length of the basket, for nets, scissors, a pair of forceps, and a fer small phials. Each vessel should have a lid of perforated zinc, to 
prevent the escape of objects during transit; the jolting of a railway train or coach might otherwise waste the contents. The stone jars used for the purpose, should have a cord attached round the rim of each for convenient handling at the brook side.

Pond fishing.-Every variety of stream or stagnant pond may be fished to advantage; but the specimens obtained from clear running brooks will, in general, differ greatly in character from those which the drag net brings from a dark still pool. Ponds which have formed in gravel pits, are generally well stocked with newts, mollusks, and tadpoles; but for the varieties of the beetle family, old ponds in meadows, and which are the resorts of cattle, are the best; ditches and rank brooks are the usual haunts of caddis worms, diving spiders, polypes, and the more beautiful varieties of water bugs; but every locality has its special attractions only to be learnt by experience.

Supposing that you have made a halt beside a pleasantly shaded brook, with hedge sparrows, robins, and black-caps warbling about you. You prepare by selecting a suitable spot free from brushwood, and where the edge of the water may be reached without danger. The first thing to be done is, to fill a few jars with clear water, and to throw into each a few strips of any common water weed, of which callitriche is always the best, and most generally attainable. If the water is very foul it will be better to travel a little distance for a supply, because the specimens are wanted as cleanly as possible, and if thrown into clean water when caught, their own motions will tend 
to cleanse them, and fit them for the glass jars at home. The shore should be fished first, and the operation should be conducted with as much quiet as possible; any disturbance will be sure to drive away many of the livelier creatures. Take a small net attached to a walking stick or short rod, and thrust it out from you as far as possible over the water; then quickly dip and draw it towards you, and land it at your feet at some little distance from the edge of the water. Sort out the contents of the haul into separate jars, though, as you cannot have as many jars as the kinds which the net will bring up, a little judicious grouping will be necessary. Spawn of all kinds may be placed together in the same jar with mollusks, tadpoles, caddis worms, and colymbetes; most beetles must be kept by themselves, on account of their voracity, as must also the several kinds of carnivorous larvæ, such as those of the Dytiscus, and the dragon fly, and water worms of the genus Nais.

When the sides have been well fished, the deeper water may be operated on by means of the drag-net, and the produce disposed of in the same way.

On arriving home, sort over the jars seriatim, and dispose of the specimens according to the capacity and arrangement of your cabinet. The glass jars should be each furnished with a few tufts of some growing weeds, and with clear water. Some of the specimens will require to be washed to remove offensive matter, and some few will need a bottom of small pebbles, and a jar nearly filled with healthy vegetation. Anacharis, Myriophyllum, Nitella, Chara, Ricoia, and choice Confervoids, are the 
best for the cabinet, on account of the limited space in which they must be kept, and the elegance they impart to the collection. In the larger jars it would be well to keep some tufts of vallisneria in order to propagate it to supply vacancies in the tanks. When the stock has been housed in the cabinet, whatever is left may be transferred to the bell glass for further examination. It would be better not to wash or disturb the refuse weed and sediment of the collecting jars, but to throw the whole into the vase. After a few hours it will settle down, and a lens will assist in the detection of whatever curiosities may swarm out of the refuse weed. Objects for the compound microscope may in this way be obtained and preserved in plenty.

\section{CHAPTER III.}

\section{THE STOCK.}

I HAVE already indicated some of the varieties best suited for the cabinet, but will here briefly enumerate those which form the leading features of attraction, leaving the development of the collection to the perseverance of the student. The great division of Coleoptera will furnish by far the largest number of showy species, all of them interesting and lively creatures, many of them possessed of great beauty. The ravenous Dytiscus marginalis and dimidiatus, with their strong hooked claws, and brightly bronzed elytra; and the pretty, docile, and harmless Colymbetes, with its shining silver breast-plate, and jet black limbs and elytra, must take the first place among the beetles for beauty of form and colour. The large, 
harmless Hydrous piceus, the lively Notanecta, Gyrinus, and Nepa, are essential to the collection.

Among the larva, those of the Caddis fly should be kept in abundance, on account of the amusement afforded by their strange habits and their remarkable metamorphosis. Larva of the Dytiscus, known as the Water Tiger, of the Dragon fly, the gnat, the May fly, and of the two-winged fly, Stratiomys Chamaleon, the pretty blood-worm, which is the larva of the Chironomus plumosus, a very pretty gnat, with feathered antennæ; and the telescope-tailed grubs of Helopkilus pendulus, which, in its larva form, is one of the most curious examples in the cabinet, and, in its imago, is frequently mistaken for the honey-bee.

The drag-net will also bring out many curious watermites, than which there can be no more interesting subjects for the microscope, or prettier objects for ordinary observation. While writing this, I have before me several specimens of the beautiful mites, Hydrachna geographica and abstergens (Müller), in a jar of Nitella; they are ever in action, treading the water as if it were air, with a kind of motion that cannot be termed swimming, but rather a walking or dancing, maintained with the greatest ease at any level, or at the bottom of the ressel. Another, and much more showy one, is the bright carmine-coloured mite Limnochares holosericea (Latreille), of which I find an abundance in a neighbouring brook. Its pretty, spidery motions, and vivid colouring, render a jar, containing a dozen specimens, very attractive to the eye of a student of nature. 
THE WATER CABINET.

The Diving Spiders are amusing, and should be kept in plenty in large jars, well stocked with healthy weed; and the curious Raft Spider may also be preserved in a

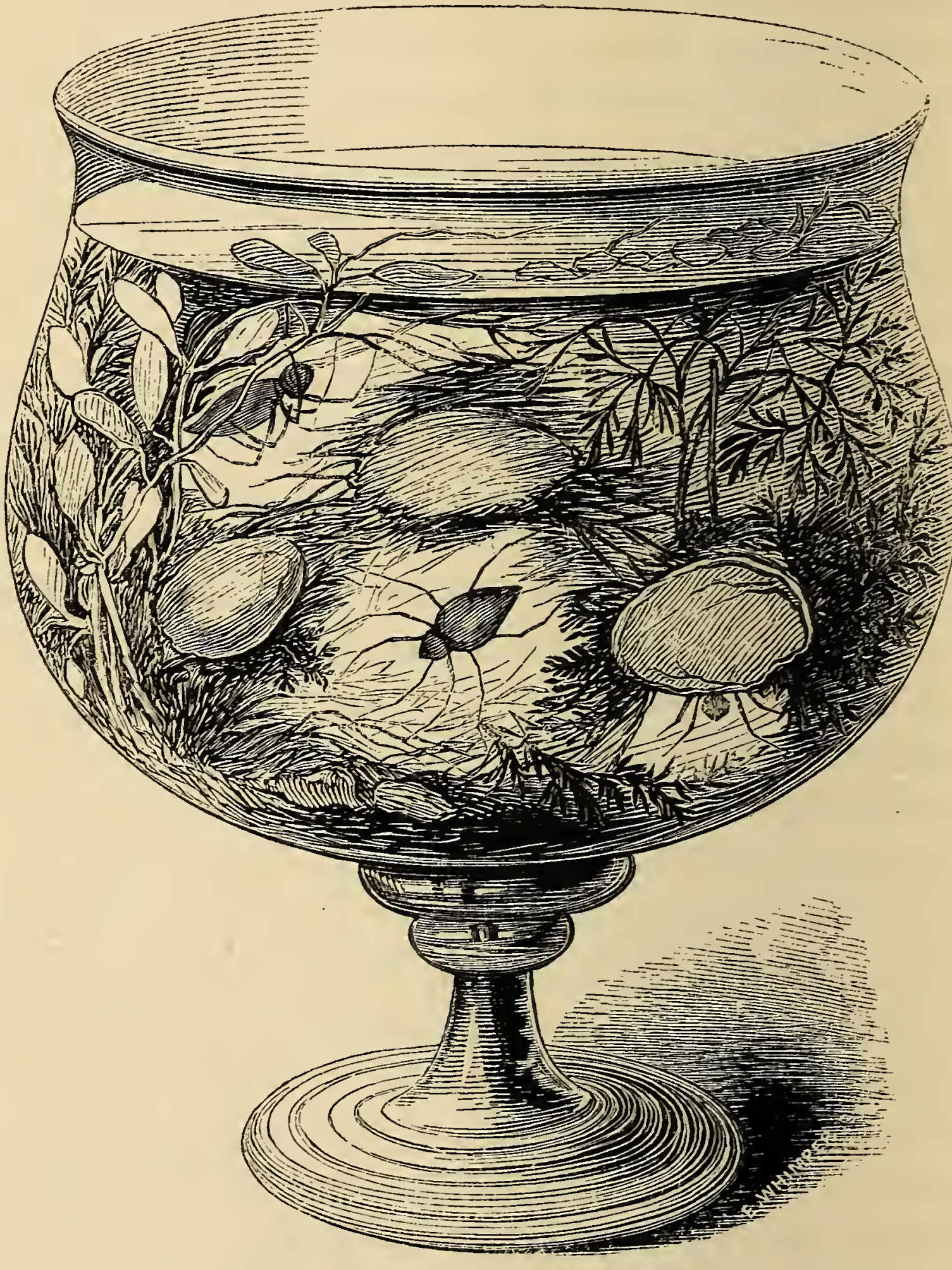

DIVING SPIDER AND NESTS.

shallow vessel, closely covered with gauze. Aquatic Spiders are most abundant in clear brooks and ditches 


\section{THE WATER CABINET.}

near rivers; the small tributaries of the Lea, and the dykes that abound in the marshes at Tottenham, supply me with specimens whenever I seek them.

Among the water-worms most easily obtained, the hairlike Gordius aquaticus (Linnæus), and the curiouslyformed Nais, may be recommended as curious and interesting. The latter requires a bottom of sand in which to burrow, and should be covered with only a few inches of water. When it takes to its new home, it plunges its body into the sand or mud, and extends its telescopetail upwards to the surface for air, adapting its length to the depth of the water.

The generation and development of reptilia and mollusca may be better studied by the use of jars for the specimens, than by their immersion in the aquarium. Tadpoles, the larva of newts, and the spawn of mollusks, may be preserved in the cabinet for purposes of study, much better than in the tank; each species being separate in a bright and portable vessel, every minute change can be observed, and a lens applied at any time, or the specimens removed for close inspection without difficulty. I find it a good practice to remove any spawn, which may be deposited on the large vessels, to the small jars on my shelves. There the little Lymnea and Planorbis are developed in hundreds, without molestation; and if increase of Paludina vivipara be required, a jar is at once converted into a breeding tank by throwing a couple into it, with a bunch of Callitriche, and any vegetable waste from the tanks. In the aquarium, the young mollusks are devoured almost as soon as they are born; and the 
pleasing spectacle of their increase, coming forth from the gelatinous mass in hundreds, like minute beads of gold, is lost without the aid of the cabinet in which to rear them. The young of most species of univalve mollusks are vagrant in their habits, and the jars in which spawn is hatched should be closely covered with perforated card or gauze, fitting closely by means of India rubber rings.

Since it is unnecessary in this work to give a classified history of the several creatures that may be kept in watercabinets, I shall devote the remainder of the space at my command to notices of a few of the most attractive and best known species, and to a few hints on the general management of the cabinet.

\section{CHAPTER IV.}

LARVA.

THE great class of insects comprises many remarkable and diverse forms, among the 560,000 species which $\mathrm{Dr}$. Imhoff estimates to be now known to naturalists. Yet, various as they are, it is by no means impossible to define what are the distinctive features by which this class is separated from those which approach it in conformation and habits. A true insect has the body divided into three parts - the head, the thorax, and the abdomen. It has never more than six legs, and these are attached to the thorax. The segments of the body seldom exceed thirteen in number, one of which forms the head, three the thorax, and the remaining nine the abdomen. The 
possession of one or two pairs of wings gires them their prominent characteristic to the eye, but it is the successive metamorphoses that arrests universal attention, and calls forth the admiration and wonder of mankind. In the progress of an insect from the minute egg to its completed form, we see the most remarkable series of developments which animal life erer displays in all its endless procession of forms - the egg, the worm, the chrysalis, the fly - a strange unfolding, for the first time accurately observed by Swammerdam, who detected, under the wrinkled skin of the disgusting worm, the complete outline of the lovely butterfly.

This metempsychosis may be studied in its sereral strange details by the aid of the Water-Cabinet. The first condition of the newly-hatched egg is that known as the grub, or caterpillar-scientifically called the larva. The larra generally bears no earthly resemblance to the imago, or perfect insect, into which it is to be hereafter dereloped, but leads a life of sensual enjoyment-it eats, eats! it is gluttony concentrated in type and act. It changes its skin several times, slips one coat off and acquires a new; growing, and eating, and changing garments, till, like man himself, it seeks a temporary tomb, from which it is to soar to the skies like a soul liberated. This second form is popularly known as the chrysalis, or aurelia, scientifically called the pupa. In this form the insect remains in a state of complete or partial torpidity for a few days, weeks, or months, according to the particular species.

The day of its deliverance arrives, its bonds burst, and 
it comes forth "a thing of beauty" to sport in sunbeams, and, for but a brief season, lead a life of joy-

"Fluttering round the jasmine stems, Like winged flowers or flying gems."

But beauty of the high poetic kind is not the inheritance of every member of the class insecta; and the watercabinet presents us with many that have but analogical resemblances to the typical structure of the moth or the fly, though the naturalist finds beauty in a beetle, and points of profound interest in a maggot or grub.

Since larva are distributed through at least three elements, being, according to the species, inhabitants of earth, air, and water, the breathing apparatus arrests our attention, as constituting a distinct feature in the anatomy of the insect. A caterpillar may be regarded as all stomach, and the cravings of this immense digesting tube easily account for the voracity of larva of all kinds. In the larger animals, the food is elaborated into blood, and brought to the lungs to be oxygenated by means of contact with the air, but the insect does not breathe at the mouth, but at the other end, or by means of tubes arranged along the sides of the body. In a caterpillar there are usually eighteen of these tubes, the orifices of which may be seen in action. These tubes all run into two larger lateral tubes, or wind-pipes, arranged one on each side of the body ; and from these lateral tubes innumerable smaller ones diverge, and convey air to the vessels in which the digested food is contained, and thus supply it with oxygen. Swammerdam was the first who suc- 
cessfully anatomised this class of animals, and to him we are indebted for the microscopic anatomy of grubs, and a revelation of their inner economy generally.

The Dragon Fly, Libellulidae (Leach), a wellknown summer beauty-the mere mention of which is always sufficient to set one's heart beating for rustic coolness, and the hushed music of the beechen shadesis, in its larra form, an interesting object for the cabinet. Between the larva and the imago of this insect, the difference is striking indeed; as a lady, not addicted to scientific studies, once characterised the larva-using Pope's lines-as,

\section{"A monster of such hideous mien, That to be hated needs but to be seen."}

But the gauze-winged and gaily-coloured fly merits all the praise bestowed upon it by the French, who call them Demoiselles, so light, fairy-like, and visionary are its form and movements. Scientific writers have applied many descriptive names to it, such as Calepteryx (pretty wing), Puella (girl), Sponsa (bride), and Virgo (virgin). The larva of the dragon fly exhibits, in a very striking manner, the mode of respiration in aquatic insects. It is not an active creature; for though it has six legs, it seldom uses these except in the capture of prey; its locomotion is chiefiy performed by the tail in the action of breathing. When thrown into a jar with some fragments of weed and a few light chips, these will be seen to be drawn towards the tail of the creature, by the current occasioned by the absorption of water; and then again driven off, with con- 
siderable force, as the water is again ejected. The quantity drawn into the body by this hydrostatic action must be considerable, since the dimensions of the larva regularly change with the breathing action, the body becoming collapsed when the stream is ejected, and again swelled out with the suction that follows. If it be thrown into water, tinged with cochineal, and then quickly removed again into clear water, the coloured stream will be seen to be projected several inches, and with force sufficient to propel the creature forward by a series of successive jerks.

Besides the act of breathing, then, this anal pump has locomotive uses; and it also aids the creature in obtaining food by drawing minute creatures towards it in a manner similar to those animals which are furnished with cilia.

But the microscope reveals a still more curious fact, in the anatomy of this larva, which has been most faithfully described by Kirby and Spence. The under lip, when closed, entirely conceals the mouth, and it not only retains, but actually seizes, the animal's prey, by means of a very singular pair of jaws with which it is furnished. Conceive your under lip (to have recourse, like Reaumur, on another occasion, to such a comparison) to be horny instead of fleshy, and to be elongated perpendicularly downward, so as to wrap over your chin, and extend to its bottom-that this elongation is there expanded into a triangular convex plate, attached to it by a joint, so as to bend upwards again and fold over the face as high as the nose, concealing not only the chin and the first mentioned elongations, but the mouth and part of the cheeks. Conceive, moreover, that to the end of this last-mentioned 
plate are fixed two other convex ones, so broad as to cover the whole nose and temples-that these can open at pleasure, transversely, like a pair of jaws, so as to expose the nose and mouth, and that their inner edges, where they meet, are cut into numerous sharp teeth, or spines, or armed with one or more long sharp claws-you will have as accurate an idea, as my powers of description can give, of the strange formation of the under lip in the larva of Libellulina, which conceals the mouth and face, precisely as I have supposed a similar construction of lip would do yours. You will probably admit that your own visage would present an appearance not very engaging, while concealed by such a mask; but it would strike still more awe into the spectators, were they to see you first open the two upper jaw plates, which would project from the temples like the blinders of a horse ; and next, having, by means of the joint of your chin, let down the whole apparatus and uncovered your face, employ them in seizing any food that presented itself, and conveying it to your mouth. Yet this procedure is that adopted by the larvæ of the dragon-fly, provided with this strange organ. While it is at rest, it applies close to and covers the face. When the insects would make use of it, they unfold it like an arm, catch the prey at which they aim, by means of the mandibuliform plates, and then partly refold it, so as to hold the prey to the mouth, in a convenient position for the operation of the two pairs of jaws with which they are provided. The form of this masked jaw is represented, but not very clearly, in Rennies' "Insect Transformations," p. 164. 
When its season of larva life is over, it retires to the bottom of the ressel to repose, and becomes a pupa. When the crumpled form of the gaudy fly begins to ex-

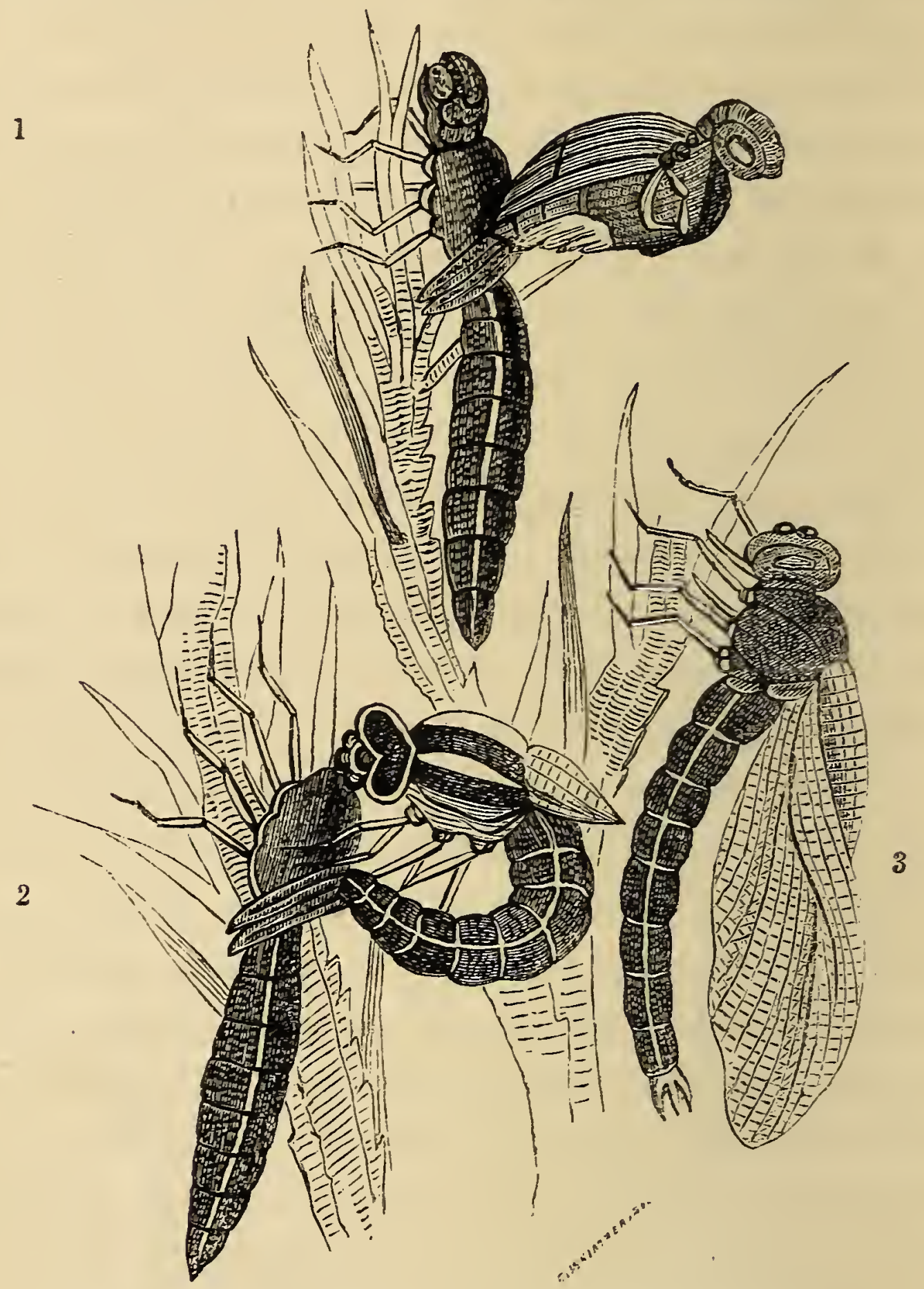

TRANSFORMATION OF THE DRAGON FLY.

1. The Fly just emerging. 2. The Fly. nearly free, and forming an arch. 3. The $B I y$ liberated, and with its body bent, to hasten the drsing of the wings.

pand within, and to knock at the door of its sepulchre, the pupa quits the watery element for ever, and betakes 
itself to the dry land, or to the slip of cork placed in the jar for its use. There, the apparently painful process of its unfolding takes place, and the fly slowly emerges. The envelope bursts asunder, and the head of the lovely, but blood-thirsty damsel, emerges to the light. Next appear the legs, not in action, but gathered up to the breast, as if in spasm, and, for a time, the effort is suspended, and the helpless, half-formed beauty hangs back her head, as if languid with the exhaustion of pain. Once more she pants for freedom, sighing to sun herself in the blue ether, and another struggle is made. This time she clutches at the pupa case with a convulsive grasp, and drags forth the whole of her delicate body from the grave, and there remains motionless, still clinging to it, as if contemplating the baseness of her origin-for beauty is ever the offspring of the dust. She is free at last-but, ah! how helpless. Her wings are damp, and closely folded, and would not yield to the wish for flight, even were she already possessed of the power to stir them into action. She is on the threshold of a new world-a creature born of the dust, just escaped from the dust; and now as we watch her wings dry and expand, away she goes-a thing of light and loveliness soaring heavenward. Like the mortal ark, out of which the spirit of man escapes, we may, without losing sight of the disparity of the subjects, speak of the chrysalis of the dragon fly as-

"A worn-out fetter, which the soul

Has broken, and thrown away." 
THE GNAT-Culex pipiens(LINNAU8)

In the operation of dragging, many curious larva are brought out, and the mud should be searched carefully for them before washing the net for another cast. The larva

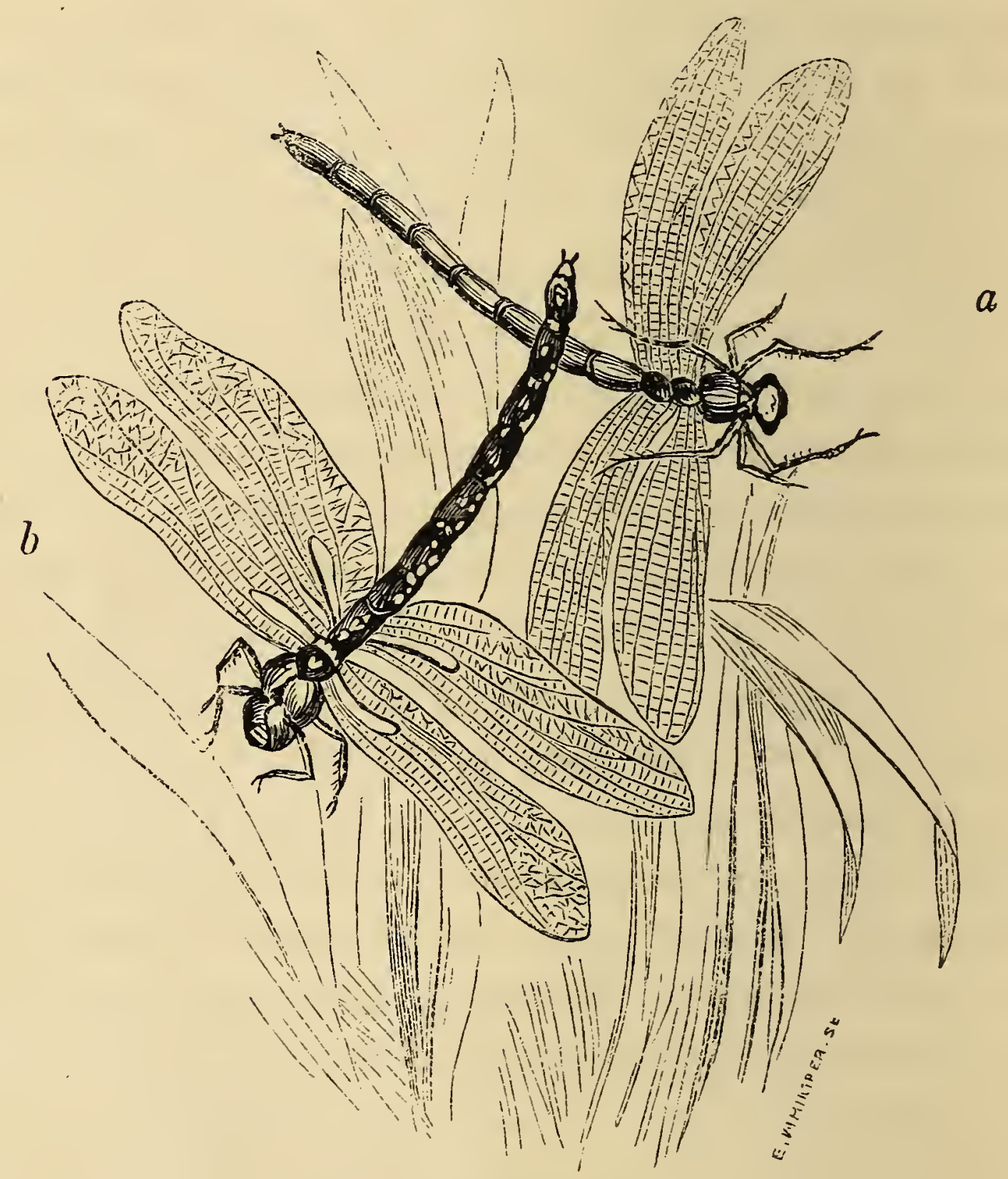

\section{DRAGON FLIES.}

a. Virgin Dragon Fly-Calepteryx Virgo.

b. Green Dragon Fly- Eshna varia.

of the gnat is one of the most interesting of these, and during summer may be obtained in hundreds if a little of 
the brook water be dipped to fill the jar with, and a few light weeds thrown in to supply oxygen. These larva are the produce of eggs deposited in a curious manner.

The gnats repair to the water soon after day-break, and commence an operation of a truly naval kind, such as would have delighted the savage heart of Peter the Great, could he have witnessed it in the midst of his dreams of achieving naval power. In fact, the mother gnats construct rafts of eggs, and each egg is added as a separate timber of the vessel, till a boat-like structure is produced. The skill as well as the neeessity of the construction is well tested by the fact that each separate egg would of itself sink to the bottom, whereas being protruded one by one into the angle formed by the hind legs which serve as stocks for the future ressel, and successively glued to each other by the fluid which exudes with them, they gradually assume, under her guidance, a neat boat-like form of about three hundred minute pyramidal eggs.

"The most violent agitation," says Kirby, "cannot sink it, and what is more extraordinary, and a property still a disideratum in our life-boats, though hollow it never becomes filled with water, even though exposed."

The grubs at last come forth, and lead a very merry sort of life under the shadow of the sedges. Placed in the jars they appear at first sight like newly hatched fry of fishes, but we soon detect the segments of their pellucid bodies, and, as might be expected in water larva, they breathe at the wrong end, and hence most of their merry morements are performed between the surface and the 


\section{THE WATER CABINET.}

bottom; every time they descend they carry with them a minute bubble from the surface. Under a good lens the pretty creature changes its form considerably, and comes out in the pantomime style, with huge horns, goggle eyes, and starched frills of shaggy hair; but then the tail becomes the object of attraction, and we watch the breathing action of the curious funnel which breaks away at an angle from the last segment of the body.

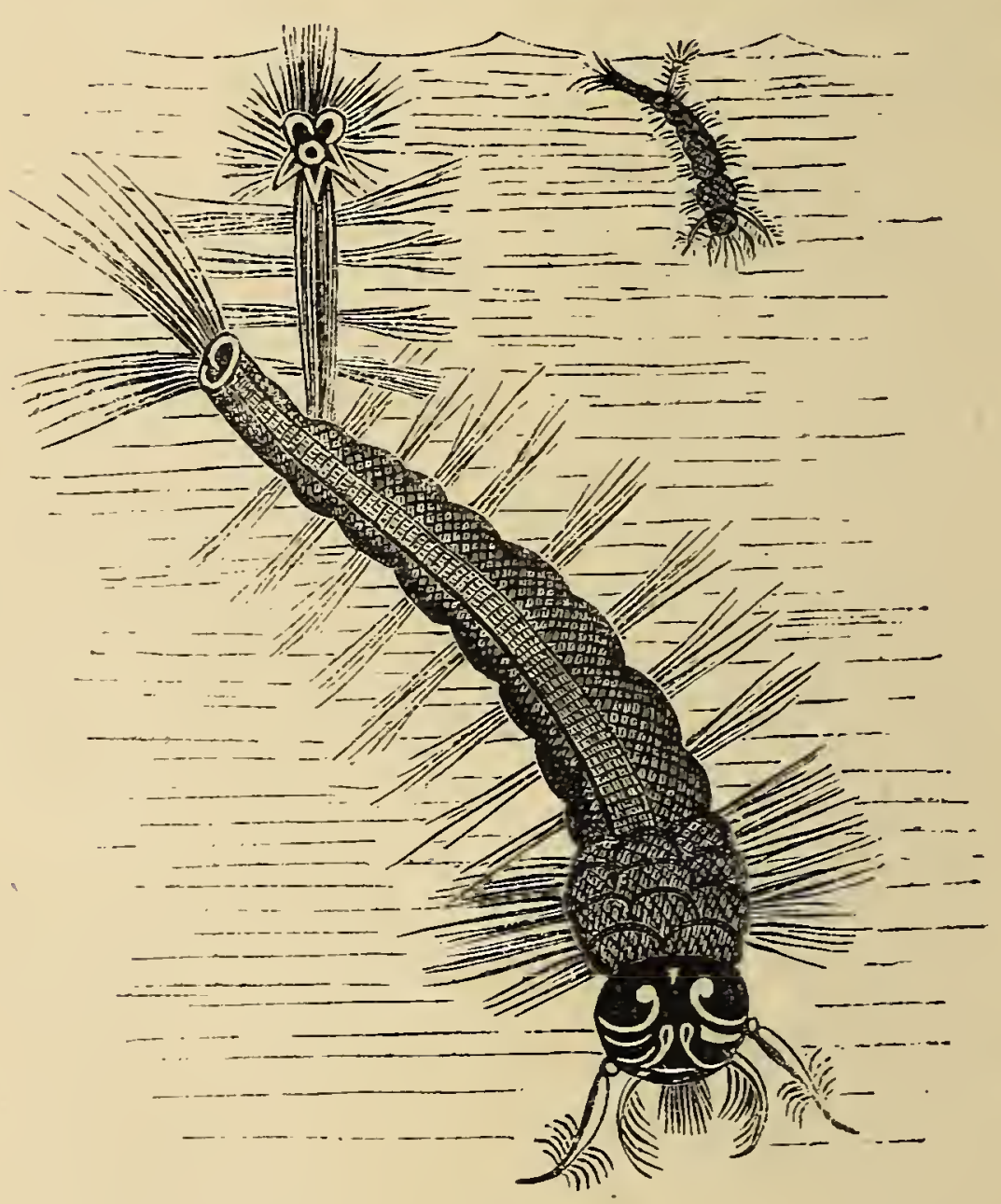

LARVA OF THE GNAT, NATURAL SIZE AND MAGNIFIED.

Swammerdam first observed that the breathing tube and tail are both anointed with oil, and that if the larva is handled roughly the oil is removed, and the grub "can no longer suspend itself on the surface of the water. I have, on these occasions, observed it put its tail in its 
mouth, and afterwards draw it back, as a water fowl will draw its feathers through its bill to prepare them for resisting water." I have now (July,) some thousands of the larva of this and other species of gnats, aud they are the most lively creatures in my collection. The flies come off in large numbers, and escape through the open window; or, if the window be closed, they swarm on the glass, and keep up a musical humming, closely resembling that of a swarm of bees at a distance.

A more elegant example of this kind of breathing apparatus is seen in the grub of the two-winged fly,

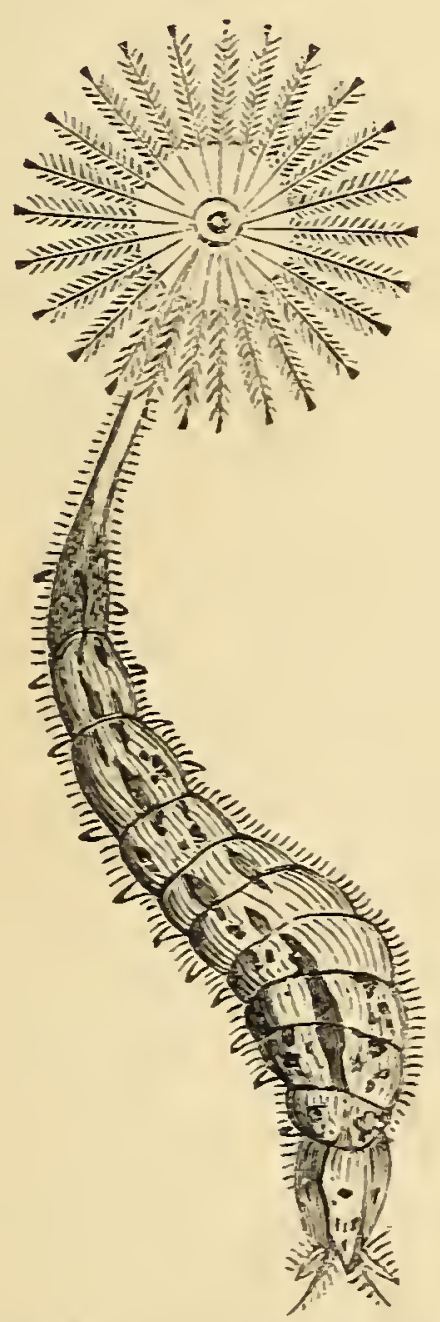

LARVA OF STRATIOMYS.

Stratiomys Chamaleon. The funnel tail spreads into a beautiful star of thirty distinct rays, and with this struc- 
ture, the creature suspends itself to the surface of the water, as if it were a ceiling, and as it moves to and fro its changes of position may be noted by the shifting of the dimple on the surface.

In the little gnat, Corethra plumicornis (MEIGEN) we have some further examples of the peculiar conformation of the larva, to enable it to respire in the water; but the larva is so transparent that it requires an expert microscopist, and an effective instrument to work out the details as represented by Reaumur and Dr. Goring. The larva of this species is plentiful in our brooks, and worthy of close scrutiny by the aid of the microscope. Just now the gnats are abundant in meadows near streams, and to them we are indebted for that soft humming which has been appropriately termed the "music of the wild," and on which good old Gilbert White exhausted his ingenuity to find an explanation. The social communities of these ephemeral creatures are strictly music parties, and whenever we suffer them to assemble about our heads, when rambling in the hedgerows, we are entertained by their fairy-like performances. Expertum est.

The Case Fuy Phryganea grandis.-There are several species in the family of Phryganea, which is the only tribe in the order Trichoptera, but such strong resemblances exist between the several members of the family that some entomological experience is necessary to enable the student to distinguish them. In an aquarium, the caddis worms are very amusing, and since they thrive there, they are very suitable additions to the happy family. We see them busy at the bottom, adding fragments of 
weed, pebbles, minute shells, even if the snails within them are alive, and any small debris that their fingers can seize hold of. Last season I had amongst a large number of cads, one that had his case nearly destroyed by accidentally falling from the table. I removed from him what remained of his case, and threw him into a jar with a soldier plant and a few Lymnea. He set to work to repair his tabernacle, and the Lymnea helped him, for they nibbled a plant of Stratoides into shreds. These shreds the cad gathered, and every day he added a fresh piece, so that, in about ten days, he appeared in a suit of green, his clothes bulged out to an enormous size, and everywhere studded with points and corners, the most comical sight that could be imagined. Since he could find nothing of a small neat pattern, he took what he could, and became a perfect Jack in the green, nearly an inch and a half in length, and thicker than a carpenter's lead pencil.

The movements of these creatures are as comical as their specimens of tailoring. We see them mounting a stem or leaf with great gravity, when suddenly up goes the tail, the legs hold tight, and the case turns completely over, as if on the first of May, Jack-in-the-green were to dance on his head. When the creature is hidden, and the case sways to and fro like a buoy attached by too short a rope, the sight is very curious. This case-maker is the larva from a fly which bears resemblances to the two families which stand on either side of it-the Lepidoptera, or true butterflies, and the Neuroptera, of which the dragon flies and other membranaceous winged insects are 
members. As soon as he enters the world, he begins to show his skill in tailoring, and by means of silken threads and gluten constructs his case of bits of stick, straw, dead leaves, or shells, in fact, whatever he can get, and as long as he retains the worm-like form the case is his castle, and he can defy the world. The case outside is generally a rough affair, but if you draw out the cad you

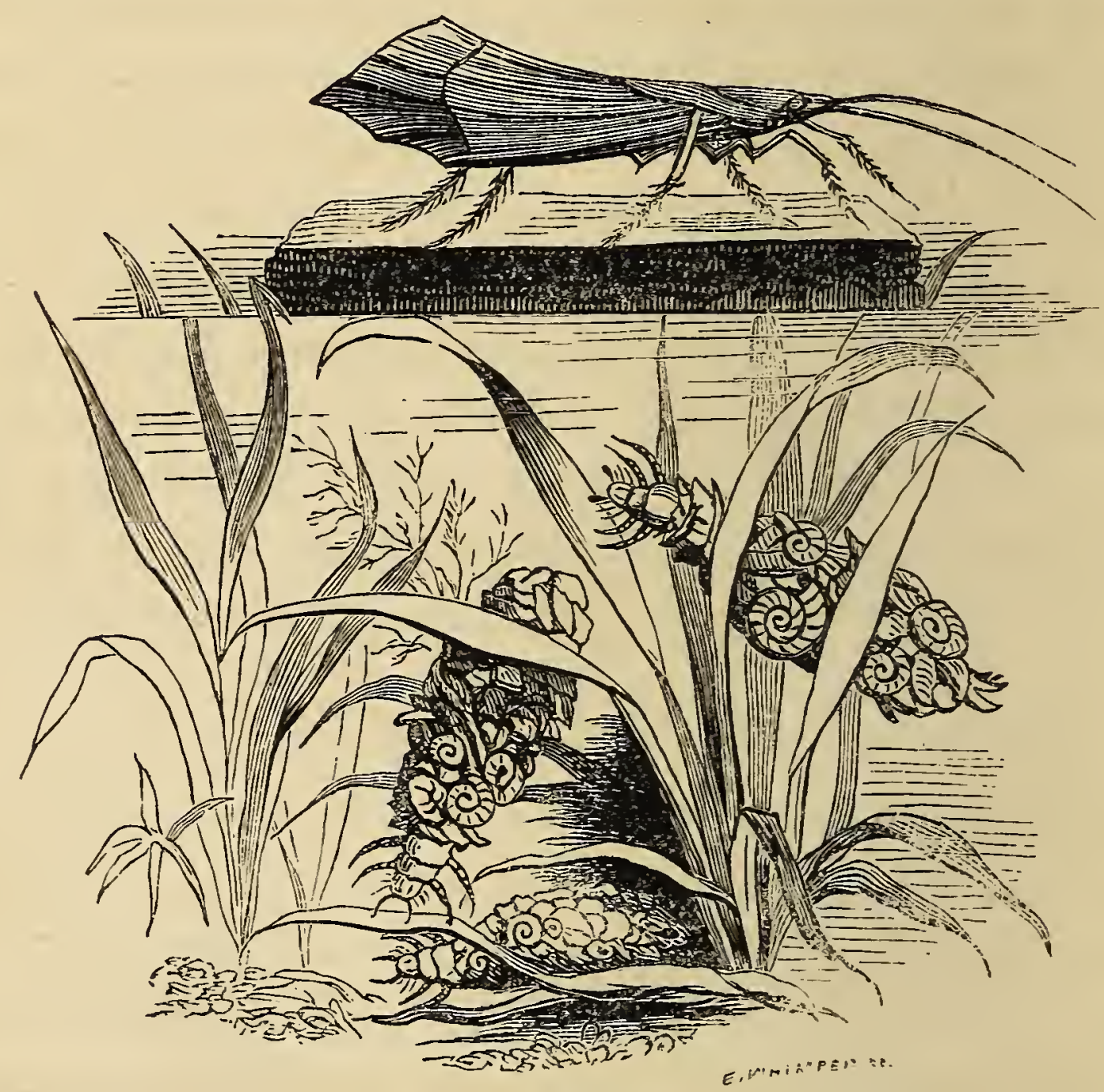

LARVE AND IMAGO OF CASE FLY.

will see that inside it is perfectly cylindrical, smooth, and polished, and around the doorway, through which the larva makes acquaintance with the world, it is neatly finished with a very circular rim. When you have removed a cad, if you throw him into a tank you will learn 
in an instant what is the use of his case, for his soft nakedness is no sooner exposed, than the minnows finish him, and find the flavour excellent. But to see a cad in his proper uniform molested is a very rare sight indeed. $\mathrm{He}$ passes his larva life innocently, and is an amusing fellow; when he feels the numbness of death creeping over him, the cad draws in his six legs, and sets to work inside to weare a winding-sheet and to shut the shutters, for he knows that his time is come, and there is no one to do such melancholy offices for him. All alone in his solitary cell, the hermit works day and night, and hourly his fingers grow more feeble. We look and find the shutters closed, and by this time the larva has changed into a pupa.

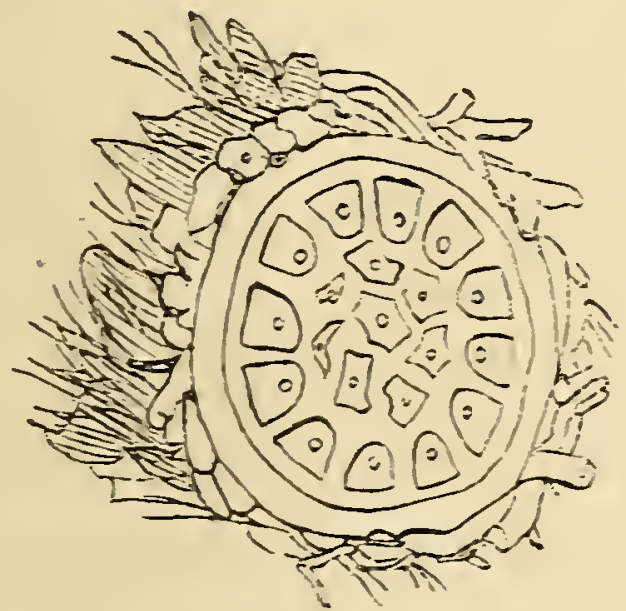

GRATING OF CASE-WORM, MAGNIFIED.

The mode in which the worm closes its cell is curious enough. Orer its entrance it weaves a grating of silk, which hardens in water and remains insoluble. It may be seen very plainly by the naked eye, but under a good lens increases in interest. The grating is placed a little inside the margin of the opening, and fits exactly within it, and its object is to protect the pupa from invasion, 
and at the same time, to admit water for respiration. De Geer describes one of these gratings in which the pierced holes were disposed in concentric circles, as represented in the engraving. This, however, is not, as far as I am aware, the usual form of the grating, many that I have examined were formed in regular rays from a centre like the spokes of a wheel.

But the escape of the pupa, when about to undergo its last metamorphosis, is as interesting as the fact of its closing the shutters to announce its own death. It is provided with a pair of hooked mandibles, with which to gnaw through the grating, and no sooner have these accomplished their purpose than they fall off, and the pupa takes its last shape of a four winged fly, as represented in the cut.

\section{H A P T E R V.}

\section{COLEOPTERA.}

THE beetle tribe are distinguished from other insects by the possession of elytra, or wing-cases; which wingcases are, with regard to the typical structure of an insect, to be regarded as really the first pair of wings hardened into a horn-like consistence to protect the others. The wing-cases are of little or no use in flight, this action being accomplished by means of the second pair, or the true wings, which are generally of large size, and when not in use are neatly folded up beneath the elytra. The division of the body into three parts-head, thorax, and abdomen-is very plain to the eye; but the seg- 
ments, of which the several parts are composed, are frequently so consolidated that it is difficult to detect or count them. For instance, the thorax, theoretically, consists of three segments; but, practically, the first of these is usually so largely developed as to appear to constitute the thorax in itself. The (theoretical) nine segments of the abdomen are, in like manner, reduced to six or seven, in consequence of the last two or three being consolidated into one.

The order is an immense one, as to its range and variety, and hence there are in it many curious exceptions to the general conformation of a beetle. Some are utterly incapable of flight, owing to the non-possession of elytra, or wings; some have elytra only; and in some the elytra meet and unite along the suture; so that, if the insect had wings underneath, it would be impossible for it to use them.

The specimens of coleoptera, kept in the water-cabinet, are among the most interesting of the whole collection, whether in the larva or imago form; and to this order we are indebted for a large number of aquatic species, that may be kept in jars, and some few that may be introduced without danger to the tank.

Dytiscus Marginalis is one of the handsomest of water-beetles, and its habits are amusing and instructive. It possesses an insatiable appetite; and great muscular power, as we soon discover when removing it from one jar to another, for if it succeeds in planting its claws firmly on the edge of the ressel, it is difficult to more it. It belongs to the large tribe of aquatic carnivora, ranged 
in the section Pentamera, in which the tarsi of all the feet are five-jointed, the fourth being of ordinary size.

The Dytiscus is a true water-beetle, being aquatic in both its larva and perfect forms. The larva, known as the water-tiger, is found in plenty in the muddy ditches round London, and is a strong, stubborn, ugly, and ravenous worm, with a tail formed for respiration, and

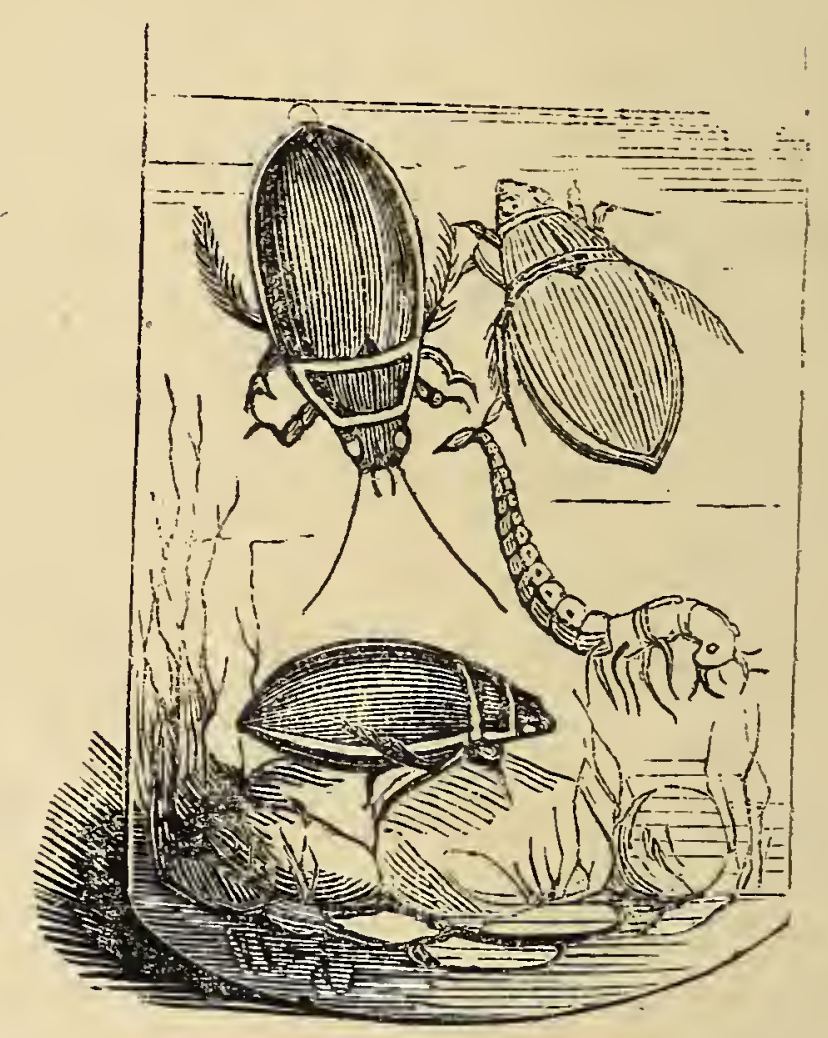

DYTISCUS AND LARVA (REDUCED).

curved mandibles to tear its prey to pieces. It is very active, and may be kept.without difficulty; but nothing else should be placed in the same jar, unless intended as food for this savage. A small fish thrown is eagerly clutched, and held firm by the claws; and the larva then plunges its mandibles into it, and is soon buried headdeep in the mangled body of its prey. I have generally fed them on beef, but they prefer small fish, or larva of 


\section{THE WATER CABINET.}

the dragon-fly, and do not go through their metamorphosis well without such food.

The imago is a handsome creature, with strong hooked claws, furnished with amber hairs, which, under a lens, resemble very closely the claws of a crab. The elytra are beautifully tinted with rich green and bronze, and the divisions of the head and thorax separated from the abdomen by sharp, whitish lines. Small fishes make the best diet for this beetle; but as this food fouls the water, it is best to keep them in clear jars, with a few pebbles and weeds, and once a week remove them to another ressel, to be fed. This plan preserves the brightness of the beetle jar, and prevents the annoyance of effluvia.

Hydrous Piceus. - This is the largest of our native aquatic beetles, and, with the exception of the stagbeetle, it exceeds in bulk any other species of indigenous Coleoptera. It is common in the brooks and ponds in southern counties, but becomes rare as we travel northwards. In the larva state this is a rapacious and bloodthirsty insect, and of so destructive a character as to deserve its French name of ver-assassin. In that early condition it resembles a large soft worm, of a somewhat conical form, provided with six feet, and having its large scaly head armed with two formidable jaws. The head moves with such freedom in all directions, that it can readily seize small shell-fish and other mollusca floating on the surface, without altering the horizontal position of the body maintained in swimming; and it is even bent backwards, and devours its prey more conveniently by using the back as a kind of support. These larvæ swim 


\section{THE WATER CABINET.}

with facility, and have two fleshy appendages at the tail, by means of which they suspend themselves at the surface with their heads downwards, when they have occasion to respire (Cuvier). The beetle differs greatly in habit from the grub; it is by no means carnivorous, but quite harmless, docile, playful, and tameable. It is a noble creature for the cabinet, and may even be kept in the Aquarium safely. In its complete form it is as interesting

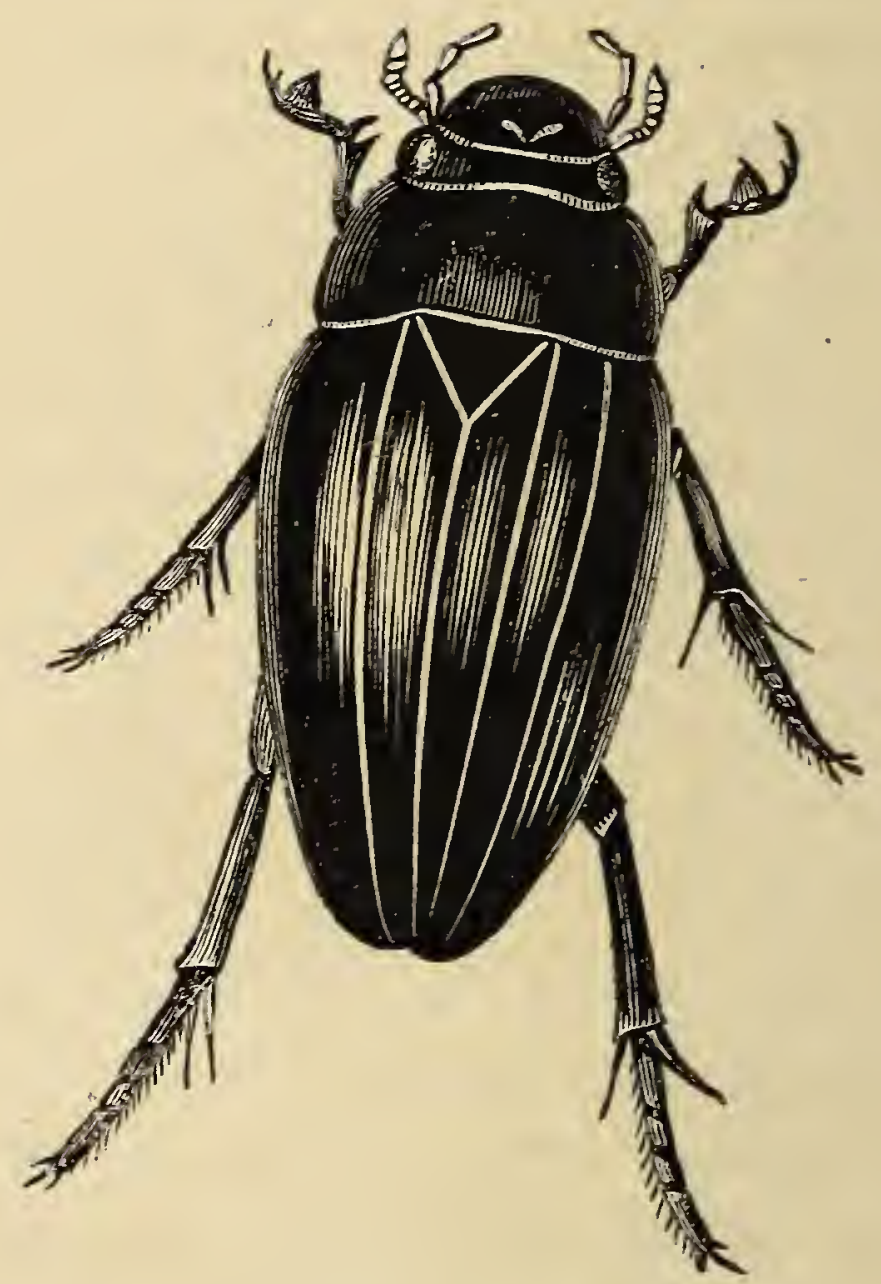

HYDROUS PICEUS.

for its gentleness as it is in the larva state for its rapacity and destructiveness. The female spins an elegant and waterproof cocoon for the reception of its eggs, and when they are deposited she watches them with a maternal solicitude not frequently exhibited by creatures of this family. 


\section{THE WATER CABINET.}

The hydrous piceus is here represented of the natural size ; the ground colour is black, with a shade of bronze, and the margins of the elytra are tinged with green and purple. Each wing case is marked with dotted lines, the breast is dingy yellow, and the antennæ and organs of the mouth dull red. The legs are black, and the hairs which fringe the tarsi reddish brown.

Colymbetes, of several species, may be obtained in plenty from clear brooks in every part of the country.

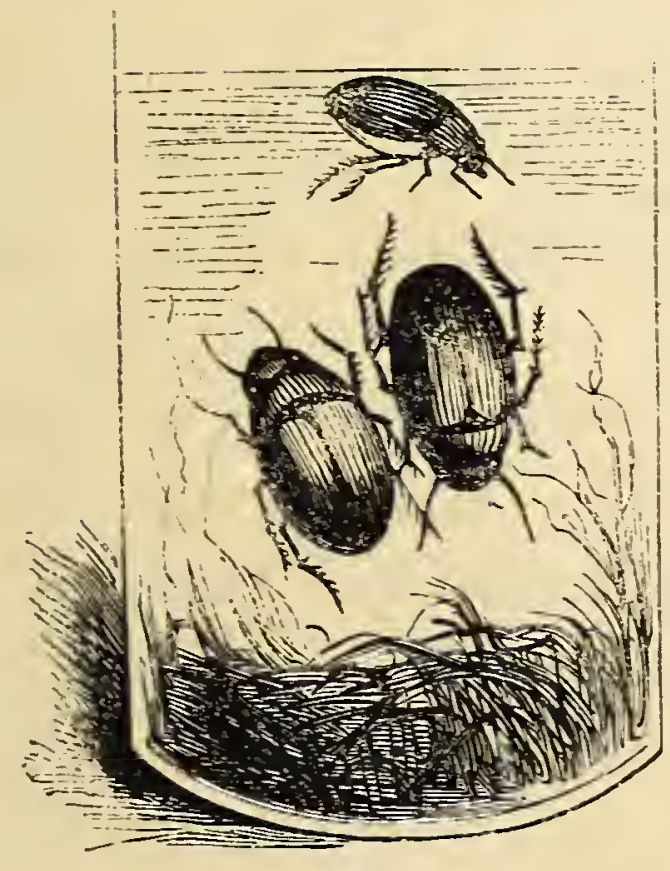

COLYMBETES.

These are elegantly-formed and lively beetles ; their elytra, legs, thorax, head, and breast of the same jet-black hue, and highly burnished, though, when immersed, the breast and abdomen glisten with an intensely metallic silvery lustre, owing to the film of atmospheric air which the beetle obtains from the surface, and which adheres to the hairy covering of the abdomen. This silvery species is here represented in its natural size. They are comparatively harmless, though I have just witnessed the demise 
of one that was attacked and eaten by his pretty kindred, the wing-cases and head only remaining to testify of his former individuality. This is a delicate beetle, that requires very pure water and a neat arrangement of aquatic plants, to give full effect to its beauty as a cabinet specimen, and, when carefully preserved, a jar of them forms a conspicuous and attractive object. I have several specimens of a smaller species in a very fine jar of confervoids; they are incessantly in motion, threading their way through the interstices of the delicate regetation in a business-like way, that seems to say, "I'm on an important errand-have not a moment to lose, and, above all things, I must take care of the bubble of air that sticks to my tail."

Grrinus Natator.-This is a member of an interesting and pretty family. Gyrinus takes its name from the tendency most of the beetles of the tribe have to move in circles, and this particular species exemplifies the habit of the tribe in a very striking manner. It is a very sociable beetle, always found in company with others of its kindred, forming little communities, which pass their time in whirling and spinning upon the surface of still pools, like congregations of dancing dervishes. They are as shy as they are nimble, and it requires some dexterity to net them, for they dive and scatter on the approach of a footstep; but if the observer remains quiet a few minutes by the water's edge, or on a plank or bridge above the pool, they soon resume their gambols under his eye, and in the sunshine appear like minute buttons of burnished metal rapidly revolving or darting to and fro upon the surface, 


\section{THE WATER CABINET.}

and for a length of time, that proves them to be by no means subject to giddiness.

The species of Gyrinus are not numerous in Britain, not more than eight being known to naturalists; but the paucity of species is compensated by the profuseness of the individuals, and of these natator is the most abundant.

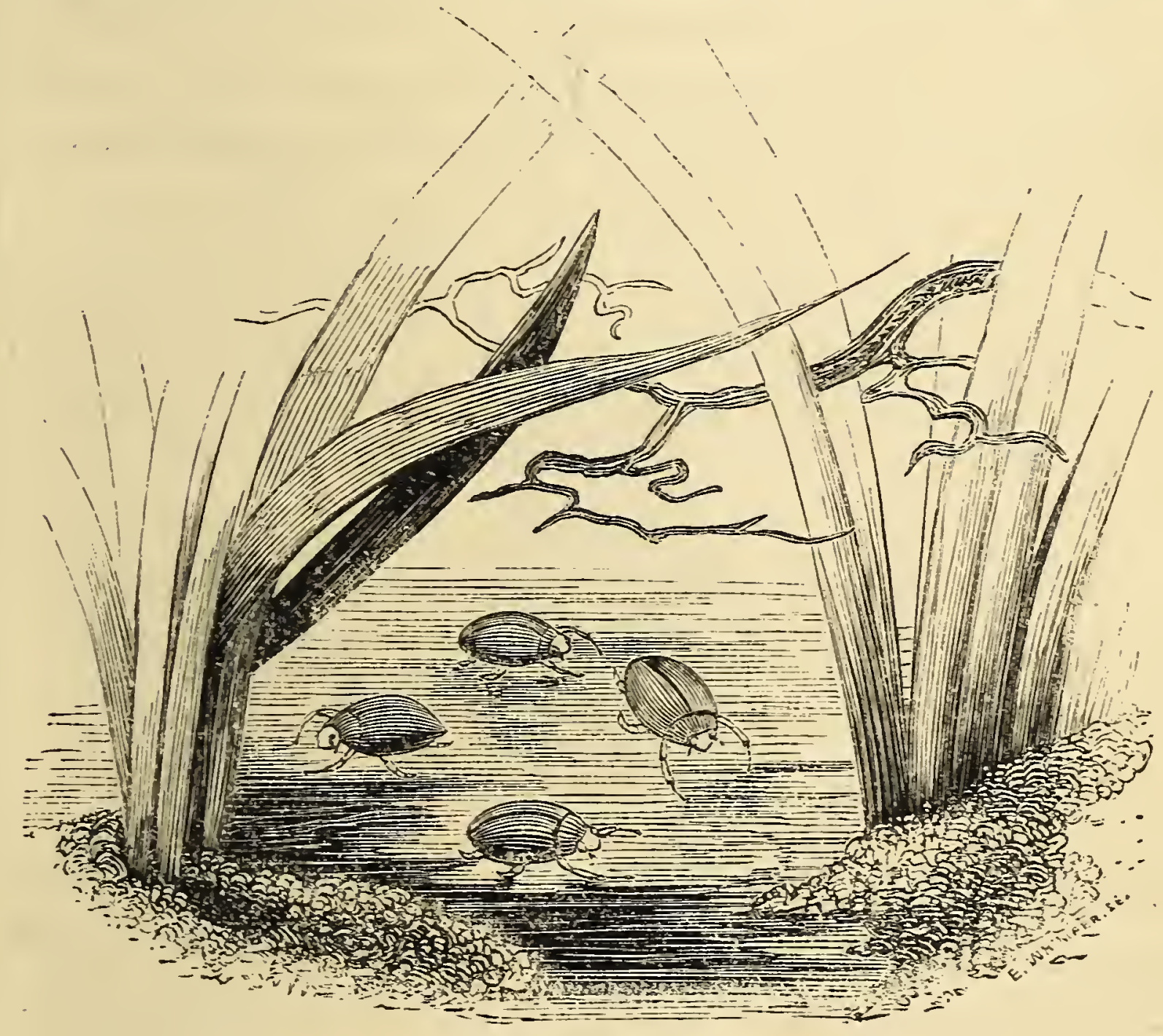

GYRINUS NATATOR.

When placed under a lens, this beetle bears the form represented in the next page. The colour is blue-black, with a resplendent metallic lustre, in which shades of copper, silver, and bronze occur, as we view it at various angles to the rays of light. The thorax is marked with three transverse lines on each side, of which the 
anterior one is punctured, and runs parallel with the margin. The elytra are turned in at the sides, and the surface of each is marked with eleven striæ or longitudinal lines, composed of minute punctures. The terminal segment of the abdomen, together with the legs, are of a rust-red.

If we inquire by what means it is enabled to perform its elegant performances on the water, and which very closely resemble those of a skilful skater on the ice, we

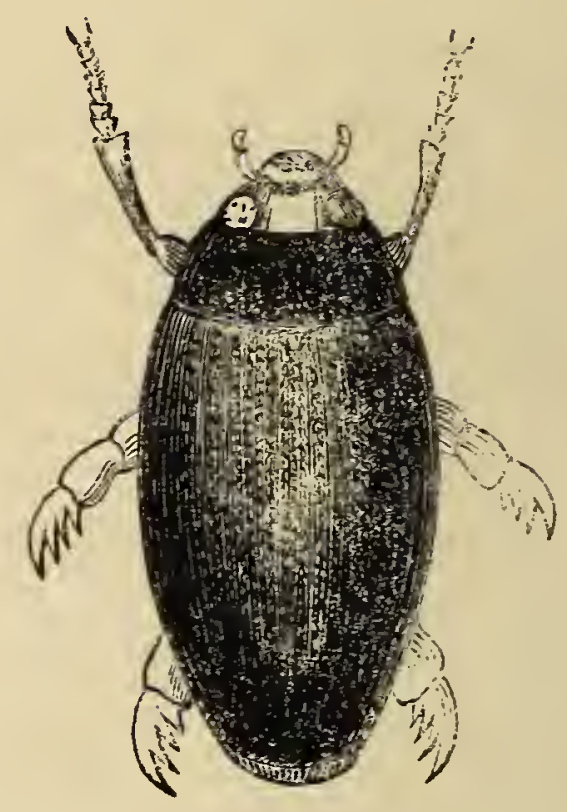

find that its structure is eminently fitted for such peculiar movements. In the first place, the antennæ are short and thick; if they protruded forward to a great length, as in Longicornes, they would seriously impede the freedom of action, which is the life and joy of this nimble fellow. They are clavate, and consist of seven closely-jointed rings, each antenna being attached by a slender peduncle to the upper and internal edge of a large radical joint furnished with an auricle at its outer side, which, like the lid of a box, shuts in the antennæ when unemployed, and protects 
them from the water (Kirby). The anterior legs are long, and formed for walking or to act as instruments of prehension; the four hinder ones are very short, and ciliated externally, bearing a strong resemblance to the paddle of an oar. "The head is sunk in the thorax as far as the eyes, and the latter are divided by a process from the anterior part of the head, in such a manner that there appear to be two eyes above and two below - a mode of structure admirably adapted to the wants of the insect, which requires at the same time to observe objects both in the air and water." The hinder legs are capable of a free oar-like action, which render this gyrinus the most expert of swimmers, and the circular movements are accomplished by the more rapid action of the oars on one side than on the other. So equipped, the whirlwig leads a merry life; he skates away from morning to night, never in fear of being drowned, and seemingly never tired.

\section{CHAPTER VI.}

HETEROPTERA.

IN the Cuvierian arrangement the land and water bugs stand between the true beetles and butterflies, and in those members of the order which possess wings, the chief characteristic is, that the anterior pair fold nearly horizontally, partly lapping over each other, and are of a leathery texture at the base. The majority of the members of the order are inhabitants of tropical climates, and some of them display colours equal to those of the true beetles. Not a few have the power of emitting powerful odours, in 
some cases of an agreeable nature, and in others-as the common bed bug - of a most disgusting nature. The order readily separates itself into two great divisions-namely, the Geocorisa, or Land Bugs, and the Hydrocorisa, or Water Bugs. Both divisions supply a few specimens for the Water Cabinet, but the most important are those belonging to the second class.

Among the first class in this order the most interesting is Hydrometra stagnorum, or the Water-measurer, which may be seen treading the surface of still brooks and rank pools in summer-time, in company with swarms of tipulidan gnats (Chironomi), whirlwigs, and two other aquatic bugs, the Gerris locustris and the Velia currens of Latrielle. The Hydrometra is a lively creature, a body so slender as to be little more than a black line half an inch in length, from which the long and angularly-jointed legs proceed in regular pairs. Under the microscope the divisions of the body are very plainly and prettily marked, and the terminal processes of the legs are made after the model of those water-shoes with which a certain clever Norwegian lately undertook to walk on water with nearly as much ease as on land. Whether the mechanician ever succeeded in this enterprise is not on record, but it is on record in the Book of Nature that this, and many other similarly-formed creatures, have found on the aqueous element a safe flooring for their feet ever since the first hour of creation, ere He who equipped them, had sent his Son to walk upon the waves.

Notanecta and Nepa are of the same order, but are true water-bugs, formed for diving and sub-aqueous life. 
The Notanecta, or Boat-fly, is a rapacious creature, that spends much of its time lying in wait for prey, but which exhibits immense activity. when it captures its booty, darting down with it, and holding it firmly by the forelegs, which are formed as claws. It is ingeniously adapted for the predaceous aquatic life it leads; the general form is well adapted for propulsion through water, and the hinder legs have an oar-like form, and are fringed with bristles along the edge, by which their striking surface is much increased. The boat-fly is an artistic swimmer; it varies its motions considerably, and delights in swimming on its back, a feat in which it is aided by its eyes being so placed as to enable it to see both above and below, and thus gain early intelligence of danger, or of the approach of its prey. Owing to their liveliness and voracity, they afford much interest when domesticated, and should be treated as directed for Dytiscus.

The Water Scorpion is a good representative of the Nepidce, and has the distinguishing features of its tribe very strongly marked. The Water Scorpion is a very common inhabitant of our brooks, and its singular form quickly arrests the eye of the sportsman when turning over the contents of the drag-net. $N$. neptunia and $N$. cinerea are, perhaps, the most common; and either of these is an admirable object for the microscope. The water-scorpion is the victim of the parasitic water-mite (Hydrachna abstergens), which inserts its egg in the body of the Nepa, and thus compels it to support the young of its worst enemy, a task which it performs at the 
cost of its life. I have several times introduced the Hydrachna into my jars of Nepa, but have never yet witnessed the parasitic deposit of the eggs. In confinement, the Nepa is the least hardy of any creature in the collection, if the sun strikes the jar it perishes, and it will not live long unless it has means of occasionally leaving the water-hence a broad jar should be used for it, and a small piece of pumice stone should be floated in it, to form an island on which the insects may take refuge.

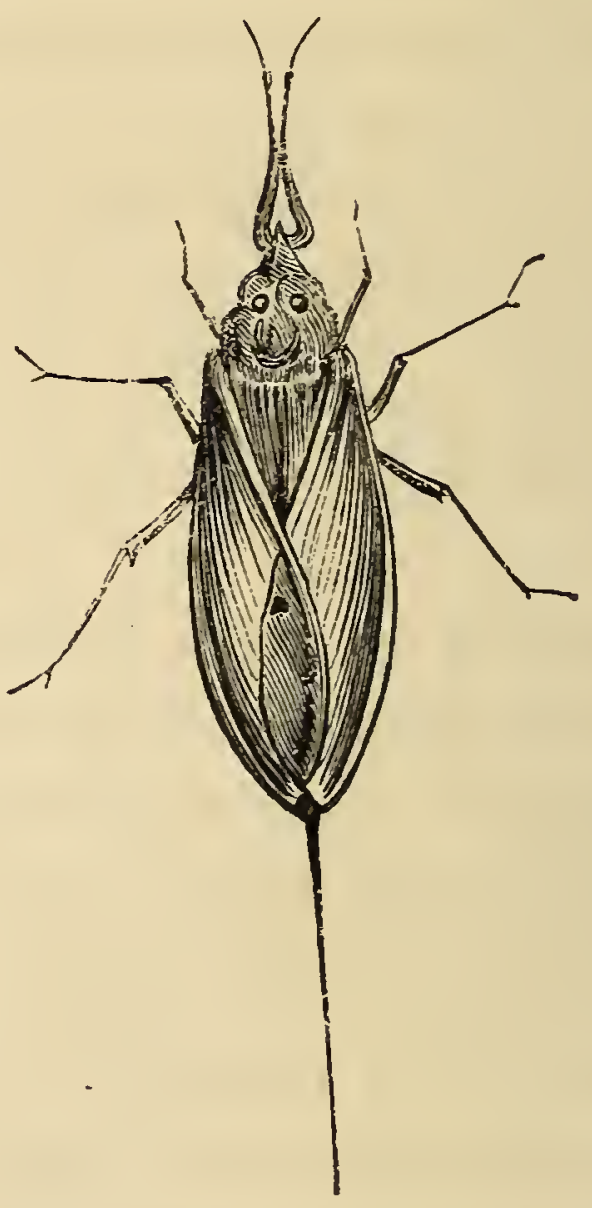


THE WATER CABINET.

\section{CHAPTER VII.}

THE FROG.-NOTES ON MANAGEMENT.

The Frog.-The Ranida or true frogs, and the Bufoida or toad tribe, contribute, whether in the larva or perfect form, some very lively, entertaining, and instructive specimens. I am sorry that my space is so limited as to prevent the insertion here of such full notices as this subject deserves, and must content myself by assuring the reader that but little progress can be made in the study of Zoology without a patient study of the history of the frog.

During the spring and summer the brooks abound with what boys call "loggerheads," or tadpoles; these are the larva of the frog. They may be caught easily, and preserved in jars of growing weed, for observation of their development. I have now (August 18th,) several specimens of Bufoida, in which even the first stage of metamorphosis has not commenced, though, since June, some hundreds of toads and frogs have attained completeness in my vessels, many of which are now inmates of the garden, some of them exceedingly tame.

In the egg state we find abundance, during April, in every pond and brook, adhering in gelatinous masses to the under leaves of aquatic plants. The eggs gradually acquire a dark tint, and at last the young "tads" emerge, and begin their quiet existence in this first rudimental form. In this state they are very lively in their motions; the eyes are very distinctly visible, and the mouth is 
placed, as it were, on the breast. They are not wholly herbivorous ; for though they nibble the fronds of Riccia and threads of Conferva, they do not scruple to eat their dead kindred, and half a dozen may be seen engaged upon the carcase of a defunct brother. In this stage the gills form a fine microscopic object. As the " tad " increases in bulk, the hinder part of the body swells, and at last the budding of the hind legs may be distinctly seen. These at last acquire some degree of completeness, and then the other
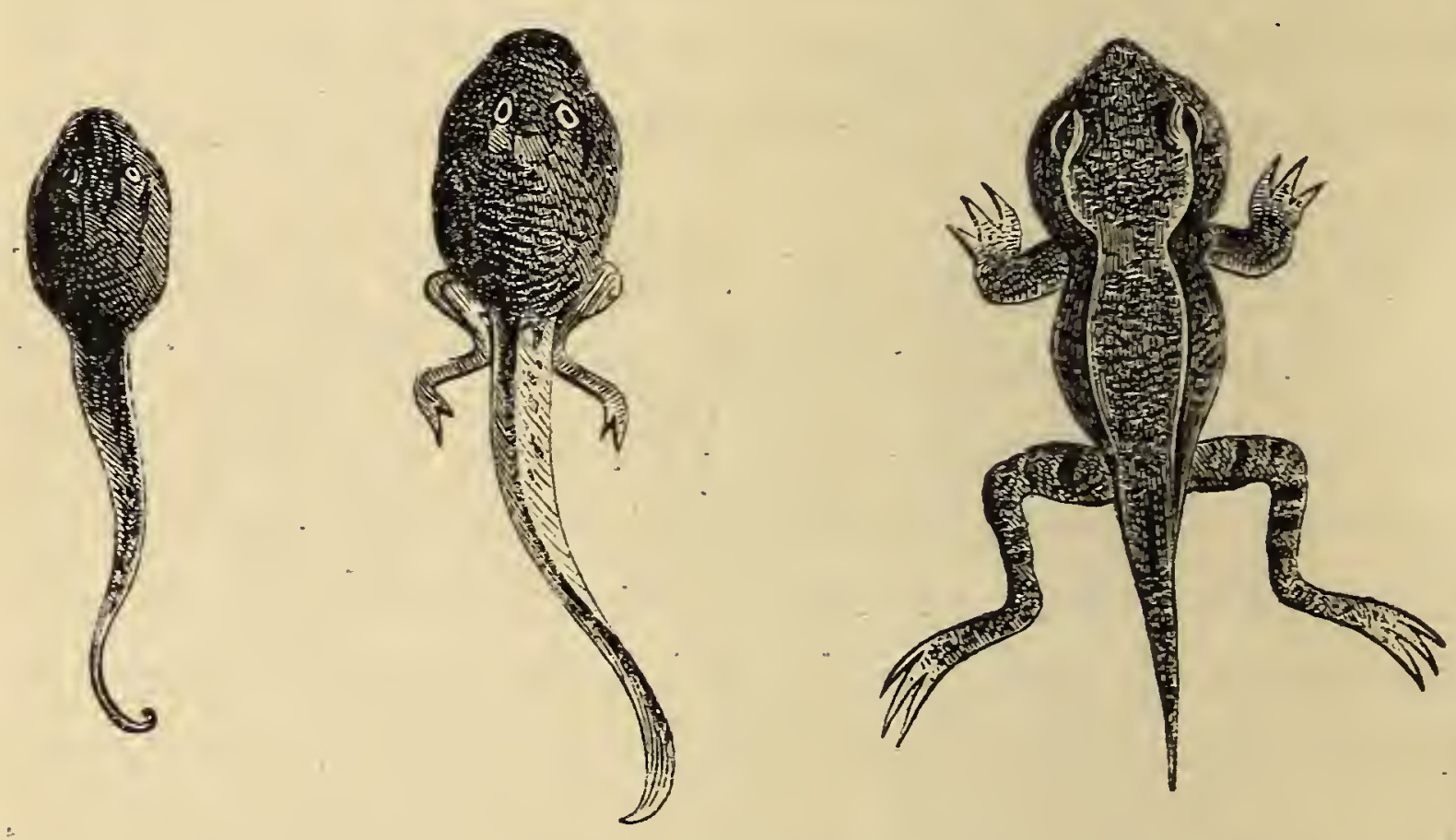

pair of legs sprout in a similar manner, and the tail begins to shrink rapidly as the general bulk of the reptile increases. The gills now rapidly disappear, and the body grows at the expense of the tail, and before the latter appendage is completely extinguished, the jurenile Ranus takes his first dose of atmospheric air, by mounting a leaf of frog-bit or a slice of cork. He now leads an amphibious life, and at last quits the water altogether, climbs up the glass side of the tank or jar, and escapes, 
unless confined by a glass lid or gauze. But he is now a true frog, delicately mottled, agile in his movements,

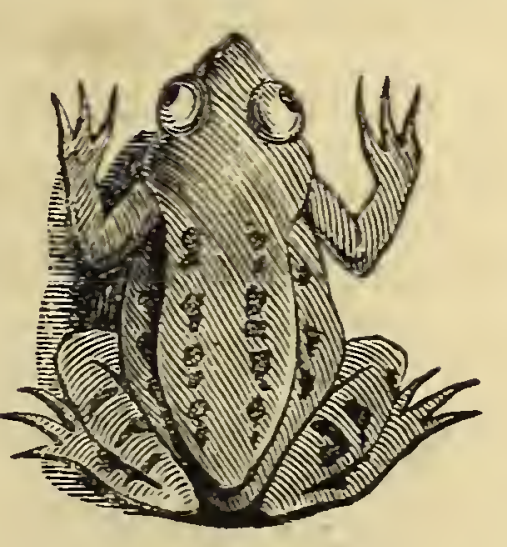
very clever in jumping and swimming-his tadpole tail entirely absorbed, and his whole system metamorphosed. If he interested us before, he is still more interesting now, for in the structure and economy of his frame Nature reveals phenomena typical of animal life in all its orders and gradations. Hence the frog is the victim of the philosopher; he suffers spasm under the galvanic wire, blindness under the glare of the microscope lamp, tetanus through being dosed with strychnine, and innumerable other agonies in which operators detect analogies that throw a light on the fundamentals of animal life, and that even aid in the explanation of the subtle organism of man himself.

Management of the Cabinet.-The instructions already given for the management of Aquaria will be found to embrace most of the points involved in the management of beetle and larva jars, for these are but Aquaria on a smaller scale. The chief matter is to separate the species as much as possible, so that the carnivorous kinds shall not destroy the harmless ones; and on this plan the study of each kind is greatly facilitated. Since the jars afford the best means for the culture of choice aquatic specimens of the various kinds of Riccia, Conferva, Nitella, Lemna, and other minute water-weeds may be used for maintaining the necessary balance in 


\section{THE WATER CABINET.}

each, and if some of the vessels are filled with brookwater only, the student will come into possession of many beautiful specimens of both animal and vegetable life, the search for the names and histories of which will be even more profitable than the contemplation of their beauty. The first specimen I ever possessed of the beautiful confervoid Hydrodictyon utriculatum was obtained in this way-the water, after depositing a green sediment, gave birth to a rich net-work of vegetation, in which this conferva was conspicuous. Several of the jars which I prize the most are those which have been simply filled at the brook side, and left for the minute germs of animal and vegetable life to develope in their own way, and it is not long before a rich growth takes place, that affords abundant material for observation with the microscope. Feeding is necessary only in the case of carnivorous larva and beetles, and for these small fish is undoubtedly the best; the herbivorous creatures supply themselves. As a general rule the water in the jars should never be changed; it is by leaving things to themselves that the best display is to be obtained, especially if chara and other low forms of vegetation are preserved.

Nitella is almost too delicate for the tank, but an admirable plant for growth in jars in which cabinet specimens of larvæ are kept. I rarely place it in the aquarium, considering it too choice a thing, its delicate structure rendering it barely perceptible amidst the more luxuriant growths with which it gets entwined. Still; it does well there, but cannot be studied unless a bunch is placed in a glass jar for separate culture. It consists 
only of joints and threads of a pale, but pleasing, green, grows rapidly, and gives out abundance of the vital phlogiston, about which aquarians are compelled to say so much.

The microscope at once increases a hundred fold the pleasure of instruction which the cabinet is capable of affording us. For the minuter forms of animal life, and for observing the circulation in the frog, or in vallisneria, \&c., a good compound microscope is necessary. But for ordinary purposes, I should recommend a Coddington lens, or the pocket Aquarian lenses, sold by

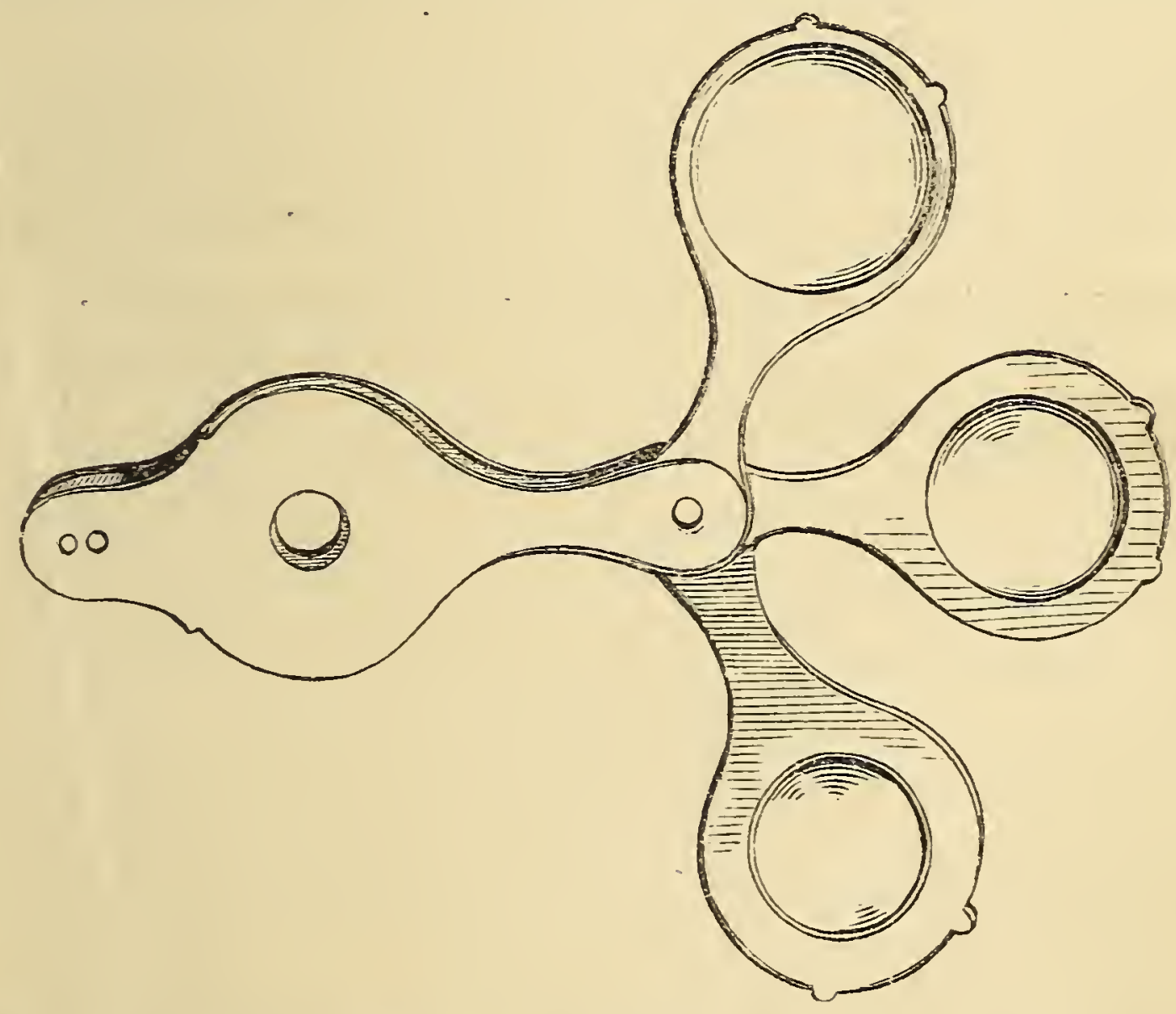

Mr. Cox, of 100, Newgate Street. They are made of three powers, fitting into a case, and may be used separately, or combined according to circumstances. The one here figured costs 7s. 6d., but a cheap common lens, fitted 


\section{THE WATER CABINET.}

with frame and handle, may be had of Mr. Cox for from half-a-crown to five shillings.

The present work does not afford me space to discuss the educational and ornamental uses of the aquarium, and I have confined myself to its mere elements, dealing with those in a way that I think will be most useful to beginners. The aquarium has uses of a higher character than such as may suggest themselves by the perusal of these few pages, and is capable of extension so as to combine with it the most attractive features of the wardian case, and, to some extent, a vivarium for a selection of amphibious and true land animals. These matters are pretty fully discussed in my work on Rustic Adornments, to which I have already called the reader's attention, and to its pages I once more refer for more extended information on this and other subjects of a kindred nature. 


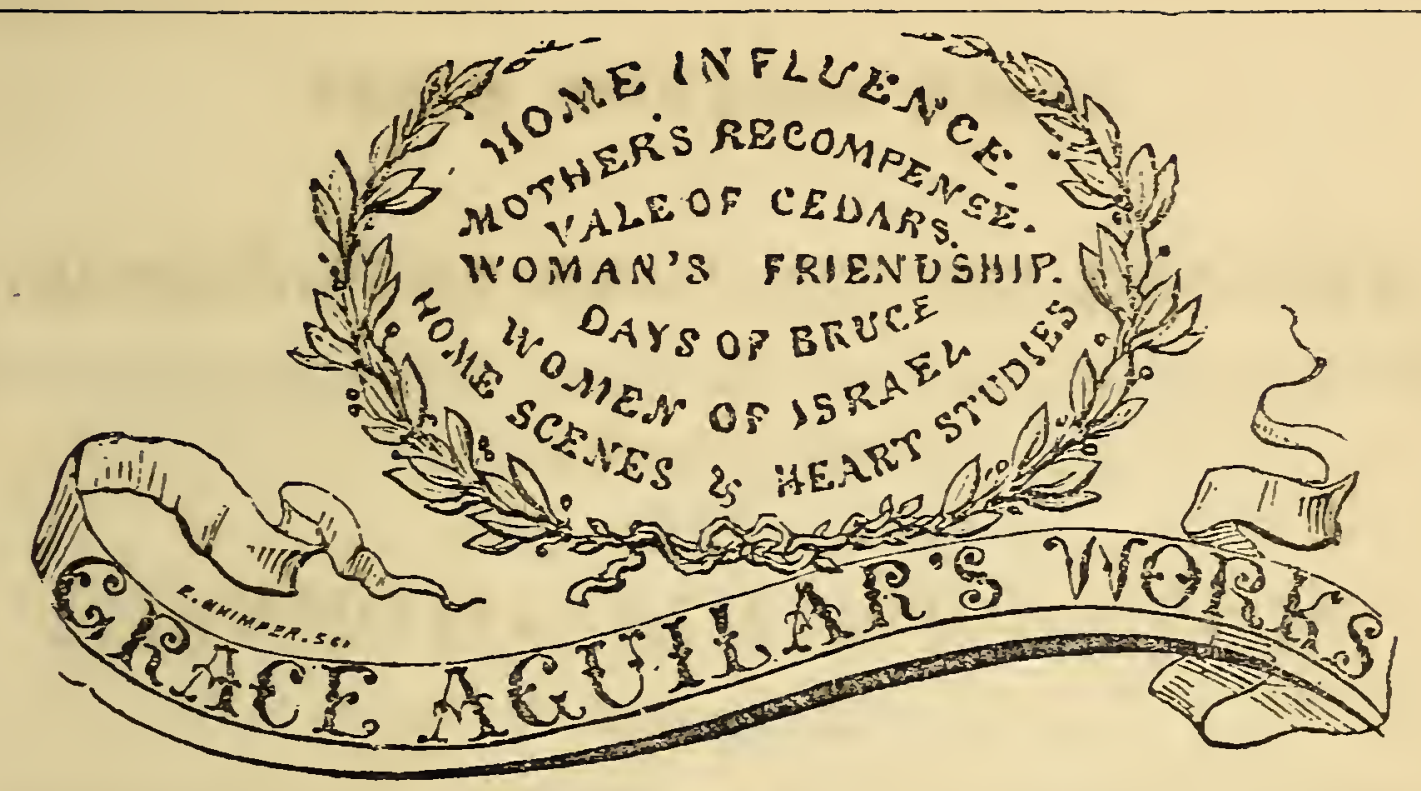

I.

In 1 vol., fcap. Svo, illustrated with Frontispiece, price 6s. 6d., with a Memoir of the Author,

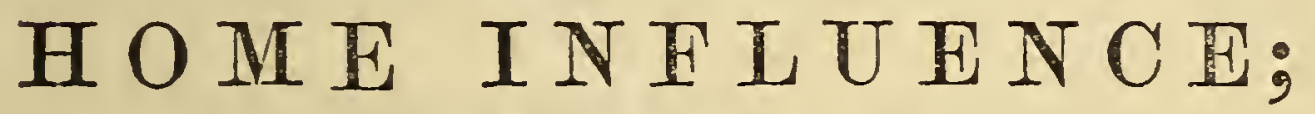

A TALE FOR MOTHERS AND DAUGHTERS.

By GRACE AGUIIAR.

"Grace Aguilar wrote and spoke as one inspired ; she condensed and spiritualized, and all her thoughts and feelings were steeped in the essence of celestial love and truth. To those who really knew Girace Aguilar, all eulogium falls short of her deserts, and she has left blank in her particular walk of literature, which we nerer expect to see filled up."-Pilgrimages to English Shrines, by MIrs. Hall.

"A clever and interesting tale, corresponding well to its name, illustrating the silent, constant influence of a wise and affectionate parent, over characters the most diverse."-Christian Lady's Magazine.

"This interesting volume unquestionably contains many valuable hints on domestic education, much powerful writing, and a moral of vast importance." - Englishwoman's Magazine.

"It is very pleasant, after reading a book, to speak of it in terms of high commendation. The tale before us is an admirable one, and is executed with taste and ability. The language is beautiful and appropriate; the analysis of character is skilful and varied. The work ought to be in the hands of all who are interested in the proper training of the youthful mind." - Palladium.

"In reviewing this work, we hardly know what words in the English language are strong enough to express the admiration we have felt in its perusal." - Bucks Chronicle.

"The object and end of the writings of Grace Aguilal were to improve the heart, and to lead her readers to the consideration of higher motires and objects than this world can ever afford."-Bell's Weekly Messenger.

" 'Home Influence' will not be forgotten by ang who have perused it."-Critic.

"A well-known and valuable tale."-Gentleman's Magazine.

"A work which possesses an extraordinary amount of influence to clevate the mind and educate the heart, by showing that rectitude and virtue conduce no less to material prosperity, and worldly comfort and happiness, than to the satisfaction of the conscience, the approval of the good, and the hope and certainty of tiss hereafter." - Herts County Press.

London: GROOMBRIDGE \& SONS, 5, Paternoster Row. 


\section{GRACE AGUILAR'S WORKS.}

II.

\section{THE SEQUEL TO HOME INFLUENCE.}

Printed uniform, in 1 vol., illustrated with a Portrait of the Author, price 7 s.,

THE

\section{MOTHER'S RECOMPENSE;}

A SEQUEL TO

\section{"Home Influence, a Tale for IMothers and Daughters."} By GRACE AGUILAR.

"Grace Aguilar belonged to the school of which Maria Edgeworth was the foundress. The design of the bock is carried out forcibly and coustantly, 'The Home Influences' exercised in earlier years being shown in active germination."-Atlas.

"The writings of Grace Aguilar have a charm inseparable from productions in which feeling is combined with intellect; they go directly to the heart. ' Home Influence,' the deservedly popular story to which this is a Sequel, admirably teaches the lesson implied in its name. In the present tale we have the same freshness, earnestness, and zeal--the same spirit of devotion, and love of virtue-the same enthusiasm and sincere religion which characterised that earlier work. We behcld the mother now blessed in the love of good and affectionate offspring, who, parents themselves, are, after her example, training their children in the way of rectitude and piety."-Morniny Chronicie.

"This beautiful story was completed when the authoress was little above the age of nineteen, yet it has the sober sense of middle age. There is no age nor sex that will not profit by its perusal, and it will afford as much pleasure as profit to the reader."-Critic.

- "The same kindly spirit, the same warm charity and ferrour of derotion which breathes in every line of that admirable book, Home influence,' will be found adorning and inspiring 'The Mother's IRecompense." "-Morning Advertiser.

"The good which she (Grace Aguilar) has effected is acknowledged on all hands, and it cannot be doubted but that the appearance of this volume will increase the usefulness of one who may yet be said to be still spealring to the heart and to the affections of human nature."-Bell's Messenger.

"It will be found an interesting supplement, not only to the book to which it specially relates, but to all the writer's other works." Gentleman's Magazine.

" 'The Mother's Recompense' forms a fitting close to its predecessor, 'Home Influence.' The results of maternal care are fully developed, its rich rewards are set forth, and its lesson and its moral are poweriuiiy enforced."-Morning Post.

"We heartily commend this volume; a better or more useful present to a youthful friend or a young wife could not well be selected."-Herts County Press. 


\title{
GRACE AGUILAR'S WORKS.
}

III.

In 1 vol., fcap. 8vo, illustrated with Frontispiece, price 6s. $6 \mathrm{~d}$.

\section{WOMAN'S FRIENDSHIP;}

\section{A STORY OF DOMESTIC IIFE.}

\author{
By GRACE A GUIIAR. \\ "To show us how divine a thing \\ A woman may be made." - WORDSWORTH.
}

"This story illustrates, with feeling and power, that beneficial influence which women exercise, in their own quiet way, over characters and events in our every-day life."-Britannia.

"Th eboor is one of more than ordinary interest in various ways, and presents an admirable conception of the depths and sincerity of female friendship, as exhibited in England by Englishwomen."Weekly Chronicle.

"We began to read the volume late in the erening; and, although it consists of about 400 pages, our eyes could not close in sleep until we had read the whole. This excellent book should find a place on every drawing-room table-nay, in every library in the kingdom." Bucks Chronicle.

"We congratulate Miss Aguilar on the spirit, motive, and composition of this story. Her aims are eminently moral, and her cause comes recommended by the most beautiful associations. These, connected with the skill here evinced in their derelopment, ensure the success of her labours." - Illustrated News.

"As a writer of remarkable grace and delicacy, she devotes herself to the inculcation of the virtues, more especially those which are the peculiar charm of women."-Critic.

"It is a book for all classes of readers ; and we have no hesitation in saying, that it only requires to be generally known to become exceedingly popular. In our estimation, it has far more attractions than Miss Burney's celebrated, but orer-estimated, novel of 'Cecilia." - Herts County Press.

"This very interesting and agreeable tale has remained longer without notice on our part than we could have desired; but we would now endearour to make amends for the delay, by assuring our readers that it is a most ably-written publication, full of the nicest points of information and utility that could have been by any possibility constructed; and as a proof of its value, it may suffice to say, that it has been taken from our table again and again by several individuals, from the recommendation of those who had already perused it, and so prevented our giving an earlier attention to its manifold claims for favourable criticism. It is peculiarly adapted for the young, and wherever it goes will be received with gratification, and command very extensive approbation."-Bell's Weekly Messenger.

"This is a handsome volume; just such a book as we would expect to find among the volumes composing a lady's library. Its interior corresponds with its exterior; it is a most fascinating tale, full of noble and just sentiments."-Palladium.

Iondon: GROOMBRIDGE \& SONS, 5, Paternoster Row. 


\section{GRACE AGUILAR'S WORKS.}

\section{IV.}

In 1 vol, fcap. 8vo, illustrated with Frontispiece, price 6s,

$$
\text { THE VALE OE CEDARS; }
$$

The $\mathfrak{A}$ tartnr.

\section{A STORY OF SPAIN IN THE FIFTEENTH CENTURY. \\ By GRACF AGUILAR.}

" The authoress of this most fascinating volume has selected for her field one of the most remarkable elas in modern history - the reigns of Ferdinand and Isabella. The tale turns on the extraordinary extent to which concealed Judaism had gained footing at that period in Spain. It is marked by much power of deseription, and by a woman's delicacy of touch, and it will add to its writer's wellearned reputation." - Eclectic Review.

"The scene of this interesting tale is laid during the reign of Ferdinand and Isabella. The Vale of Cedar's is the retreat of a Jewish family, compelled by persecution to perform their religious rites with the utmost secrecy. On the singular position of this fated race in the most Catholic land of Europe, the interest of the tale mainly depends; whilst a few glimpses of the horrors of the terrible Inquisition are afforded the reader, and heighten the interest of the narrative."-Sharpe's Magazine.

"Anything which proceeds from the pen of the authoress of this volume is sure to command attention and appreciation. There is so much of delicacy and refinement about her style, and such a faithful delineation of nature in all she attempts, that she has taken her place amongst the highest class of modern writers of fiction. We consider this to be one of Miss Aguilar's best efforts."-Bell's Weekly Messenger.

"We heartily commend the work to our readers as one exhibiting, not merely talent, but genius, and a degree of earnestness, fidelity to nature, and artistic grace rarely found." - Herts County Press.

"The 'Vale of Cedars' is indeed one of the most touching and interesting stories that have ever issued from the press. There is a life-like reality abont it, which is not of ten observed in roorks of this nature ; while we read it we felt as if we were witnesses of the various scenes it depicts."-Bucks Chronicle.

"It is a tale of deep and pure devotion, very touchingly narrated." -Atlas.

"The authoress has already received our commendation; her present work is calculated to sustain her reputation."-Mlustrated News.

"It is indeed a historical romance of a high class. Seeing how steady and yet rapid was her improvement-how rich the promise of her genius-it is impossible to close this notice of her last and best work, without lamenting that the authoress was so untimely snatched from a world she appeared destined, as certainly she was singularly qualified, to adorn and to improve." - Critic. 


\section{GRACE AGUILAR'S WORKS.}

$\nabla$.

In 1 vol., fcap. 8vo, illustrated with Frontispiece and Vignette, price 7 s. 6d.,

\section{THE DAYS OF BRUCE; \\ A Storu fram Scottish 唒istorv. By GRACE AGUILAR,}

"We have had an opportunity of observing the interest it awakens in different classes of readers, and in no instance lias it failed to rivet attention, and to induce a high estimate of the author's powers. Miss Aguilar was evidently well read in the times of Bruce. It is long since we met with a work which combines so happily the best qualities of historical fiction." - Ec'ectic Reviev.

"The life of the hero of Bannockburn has furnished matter for" innumerable tales in prose and rerse, but we have met with norecords of that famous era so instructive as "The Days of Bruce." - Britannia.

"s 'The Days of Bruce' was written when, in the vigour of intellec. tual strength, Grace Aguilar was planning many things, and all for good; it was we know her especial favourite: it is fuil of deep interest." - Mr.S. S. C. Hall, in Sharpe's MTagazine."

"It is a volume which may be considered as solid history, but is nevertheless entertaining as the most charming novel ever produced by genius. Sir Walter Scott's name as an athor would not have been disgraced by it had it appeared on the title-page instead of Grace Aguilar." - Bucks Chronicle.

"This's deeply interesting romance-a composition of great eloquence, written with practised polish aud enthusiastic energy. We are not surprised at the elegance, the warmth, and the pathos with which Grace Aguilar paints love passages: but we are astonished at the fire and accuracy with which she depicts scenes of daring and of death."-Observer.

"The tale is well told, the interest warmly sustained throughout, and the delineation of female character is marked by a delicate sense of moral beauty. It is a rork that may be confided to the hands of a daughter by her parent." - Court Journal.

"Every one who knows the works of this lamented author, must observe that she rises with her subjects. In 'The Days of Bruce' she has thrown herself into the rugged life of the fourteenth century, and has depicted thë semi-civilization of the period in a manner that is quite marvellous in a young woman. Grace Aguilar always excelled in her delineation of female characters, while the skill she evinces in the illustration of the historical personages, and herindividualization of the imaginary ones, might at once entitle her to a birthplace annong historical novelists."-Ladies' Companion.

"Her' pen was ever devoted to the cause of virtue : and her various publications, exhibiting the beauties aud enforcing the practice or the 'tender charities' of domestic life, have, we doubt not, lecommended themselves to the hearts of numbers of her countrywomen. The work before us differs from the former publications of its author, inasmuch as it is in fact an historical romance, for this species of writing the high feeling of Grace Aguilar peculiarly fitted her ; many of the scenes are very highly wrought; and while it will fix in the reader's mind a truthful idea of the history and style of manners of - The Days of Bruce,' it will also impress upon him a strong sense of the ability and noble cast of thought which distinguished its lamented author."-Englishuroman's II Tagazine. 


\title{
GRACE AGUILAR'S WORKS.
}

"We look upon 'The Days of Bruce' as an elegantly'-written and Interesting romance, and place it by the side of Miss Porter's Scot. tish Chiefs."-Gentleman's Magazine.

"A very pleasing and successful attempt to combine ideal delineation of character with the records of history. Very beautiful and very true are the portraits of the female mind and heart which Grace Aguilar knew how to draw. This is the chief charm of all her writings, and in 'The Days of Bruce' the reader will have the pleasure of viewing this skilful portraiture in the characters of Isollne and Agnes, and Isabella of Buchan.'-Literary Gazette:

"What a fertile mind was that of Grace Aguilar! What an early development of reflection, of feeling, of taste, of power of invention, of true and earnest eloquence! 'The Days of Bruce' is a composition of her early youth, but full of beauty. Grace Aguilar knew the female heart better than any writer of our day, and in every fiction from her pen we trace the same masterly analysis and development of the motives and feelings of woman's nature. 'The Days of Bruce' possesses also the attractions of a n extremely interesting story, that absorbs the attention, and never suffers it to flag till the last page is closed, and then the reader will lay down the volume with regret.'Critic.

VI.

In 1 vol., fcap. 8vo, illustrated with Frontispiece, price 6 s. 6 d., HOME SCENES \& HEART STUDIES.

\author{
Tales. \\ By GRACE AGUILAR.
}

The Perez Family.

The Stone-cutter's Boy of Possagno.

AMETE AND YAFEH.

The Fugitrve.

The Edict; a Tale of 1492.

The Escape; a Tate of 1755.

Red Rose Vilita.

Gonzalto's Dadghter.

THE AUTHORESS.

HELON.

LUCY.

The Spirit's Entriaty.

IDALIE.

Lady Gresham's Fete.

THE Group of ScULPTURE.

The Spirit of Night.

RECOLLECTIONS OF A RAMBLER.

Cast thy B'́read upon the Waters.

The Triduph of Love. 


\section{GRACE AGUILAR'S WORKS,}

FII.

Second Edition, in Two Volumes, Foolscap Evo, price 12 s.

\section{THE WOMEN OF ISRAEL;}

Or, Characters and Sketches from the Holy Scriptures, Illustrative of the past History, present Duties, and future Destiny of Hebrew Females, as based on the Word of God.

\section{By GRACE AGUILAR.}

Firimripal Contents of the carar.

First Period- Tives of the Patriarchs.
Eve.
Sarah.
Rebekah.
Leah and Rachel.

Second Period-The Exodos and the Law.

Egyptian Captivity, and Jochebed.

The Exodus-Mothers of Israel.

Laws for Wives in Israel.

Law's for Widows and Daughters in Israel.

Maid Servants in Israel, and other Laws.

Third Period-Between the dehivery of the Iat and the MoNARCHY.

Miriam.

Tabernacle Workers-Caleb's

Deborah.

[Daughter.

Wife of Manoah.

Naomi.

Fourth Period-The Monarchr.

Michal.

Abigail.

Wise Woman of Tekoah.

Woman of Abel.

Hannah.

\section{Huldah.}

\section{Rispah.}

Prophet's Widow:

The Shunamite.

Little Israelitish Maid.

Fifta Period--Babrlonian Captivitr.

The Captivity.

Review of Book of Ezra.

Suggestions as to the Identity of the Ahasuerus of Scripture.

Esther.

Review of Events narrated in Ezra and Nehemiah.

Sixth Period-Continuance of the Second Teuple.

Review of Jewish History, from the return from Babylon to the Appeal of Hyrcanus and Aristobulus to Pompes.

Jewish History from the Appeal to Pompey to the Death of Herod.

Jewish History from the Death of Herod to the War.

The Martyr Mother.

Alexandra.

Mariamne.

Salome.

Helena.

Berenice.

Seventh Period-Women of Israel in the Present as inFLEexced by the Past.

The War and Dispersion.

\begin{tabular}{l|l} 
Thoughts on the Talmud. & secution. \\
Talmudic Ordinances \& Tales & Genelal Remarlss.
\end{tabular}

"A work that is sufficient of itself to create and crown a reputation." -Pilgrimages to English Shrines, by MIr.S. S. C. Hall. 


\section{IIRS. CROSIAND'S NEW DOMESTIC STORY.}

\section{In One Volume, Foolscap 8vo, price 6 s. LYDIA; A WOMAN'S BOOK. \\ By MRS, NEWTON CROSLAND}

\section{(Late Camilla Toulmis).}

"And a capital book too-it is impossible to read many consecutive pages of this interesting volume without coming upon the evidences of superior sense and a cultivated taste; it contains incident and interest enough for a three volume novel. We foresee that it will be read and talked of." - Tait's Magazine.

"6 'Lydia' is emphatically a woman's book, written by a 'very woman, feminine alike in its virtues and in its faults."-British Journal.

"Mrs. Crosland is essentially a feminine writer-she has studied, - understands and sympathises with her sex thoroughly; there is more power in this Woman's Book than in any work its author has yet produced ; it must add to her reputation as a thinker and a writer." -Sharpe's London Magazine.

"The pen of Camilla Toulmin is sure to trace pages characterised by delicate and womanly feeling, but the present tale possesses those attributes in a very marked manner, even beyond her many previous narratives. This is no romance of 'high life' or chronicle of fashionable frivolity, but a true tale of deep domestic interest, vigorously written, and abounding with touches of genuine nature." -Globe.

"Most pleasant and intelligent. It contains scenes of great literary power."-Bell's Weekly Messenger.

"A charming volume. The finest chords are truly touched and the moral of the tale is deeply impressive and instructive," - Iondon Weekly Paper.

"There are perhaps not half a dozen writers of the day who can make any pretension to the mastery and exhibition of a great and interesting passion; and there are few persons whom we consider more likely to swell this select number than the author of this work. ' Lydia' is such an advance upon her previous productions-it indicates so much life-experience and knowledge of the human heartit is witten in such a true tone of earnestness, distinctness of purpose, and nobility of nature, that its publication cannot fail to be a new step in its author's career and reputation." - Nottingham Mercury.

"A woman's book it is in its delicacy of sentiment, gracefulness of style, and quick appreciation of character."-Iiterary Gazette.

"From any new work of Mrs. Crosland we have a right to expect much, and the present story fully answers our expectations. It is written gracefully, and communicates interest and instruction by events that arrest our attention because of their truthfulness, and the talent displayed in their narration." - Observer.

" 'Lydia' is the story of a woman's life and trials-' a woman's book ; but no man, except he be a heartless worldling, will read this story of a Noman's love and heroism without applauding what the authoress applauds, and condemning what she condemns."-Atlos.

"Mrs. Crosland's 'Lydia' is an exquisite portrait of a true woman. * The authoress is an artist; her books are works of art, carefully designed, conscientiously composed, corrected with care, having an aim and a plan, and therefore not only delighting readers of all classes, but commending themselves to the intellectual, who desire in a book something more than a mere pastime; who require it to be like a good picture, a mental study. And such is Lydia." "-Critic. 
$-2$

.




